Aus dem Institut für Anatomie und Embryologie

(Prof. Dr. med. C. Viebahn)

im Zentrum Anatomie

der Medizinischen Fakultät der Universität Göttingen

\title{
Ultrastrukturelle Charakterisierung geschlechtsspezifisch sortierter Spermien
}

\author{
INAUGURAL - DISSERTATION \\ zur Erlangung des Doktorgrades \\ der Medizinischen Fakultät der \\ Georg-August-Universität zu Göttingen
}

\author{
vorgelegt von \\ Johannes Michl \\ aus \\ Straubing
}

Göttingen 2014 
Dekan:

Prof. Dr. rer. nat. H. K. Kroemer

I. Berichterstatter:

II. Berichterstatter:

III. Berichterstatter:

Tag der mündlichen Prüfung: $\quad$ 29. 09. 2014 


\section{INHALTSVERZEICHNIS}

I. EINLEITUNG

I. 1 Entwicklung und Ultrastruktur von Säugetierspermien .............................................1

I. 2 Geschlechtsspezifische Sortierung von Spermien ...................................................

I. 3 Möglichkeiten und Grenzen gegenwärtig eingesetzter Sortierverfahren .........................5

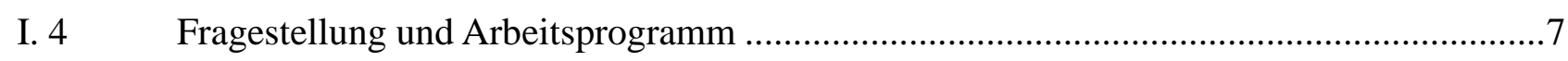

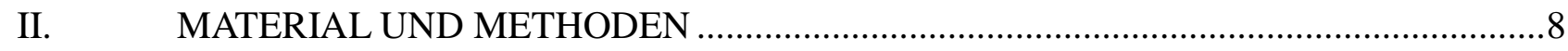

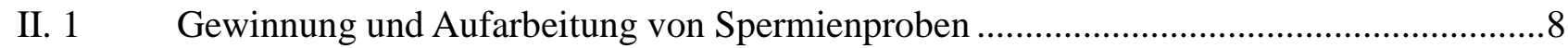

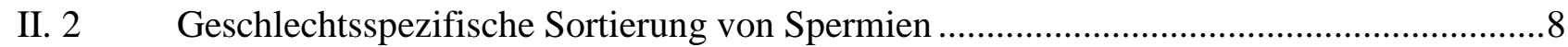

II. 3 Aufarbeitung geschlechtsspezifisch sortierter Spermien .............................................12

II. 4 Analyse individueller Komponenten des Sortierprozesses...........................................13

II. 5 Probenaufarbeitung für die Transmissionselektronenmikroskopie ................................14

II. 6 Herstellung von Dünnschnitten für die Licht- und Elektronenmikroskopie ....................15

II. 7 Bildakquisition im Transmissionselektronenmikroskop............................................ 16

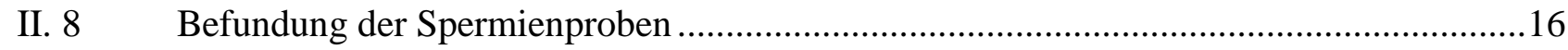

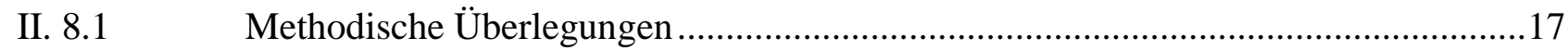

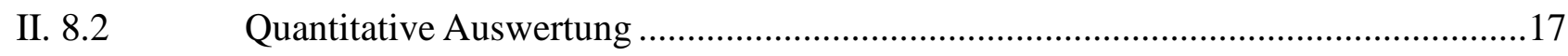

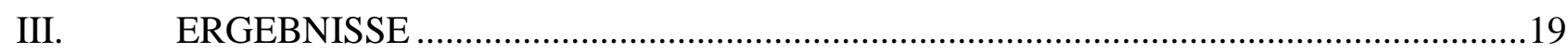

III. 1 Ultrastruktur der untersuchten Spermien ................................................................19

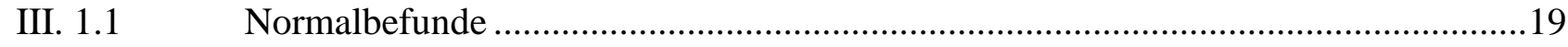

III. $1.2 \quad$ Vergleich nichtsortierter und geschlechtsspezifisch sortierter Spermien ...................20

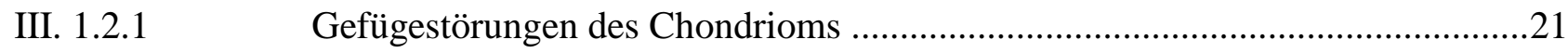

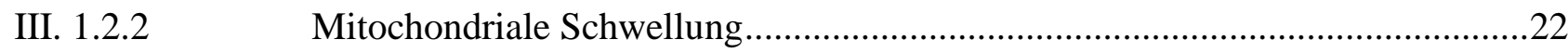

III. 1.2.3 Mitochondrienkonformation..................................................................25

III. 2 Einfluss individueller Komponenten des Sortierprozesses auf die Konformation von

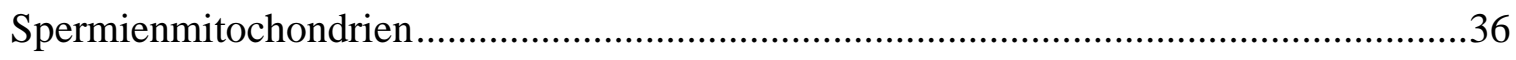

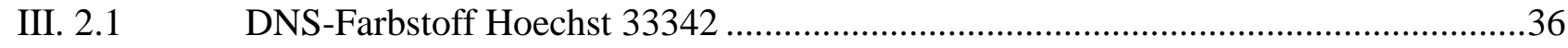

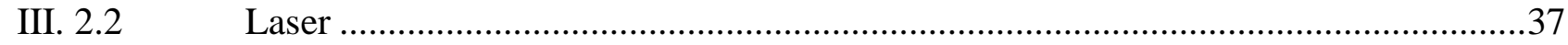

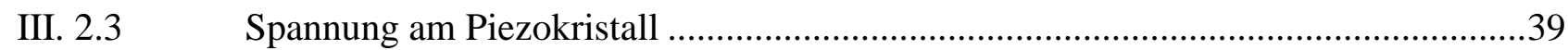

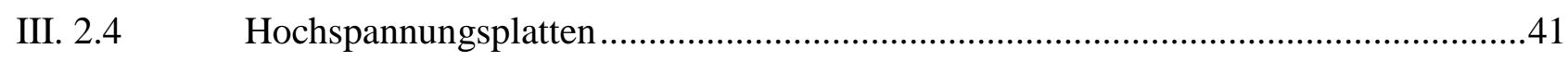

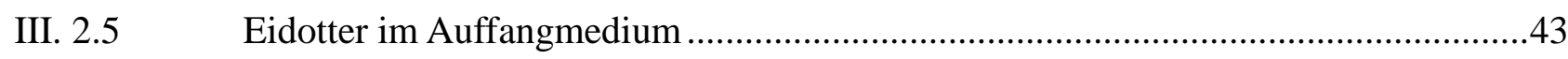


III. 2.6 Seminalplasma im Auffangmedium

III. 3 Einfluss von Aufarbeitungsschritten und Thermoresistenztest auf die Konformation von Mitochondrien geschlechtsspezifisch sortierter Spermien . .46

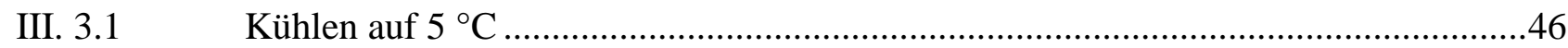

III. 3.2 Kühlen, Einfrieren und Wiederauftauen ............................................................47

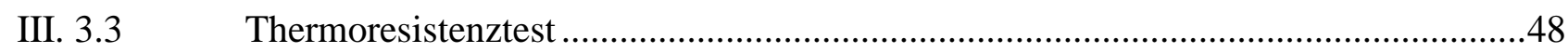

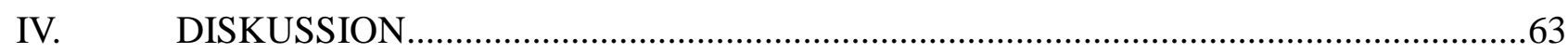

IV. 1 Ultrastruktur der Mitochondrien geschlechtsspezifisch sortierter Spermien...................63

IV. 2 Vorkommen und Funktionen kondensierter Spermienmitochondrien ............................67

IV. 3 Einfluss individueller Komponenten des Sortierprozesses auf die Mitochondrienkonformation von Spermien ............................................................... 70

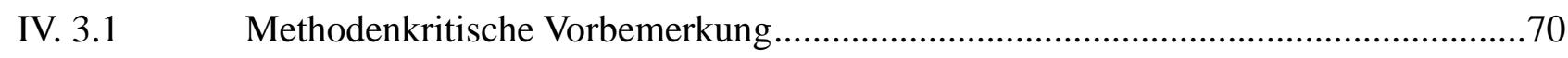

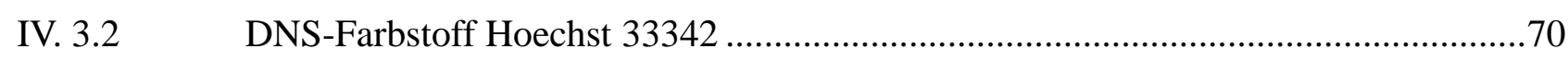

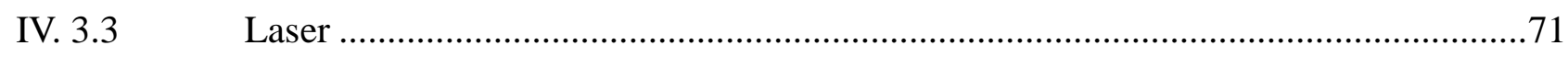

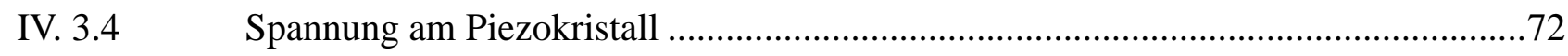

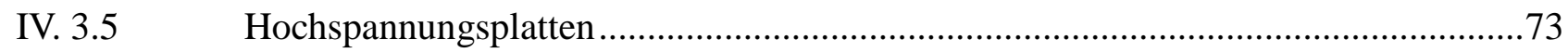

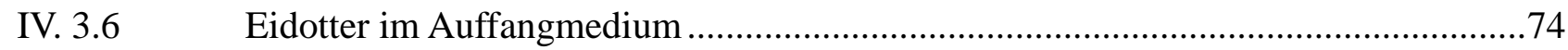

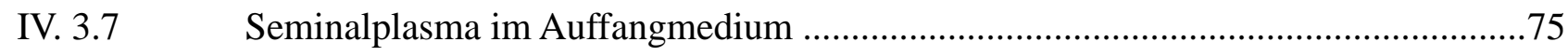

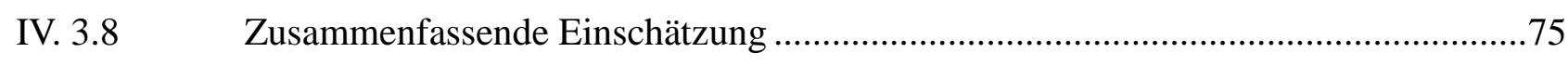

IV. 4 Einfluss von Aufbereitungsschritten und Thermoresistenztest auf die Konformation von Mitochondrien geschlechtsspezifisch sortierter Spermien ........................................... 76

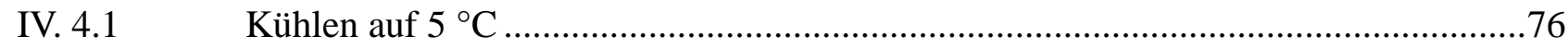

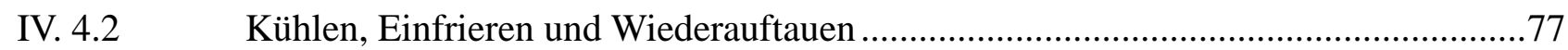

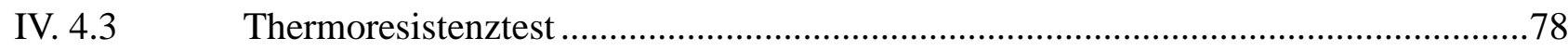

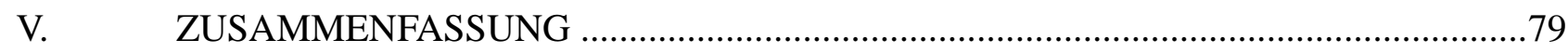

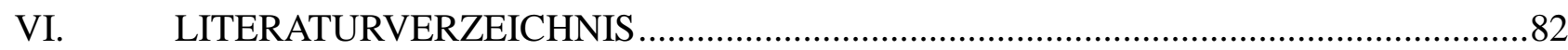




\section{EINLEITUNG}

\section{1 Entwicklung und Ultrastruktur von Säugetierspermien}

Spermien sind strukturell und funktionell polarisierte Zellen, die in den Tubuli seminiferi contorti des Hodens gebildet werden. Sie leiten sich von den an der Basis der Tubuli seminiferi lokalisierten A-Spermatogonien $\mathrm{ab}$, die durch mitotische Teilungen in B-Spermatogonien übergehen (zur Übersicht: Clermont 1972). B-Spermatogonien verdoppeln ihren DNS-Gehalt und entwickeln sich zu frühen Spermatozyten. Diese überwinden die von den Sertoli-Zellen etablierte Blut-Hoden-Schranke (Dym und Fawcett 1970), die adluminal lokalisierte Keimzellstadien unter anderem vor Autoimmunprozessen schützt (zur Übersicht: Setchell 1980, Wong und Cheng 2005). Die langlebigen primären Spermatozyten treten in die erste Reifeteilung ein und differenzieren sich in luminaler Richtung zu den sehr viel kurzlebigeren sekundären Spermatozyten, die ihrerseits im Rahmen der zweiten Reifeteilung jeweils zwei haploide Spermatiden hervorbringen (Clermont 1963). Frühe Spermatiden imponieren als besonders kleine und rundliche Zellen, flachen aber im Heranreifen, noch immer von Sertoli-Zellen gehalten, deutlich ab. Von Spermatozoen (oder Spermien) spricht man erst dann, wenn die Köpfe der Keimzellen aus ihrer Verankerung in den Sertoli-Zellen entlassen und die noch zwischen den späten Spermatiden bestehenden Interzellularbrücken gelöst worden sind (zur Übersicht: Holstein und Roosen-Runge 1981).

Die Weiterentwicklung von Spermatiden zu Spermien wird als Spermiogenese bezeichnet und ist durch komplexe Umbauvorgänge charakterisiert, die die zur Wahrnehmung der späteren Funktion zwingend erforderliche strukturelle Polarisierung der Spermien vorantreiben. Ein entscheidender Schritt in diese Richtung ist getan, sobald das vom Golgi-Apparat gebildete Akrosom seinen Platz am künftigen Vorderpol des Kerns eingenommen hat. Dieser Kern wird unmittelbar anschließend durch eine Rotationsbewegung derart positioniert, dass sein Vorderpol nach basal, der sich entwickelnde Schwanzabschnitt der Keimzelle dagegen zum Lumen des Tubulus seminiferus zeigt (zur Übersicht: Clermont 1972). Im weiteren Verlauf verschmälert sich der Kern unter Verdichtung seines Chromatins. Das an seiner Vorderseite positionierte Akrosom dehnt sich aus und legt sich kappenartig um den Vorderpol des Spermienkerns (de Kretser 1969). Es enthält zahlreiche lytische Enzyme, beispielsweise Hyaluronidasen, und wird außen und innen von einer Akrosomenmembran begrenzt (zur Übersicht: Fawcett 1975). Anschließend inserieren an dem vom Akrosom abgewandten Pol des Kerns zwei Zentriolen (de Kretser 1969), die als Zentrosom oder MTOC (microtubule organizing center) des entstehenden Spermiums bezeichnet werden (zur Übersicht: Palermo et al. 1997). Das kernnahe (proximale) Zentriol kommt dicht bei der Einbuchtung des kaudalen Kernpols 
zu liegen und wird von diesem durch die elektronendichte Basalplatte getrennt. Das weiter distal vom Kern lokalisierte Zentriol bildet das Axonem, dessen Mikrotubuli die für viele bewegliche Zilien typische 9x2-plus-2-Struktur aufweisen. Parallel zur zunehmenden Kondensation des Spermienkopfes verschmälert sich der Zytoplasmasaum des entstehenden Spermienschwanzes (de Kretser 1969).

Im reifen Spermium, das aus einem den Kern tragenden Kopf sowie aus einem in mehrere Unterabschnitte untergliederbaren, fast in seiner gesamten Länge vom Axonem durchsetzten Schwanz besteht (Abb. 1, modifiziert nach Fawcett 1975), sind sämtliche Mitochondrien im Mittelstück untergebracht und helikal angeordnet (André 1962). Ob die für diese regelhafte Anordnung ursächliche, im Rahmen der Spermiogenese stattfindende Umverteilung zuvor regellos angeordneter Mitochondrien, wie beispielsweise im Falle der Sehzellen primatennaher Säugetiere (Knabe und Kuhn 1996), unter dem Einfluss des MTOC erfolgt, ist bisher nicht bekannt. Funktionell wenig verstanden ist auch der Umstand, dass die Mitochondrien entstehender Spermien phasenweise eine „kondensierte“ Konformation annehmen (de Martino et al. 1979, Meinhardt et al. 2000), die im Gegensatz zur „orthodoxen" Konformation durch erhebliche Aufweitungen der Cristae mitochondriales sowie durch eine massive Kondensierung der mitochondrialen Matrix gekennzeichnet ist (Hackenbrock 1966). Die Form der Cristae mitochondriales ist auch in reifen Spermien ausgesprochen schlicht: In den meisten Dünnschnitten finden sich einzeln liegende, linear oder halbkreisförmig verlaufende Membranen. Die im Spermienmittelstück spiralförmig um das im Zentrum liegende Axonem sowie um die weiter außen folgenden neun Außenfibrillen angeordneten Mitochondrien benötigen offenbar mechanisch wirksame Verbindungsstreben, um ihre relative Position zueinander, zur Plasmamembran sowie zu dem zwischen Mitochondrien und Außenfibrillen eingeschobenen submitochondrialen Reticulum zu stabilisieren. Die exakte Zusammensetzung und Funktion solcher an Opossumspermien erstbeschriebenen Verbindungsstrukturen sowie auch des bei Hamsterspermien erstbeschriebenen submitochondrialen Reticulums sind bisher nicht bekannt (Olson und Hamilton 1976, Olson und Winfrey 1986, 1990, 1992).

Distal schließt sich an das Mittelstück das Mitochondrien-freie Hauptstück des Spermiums an, das durch den Besitz einer die Außenfibrillen umrahmenden Faserscheide gekennzeichnet ist (Abb. 1). Verfolgt man Querschnitte durch das Hauptstück im Verlauf von proximal nach distal, verlieren sich die Außenfibrillen schrittweise. Das den Schwanzabschnitt des Spermiums abschließende Endstück enthält lediglich Anteile des Mikrotubulusapparates sowie die Plasmamembran des Spermiums (zur Übersicht: Saacke und Almquist 1964, Fawcett 1975). 

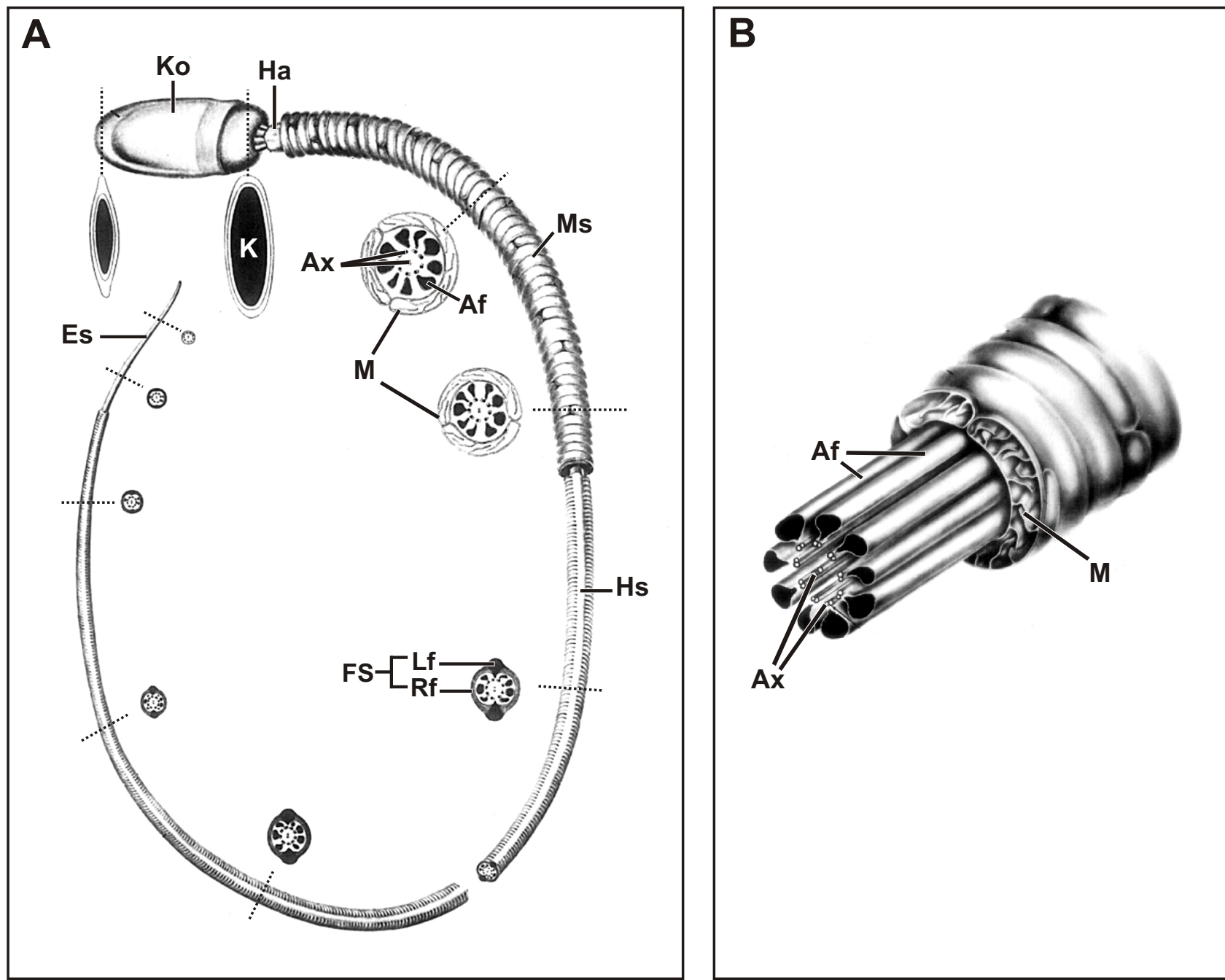

Abb. 1: Übersichtsdarstellung eines ausgereiften Säugetierspermiums (modifiziert nach Fawcett 1975). A: Dreidimensionale Rekonstruktion mit zehn exemplarischen Querschnitten. Af, Außenfibrille; Ax, Axonem; Es, Endstück; Fs, Faserscheide; Ha, Hals; Hs, Hauptstück; K, Kern; Ko, Kopf; Lf, Längsfibrille; M, Mitochondrium; Ms, Mittelstück; Rf, Ringfaser. B: Rekonstruktion des Mittelstücks. 


\section{2 Geschlechtsspezifische Sortierung von Spermien}

Die im Rahmen der Spermatogenese erfolgende Reduktion von einem diploiden auf einen haploiden Chromosomensatz führt dazu, dass reife Spermien entweder über ein X- oder über ein Y-Chromosom verfügen. Der Beitrag des Spermiums legt demnach fest, ob männliche oder weibliche Nachkommen aus der befruchteten Oozyte hervorgehen werden. Trennt man jedoch im Vorfeld die $\mathrm{X}$ - und Y-chromosomalen Spermien eines Ejakulats, so kann das bevorzugte Geschlecht der Nachkommen prinzipiell gesteuert werden (zur Übersicht: Seidel und Garner 2002).

Anforderungen und Wünsche, in dieser Weise auf das Geschlecht von Nachkommen Einfluss zu nehmen, werden von sehr verschiedenen Seiten an die Reproduktionsmedizin herangetragen und sind im Rahmen von humanmedizinischen Anwendungen nicht selten durch den Willen der Familien nach einem „Wunschkind“ motiviert (Karabinus 2009, S. 79: ,helping to balance the gender distribution among their children"). Es ist nicht überraschend, dass solche und andere nicht im strengen Sinne medizinisch indizierte Einsatzformen geschlechtsspezifisch getrennter Spermien kontrovers diskutiert werden (zur Übersicht: Dondorp et al. 2013). Dagegen besteht eine aus medizinischer Sicht eher konsensfähige Indikation beispielsweise dann, wenn ein grundsätzlich bestehender Kinderwunsch dadurch problematisch wird, dass, wie im Falle einer X-chromosomal vererbbaren Hämophilie, weibliche Nachkommen phänotypisch gesunde Konduktorinnen sind, männliche Nachkommen dagegen in jedem Fall erkranken (Fugger 1999, Karabinus 2009, zur Übersicht: Dondorp et al. 2013).

So naheliegend die geschilderten Beispiele für den Einsatz geschlechtsspezifisch sortierter Spermien beim Menschen auch sein mögen, so wenig bilden sie jedoch das Haupteinsatzgebiet dieser Technologie ab. Tatsächlich werden sortierte Spermien am häufigsten zur gezielten Steuerung des Geschlechts der Nachkommen von Nutztieren eingesetzt. Beispielsweise werden bei der Bestandserhaltung von Milchkühen vorzugsweise weibliche Nachkommen herangezüchtet, während bei Fleischrindern männliche Nachkommen von höherem wirtschaftlichen Nutzen sind (zur Übersicht: Hohenboken 1999, Seidel 2007). Bedeutsamer als diese in erster Linie wirtschaftlichen Erwägungen ist die Tatsache, dass der weltweite Bedarf an Lebensmitteln tierischer Herkunft in den nächsten Jahrzehnten massiv steigen wird (zur Übersicht: Delgado et al. 2001). Um dieser steigenden Nachfrage nach tierisch erzeugten Produkten begegnen zu können, wird der intensive Einsatz moderner Biotechnologien in der Landwirtschaft - und hierbei explizit auch die Verwendung geschlechtsspezifisch sortierter Spermien - von der FAO (Food and Agriculture Organization of the United Nations) gefördert (FAO 2009). Eine weitere, nicht zu unterschätzende veterinärmedizinischbiologische Indikation besteht darin, bevorzugt weibliche Nachkommen zu erzeugen, um die Be- 
standswahrung bedrohter Tierarten (zum Beispiel Elefanten) zu unterstützen (Hermes et al. 2009). Selbstverständlich sind die aus den skizzierten Anwendungen gewonnenen grundlegenden Erkenntnisse in vielerlei Hinsicht auch für die Weiterentwicklung der menschlichen Reproduktionsmedizin sowie für den Wissenszuwachs in der Embryologie bedeutungsvoll.

\section{3 Möglichkeiten und Grenzen gegenwärtig eingesetzter Sortierverfahren}

Überlegungen darüber, wie man geschlechtsspezifisch sortierte Spermien gewinnen oder nutzen kann, gehen bis in die Antike zurück (zur Übersicht: Garner und Seidel 2008). So ist die Überzeugung Demokrits überliefert, der zufolge die aus dem rechtsseitigen Hoden stammenden Spermien männliche und die aus dem linksseitigen Hoden stammenden Spermien weibliche Nachkommen hervorbringen sollen. Überzeugendere Ansätze stammen erst aus dem 20. nachchristlichen Jahrhundert. Beispielsweise versuchte man, X- und Y-chromosomale Spermien auf der Basis ihres Schwimmverhaltens, ihres Gewichts oder ihrer physiologischen Oberflächenladung voneinander zu trennen (zur Übersicht: Fugger 1999, Garner und Seidel 2008).

Fast alle heutzutage im Routinebetrieb erfolgreich eingesetzten Sortiergeräte nutzen jedoch den Umstand, dass X-chromosomale Spermien eine größere Menge an DNS besitzen als Y-chromosomale. Genauer besteht das Prinzip der so genannten United States Department of AgricultureBeltsville Sperm Sexing Technology (Johnson 1997) darin, dass die Erbsubstanz der Spermien zunächst mit einem Farbstoff, beispielsweise mit Hoechst 33342, markiert wird, der die Membranen des Spermienkopfes durchdringt und Bindungen mit der DNS eingeht. Die Menge an gebundenem Farbstoff hängt von der im Spermium enthaltenen DNS-Menge ab. Wenn die auf diese Art markierten Spermien das Sortiergerät durchlaufen, wird der Farbstoff mit einem Laser angeregt, woraufhin die Farbstoffmoleküle Fluoreszenzsignale emittieren, deren verschieden hohe Intensität den Unterschied zwischen X- und Y-chromosomalen Spermien widerspiegelt. Dieser Umstand wird dazu genutzt, identifizierte X- oder Y-chromosomale Spermien einheitlich entweder mit einer positiven oder mit einer negativen Ladung zu versehen, unter dem Einfluss eines starken elektrischen Feldes in unterschiedliche Richtungen abzulenken und separat in zwei Behältern zu sammeln. Die in jedem Ejakulat physiologischerweise zu einem bestimmten Prozentsatz enthaltenen membrangeschädigten (und deshalb häufig abgestorbenen) Spermien findet man in diesen beiden Sammelbehältern aber nicht, weil der Lebensmittelfarbstoff, der jeder Spermienprobe vor dem Sortieren zugegeben wird, defekte Membranen erkennt, in die Zellen eindringt und die Aussendung des für die Zuweisung einer elektrischen Ladung erforderlichen Fluoreszenzsignals abschwächt. Folglich fallen geschädigte Spermien unabgelenkt in den Abfallbehälter des Geräts (zur Übersicht: Seidel und Garner 2002). Sortiergeräte, die nach dem oben skizzierten Verfahren arbeiten, erreichen bezüglich der Trenn- 
schärfe X- oder Y-chromosomaler Spermien je nach Tierart mittlerweile Erfolgsquoten zwischen 85 und 95 Prozent. Dennoch bleibt die anschließend erzielte Rate erfolgreicher künstlicher Besamungen nicht selten hinter den Erwartungen zurück (de Jarnette et al. 2011: bis zu 16 Prozent geringere Befruchtungsraten im Vergleich zu nichtsortierten Spermien; zur Übersicht: Seidel und Garner 2002, Fritjers et al. 2009). Angesichts der Brisanz, die von den geschilderten ernährungspolitischen Zusammenhängen ausgeht, aber auch angesichts der wissenschaftlich herausfordernden und facettenreichen Frage nach den tatsächlichen Ursachen für die noch immer zu hohen Misserfolgsraten, haben sich im Jahr 2007 Wissenschaftler unterschiedlicher Fachdisziplinen unter der Ägide von Herrn Prof. Dr. med. vet. Detlef Rath (Institut für Nutztiergenetik am Friedrich-Löffler-Institut in Neustadt am Rübenberge) zu einer Arbeitsgruppe zusammengeschlossen, der auch die AG Neuroembryologie des Instituts für Anatomie und Embryologie der Universität Göttingen angehörte. Ziel unserer Bemühungen war es zunächst, geschlechtsspezifisch sortierte Spermien strukturell und funktionell systematisch zu analysieren (Cinar et al. 2010, Mönch-Tegeder et al. 2010, Taylor et al. 2010a, Cinar et al. 2011, Stinshoff et al. 2012, zur Übersicht: Rath et al. 2013). Weitere Arbeitsschwerpunkte befassten sich beispielsweise mit der Frage, welchen Einflüssen (sortierte) Spermien im weiblichen Genitaltrakt unterliegen (Bergmann et al. 2013) und ob es möglich ist, X- und Ychromosomale Spermien mit Nanopartikeln zu fusionieren, gentechnisch zu markieren und unter Einsatz neuartiger Technologien voneinander zu trennen (Taylor et al. 2009, 2010b, 2010c, Barchanski et al. 2011, Petersen et al. 2011, Taylor et al. 2011, 2012, Rath et al. 2013, Sieg et al. 2013, Taylor et al. 2013, Tiedemann et al. 2013).

Vor Arbeitsbeginn wurde zusammengetragen, was bisher über die möglichen Ursachen des noch immer zu geringen Befruchtungserfolgs geschlechtsspezifisch sortierter Spermien bekannt war. Einer der Leitbefunde für die anatomische Arbeitsgruppe war hierbei, dass die Beweglichkeit sortierter Spermien im Vergleich zu nichtsortierten signifikant herabgesetzt ist (Grossfeld et al. 2005). Angesichts dieses Befundes lag die Vermutung nahe, dass Schäden an den Mitochondrien ursächlich für die beobachteten Funktionseinbußen sortierter Spermien sein könnten. Diese Anfangshypothese wurde durch drei weitere Befunde anderer Arbeitsgruppen erhärtet: Erstens decken die von uns untersuchten Rinder, keineswegs aber alle übrigen für geschlechtsspezifische Sortierprozesse herangezogenen Tierarten, den Energiebedarf ihrer Spermien primär über die Aktivität der Mittelstück-Mitochondrien (zur Übersicht: Storey 2008). Zweitens belegen die Untersuchungen von Gallon et al. (2006) am Beispiel menschlicher Spermien eine gleichsinnige Abhängigkeit zwischen der Höhe des mitochondrialen Membranpotenzials, dem Ausmaß der Spermienmotilität und dem Befruchtungserfolg. Drittens sprechen auch die von Pelliccione et al. (2011) vorgelegten Befunde dafür, dass wenigstens ein Teil der von diesen Autoren beschriebenen Fälle menschlicher Asthenozoospermie auf 
ultrastrukturell fassbaren Defekten der Mittelstück-Mitochondrien beruht.

\section{4 Fragestellung und Arbeitsprogramm}

Überraschenderweise stellte sich heraus, dass eine systematische transmissionselektronenmikroskopische Analyse geschlechtsspezifisch sortierter Rinderspermien, die auch potenzielle mitochondriale Strukturdefekte einbezogen hätte, bisher nicht publiziert worden ist. Folglich bestand das erste Ziel der vorliegenden Arbeit darin, die Ultrastruktur standardsortierter und nichtsortierter Rinderspermien unter besonderer Berücksichtigung des Chondrioms miteinander zu vergleichen.

Hierbei konnten im Rahmen der Methodenetablierung nicht nur bekannte ultrastrukturelle Charakteristika von Rinderspermien bestätigt, sondern auch neuartige, bei Rinderspermien bisher nicht beschriebene anatomische Strukturen identifiziert werden, die möglicherweise unter anderem auch für die mechanische Stabilisierung des Chondrioms verantwortlich sind. Weiterhin stellten wir fest, dass die Mitochondrien geschlechtsspezifisch sortierter Rinderspermien ein relativ großes Spektrum struktureller Veränderungen aufweisen, dass aber in dem bisher zur Verfügung stehenden Untersuchungsmaterial eine zuverlässige Unterscheidung zwischen sortierten und nichtsortierten Rinderspermien lediglich über den Konformationszustand der Mitochondrien zu gewinnen ist.

In Kenntnis eines solchen eindeutig nachweisbaren ultrastrukturellen Unterscheidungsmerkmals war es naheliegend, die ursprüngliche Fragestellung aufzuweiten und zu versuchen, die für das geschlechtsspezifische Sortieren und Aufbereiten von Spermien etablierten Versuchsbedingungen systematisch zu modifizieren, um einzelne oder wenigstens Gruppen von Komponenten des Sortierverfahrens identifizieren zu können, die primär für die Entstehung des beobachteten Merkmals verantwortlich sein könnten. Hierbei zeigte sich, dass solche Komponenten tatsächlich identifizierbar sind und (in der Zusammenschau mit den Ergebnissen anderer Arbeitsgruppen unseres Forschungsverbundes) auch, dass es prinzipiell möglich sein müsste, neuartige Sortierverfahren zu entwickeln, die wenigstens zum Teil auf derartige Komponenten verzichten (zur Übersicht: Rath et al. 2013, Taylor et al. 2013). Die abschließende Diskussion führt aus, warum und auf welche Weise die neu gewonnenen Erkenntnisse über die Struktur des Chondrioms geschlechtsspezifisch sortierter Rinderspermien in Folgearbeiten funktionell überprüft und erweitert werden müssen. 


\section{MATERIAL UND METHODEN}

\section{1 Gewinnung und Aufarbeitung von Spermienproben}

Sowohl bei der Spermiengewinnung und -aufarbeitung als auch bei der anschließenden geschlechtsspezifischen Sortierung von Spermien handelt es sich um etablierte Verfahren, die von unseren Kooperationspartnern im Institut für Nutztiergenetik am Friedrich-Loeffler-Institut in Neustadt am Rübenberge einerseits für die routinemäßige Besamung in der Tierzucht, andererseits für experimentelle Untersuchungen durchgeführt werden. Deshalb werden die hierbei eingesetzten Materialien und Methoden unter Verweis auf die von unseren Kooperationspartnern publizierte umfangreiche Primärliteratur (Rath et al. 1997, Buß 2005, Klinc 2005, Bathgate et al. 2007, Heer 2007, Klinc und Rath 2007, Morton et al. 2007) lediglich übersichtsartig dargestellt (Kapitel II. 1 II. 3). Die für die vorliegende Dissertation entworfenen experimentellen Versuchsansätze sowie das hierfür verwendete Probenmaterial werden anschließend detailliert erläutert (Kapitel II. 4).

Das Bullen-Ejakulat (Rasse Holstein-Friesian) wurde in einer künstlichen Vagina aufgefangen und in ein Wasserbad $\left(27^{\circ} \mathrm{C}\right)$ überführt. Anschließend erfolgte die Bestimmung der Spermienkonzentration mittels einer Zählkammer (Thoma neu, Hecht, Sontheim, Deutschland) sowie die Feineinstellung der Spermienmenge auf 100×10 $10^{6}$ Spermien/ml durch Zugabe der in Klinc und Rath (2007) spezifizierten Tris-BSA-Probenlösung (199,98 mM Tris-hydroxymethyl-aminomethan; 64,72 mM Zitronensäure-Monohydrat; 95,5 mM D-Fruktose; $50 \mathrm{mg}$ Gentamicinsulfat und $3 \mathrm{mg} / \mathrm{ml}$ bovines Serum-Albumin (Fraktion V) in doppelt destilliertem Wasser $\left.\left(\mathrm{ddH}_{2} \mathrm{O}\right)\right)$ mit Antioxidantien $(1 \mathrm{mM}$ Natriumpyruvat, 15 IU (International Units) Katalase/ml).

\section{2 Geschlechtsspezifische Sortierung von Spermien}

Für die geschlechtsspezifische Auftrennung der Ejakulate in X- und Y-chromosomale Spermien wurde ein Hochgeschwindigkeits-Zellsortierer vom Typ MoFlo SX (Dakocytomation, Fort Collins, CO, USA) verwendet (Abb. 2, modifiziert nach Buß 2005), dessen Bau- und Funktionsprinzip Seidel und Garner (2002) in einer umfangreichen Übersichtsarbeit vorgestellt haben.

Bei den im Rahmen der vorliegenden Arbeit untersuchten Rinderspermien enthalten die X-chromosomalen Spermien zirka 4 Prozent mehr DNS als Y-chromosomale Spermien (Garner et al. 1983). Sie können daher nach Zugabe des Farbstoffs Hoechst 33342 (Sigma-Aldrich, Taufkirchen, Deutschland; Inkubation: $1 \mathrm{~h}, 34{ }^{\circ} \mathrm{C}$ ), der sich proportional zur DNS-Menge in den Spermienkopf einlagert, voneinander unterschieden werden. Hoechst 33342 durchdringt sämtliche Membranen des 
Spermiums und bindet in der kleinen Furche der DNS-Helix nicht interkalierend an Adenin-Thymin-Basenpaare (zur Übersicht: Seidel und Garner 2002). Während des Sortiervorgangs wird Hoechst 33342 durch einen Laser (Argon-UV-Laser Inova I 90C-6, Coherent GmbH, Dieburg, Deutschland) bei 351-364 nm Wellenlänge angeregt (Buß 2005). Das hierdurch provozierte Fluoreszenzsignal ist, wie zu erwarten, bei X-chromosomalen Spermien stärker ausgeprägt als bei Ychromosomalen Spermien (Seidel und Garner 2002). Die Menge an zugegebenem Hoechst 33342 (zwischen 15 und $25 \mu 1$ pro $\mathrm{ml}$ ) wird für jede Spermienprobe in „Probeläufen“ individuell festgelegt, um eine möglichst hohe Trennschärfe beim Sortieren zu erzielen.

Für unsere Experimente wurden die mit Hoechst 33342 markierten Spermien durch ein Mikrosieb mit $51 \mu \mathrm{m}$ Maschenweite (Becton, Dickinson and Company, Franklin Lakes, NY, USA) filtriert und mit $1 \mu \mathrm{l}$ des gelösten Lebensmittelfarbstoffs FD\&C (Food, Drugs and Cosmetics certified color

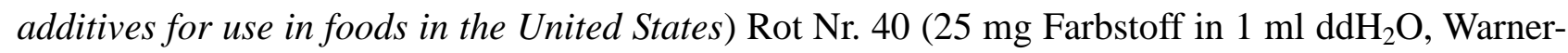
Jenkinson Company Inc., St. Louis, MO, USA) pro ml Spermienprobe versetzt. Dieser Lebensmittelfarbstoff dringt in membrangeschädigte Spermien ein und reduziert dort die Energie des von Hoechst 33342 emittierten Fluoreszenzsignals (Seidel und Garner 2002, Evans et al. 2013). Folglich können membrangeschädigte Spermien nicht mehr geschlechtsspezifisch sortiert werden.

Die auf diese Weise vorbehandelten Spermienproben wurden mit hohem Druck (zirka 2,76 bar) sowie unter Zugabe von $5 \mathrm{ml}$ einer Mantelflüssigkeit (Klinc 2005: 149 g Natriumzitrat; 500000 IU Penicillin G; 0,25 g Streptomycinsulfat in $51 \mathrm{ddH}_{2} \mathrm{O}$ bei $\mathrm{pH}$ 6,9) mit Zusatz von Antioxidantien (Klinc und Rath 2007: 100 mg Natriumpyruvat; 15 IU/ml Katalase) durch eine Düse mit elliptisch geformtem Kanal gepresst. Im Regelfall wurde eine Sortierrate von zirka 2500 Spermien/s erreicht. Die elliptische Form des Düsenkanals wurde gewählt, um die paddelförmigen Spermienköpfe möglichst einheitlich auszurichten. Verglichen mit den zuvor eingesetzten zylindrisch geformten Düsen steigt die Rate korrekt orientierter Spermien bei Verwendung elliptisch geformter Düsen auf zirka 60 Prozent (Rens et al. 1998).

Der an der Düse angebrachte Piezokristall lässt die Düse vibrieren, wodurch der zuvor zusammenhängende Strom der Spermien in einzelne Tröpfchen zerlegt wird. Für die korrekte Bestimmung des DNS-Gehalts der Spermien ist es notwendig, dass jedes Tröpfchen ein einziges Spermium enthält, und dass die Breitseite des paddelförmigen Spermienkopfes senkrecht auf den Strahlengang des Lasers ausgerichtet ist. Die Höhe der am Piezokristall eingestellten Spannung beeinflusst die Vibrationsamplitude der Düse. Werden niedrigere Spannungen angesetzt (in unseren Experimenten 5 Volt statt 25 oder 30 Volt), nimmt auch die Vibrationsamplitude ab. Hierdurch wird der auf die Plasma- 
membran der Spermien wirkende Druck gesenkt (mündliche Mitteilung von D. Rath, Institut für Nutztiergenetik, am 05. 12. 2013).

Nach dem Verlassen der Düse passieren die Spermien den Laserstrahl. Der erste von insgesamt zwei Fluoreszenzdetektoren liegt der Laserquelle direkt gegenüber und misst das von der Breitseite des Spermienkopfes abgegebene Fluoreszenzsignal. Der zweite, senkrecht zum ersten ausgerichtete Detektor misst das von der Schmalseite des Spermienkopfes emittierte Fluoreszenzsignal. Die Fluoreszenzstärke an der Schmalseite variiert in Abhängigkeit von der Orientierung des Spermienkopfes zum Laser. So lässt sich überprüfen, ob der Spermienkopf im Tröpfchenstrom korrekt orientiert ist und somit auch, ob zuverlässige Rückschlüsse auf die im Spermienkopf lokalisierte DNS-Menge möglich sind. Nach ihrer fluoreszenzbasierten Identifikation erhalten X-chromosomale Spermien eine negative, Y-chromosomale Spermien dagegen eine positive elektrische Ladung. Genau diese elektrische Aufladung unterbleibt jedoch, wenn der Lebensmittelfarbstoff FD\&C Rot Nr. 40 in membrangeschädigte Spermien eindringt und die Fluoreszenz schwächt. Solche Spermien fallen ungeladen und unabgelenkt in den Abfallbehälter des Sortiergerätes (Seidel und Garner 2002).

Identifizierte und elektrisch geladene Spermien werden innerhalb des anschließend zu durchlaufenden, von zwei Hochspannungsplatten (3500 Volt) erzeugten elektrischen Feldes in unterschiedliche Richtungen abgelenkt und in zwei jeweils $10 \mathrm{ml}$ fassenden Plastikröhrchen (Greiner Bio-One $\mathrm{GmbH}$, Frickenhausen, Deutschland) separat aufgefangen. Diese Röhrchen werden mit je 0,5 ml eines TEST-Dotter-Mediums gefüllt (TEST (Graham et al. 1972): Kombination aus TES (N-Trishydroxymethyl-methyl-2-aminoethansulfonsäure)-Puffer und Tris-Puffer). In der hier verwendeten, nach Klinc (2005) modifizierten Version dieses Auffangmediums sind folgende Komponenten enthalten: 5 g Eidotter; 0,01 g Gentamicinsulfat; 11,10 mM Glukose; 188,73 mM TES; 84,78 mM Tris

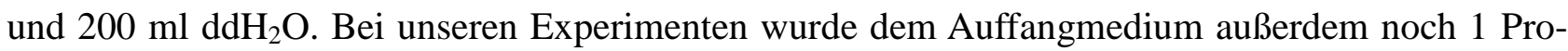
zent Seminalplasma vom Rind zugesetzt, weil Seminalplasma den Anteil motiler und strukturell intakter geschlechtsspezifisch sortierter Spermien erhöht (Maxwell et al. 1996).

Für die transmissionselektronenmikroskopischen Untersuchungen wurde der Inhalt von zwei Auf-

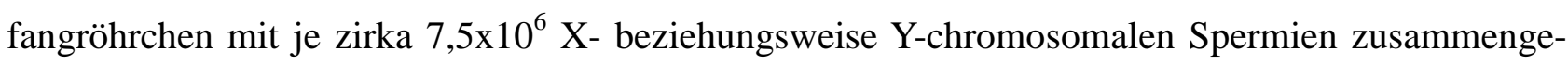
führt (gepoolt) und zentrifugiert (20 min, 838x g). Das resultierende Pellet enthält zirka $15 \times 10^{6}$ Spermien, der Überstand wird abpipettiert und verworfen. 
Düse (innen elliptisch geformt) mit Piezokristall

Laser

Hochspannungsplatten

Auffangröhrchen für X-chromosomale Spermien

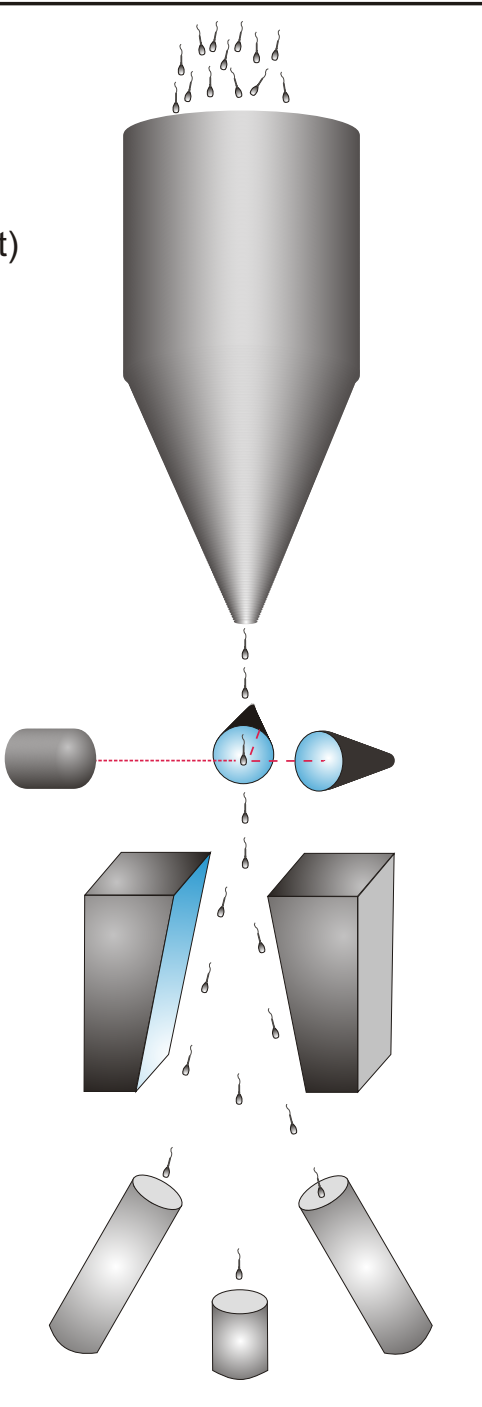

Abfallbehälter

\section{Spermienprobe}

Zwei Fluoreszenzdetektoren

\section{Auffangröhrchen für Y-chromosomale Spermien}

Abb. 2: Funktionsprinzip der United States Department of Agriculture-Beltsville Sperm Sexing Technology (Johnson 1997, Abbildung modifiziert nach Buß 2005). Eine detaillierte Erläuterung erfolgt im Text. 


\section{3 Aufarbeitung geschlechtsspezifisch sortierter Spermien}

Im Rahmen der routinemäßigen Aufarbeitung geschlechtsspezifisch sortierter Rinderspermien wurde das aus dem Sortiervorgang resultierende Pellet in einem ersten Tiefgefriermedium auf $41 \times 10^{6}$ Spermien/ml verdünnt. Das erste Tiefgefriermedium setzte sich aus 67,2 $\mathrm{ml}$ einer Stammlösung (82,59 mM D-Fruktose; 0,606 g Penicillin; 1,480 g Streptomycinsulfat; 297,59 mM Tris; 96,32 mM

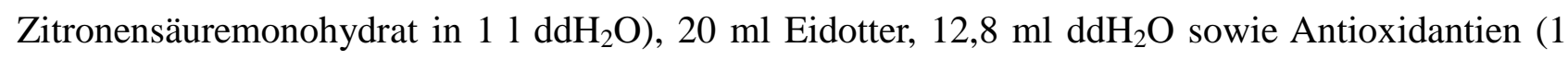
$\mathrm{mM}$ Natriumpyruvat; $15 \mathrm{IU} / \mathrm{ml}$ Katalase) zusammen. Diese Spermiensuspension wurde innerhalb von zwei Stunden auf $5{ }^{\circ} \mathrm{C}$ heruntergekühlt. Danach wurden die Spermien in einem zweiten Tiefgefriermedium auf $20,5 \times 10^{6}$ Spermien/ml verdünnt. Dieses zweite Tiefgefriermedium bestand aus 67,2 ml der oben genannten Stammlösung, 20 ml Eidotter, 0,75 Prozent Equex STM, 12,8 ml Glycerol (87 Prozent) sowie Antioxidantien (1 mM Natriumpyruvat; 15 IU/ml Katalase).

Das Tiefgefrieren der Spermiensuspension erfolgte in Plastikröhrchen mit einem Fassungsvermögen von 0,25 ml (Minituib GmbH, Tiefenbach, Deutschland). Diese waren mit $50 \mu 1$ einer 1:1 Mischung aus den beiden Tiefgefriermedien beschickt und an einem Ende mit einem PolyvinylpyrrolidonBaumwollpfropfen verschlossen. Anschließend wurden $160 \mu \mathrm{l}$ der Spermiensuspension eingefüllt, so dass jedes Röhrchen zirka $3,3 \times 10^{6}$ sortierte Spermien enthielt. Das offene Ende des Plastikröhrchens wurde nun mittels Ultraschall verschweißt. Dann wurden die Röhrchen 15 Minuten lang in 3-5 cm Abstand über flüssigen Stickstoff gehalten, anschließend in flüssigen Stickstoff eingetaucht und für mindestens vier Wochen bei $-196{ }^{\circ} \mathrm{C}$ aufbewahrt.

Wie bei der Verwendung in der Viehzucht wurden die Plastikröhrchen zur weiteren Untersuchung für $25 \mathrm{~s}$ in einem Wasserbad $\left(38^{\circ} \mathrm{C}\right)$ aufgetaut. Für unsere elektronenmikroskopischen Untersuchungen wurde der Inhalt mehrerer Röhrchen mit Spermiensuspension in ein Eppendorf-Reaktionsgefäß überführt, so dass die von uns analysierten Proben jeweils etwa $15 \times 10^{6}$ Spermien enthielten. 


\section{4 Analyse individueller Komponenten des Sortierprozesses}

Um herauszufinden, ob bestimmte Komponenten des Sortierprozesses bevorzugt für das Auftreten ultrastruktureller Veränderungen an sortierten Spermien verantwortlich gemacht werden können, wurden folgende experimentelle Untersuchungsbedingungen definiert (Tab. 1):

Tab. 1: Übersicht über die unterschiedliche Behandlung von Spermienproben

\section{ID Kurzbeschreibung}

$1 \quad$ Nichtsortierte Spermien (Kontrollproben)

2 Inkubation nichtsortierter Spermien mit DNS-Farbstoff Hoechst 33342

$3 \quad$ Standardsortierung

3+ Wie ID3, dann Hinzufügung unabgelenkter Spermien aus dem Abfallbehälter des Sortiergeräts

4 Sortiert, kein Eidotter im Auffangmedium

5 Durchlauf des Sortiergeräts bei ausgeschaltetem Laser

6 Sortiert bei reduzierter Spannung am Piezokristall (5 Volt)

7 Durchlauf des Sortiergeräts bei ausgeschalteten Hochspannungsplatten

8 Sortiert, kein Zusatz von Seminalplasma zum Auffangmedium

9 Wie ID3, dann Zugabe des ersten Tiefgefriermediums, Kühlen auf $5{ }^{\circ} \mathrm{C}$ binnen $2 \mathrm{~h}$

10 Wie ID9, dann Zugabe des zweiten Tiefgefriermediums, Einfrieren in flüssigem Stickstoff, Wiederauftauen

11 Wie ID10, dann Thermoresistenztest $\left(37^{\circ} \mathrm{C}\right.$ für $\left.6 \mathrm{~h}\right)$

ID, Identifikationsnummer der Spermienbehandlung.

Für die im Rahmen der vorliegenden Arbeit durchgeführten Untersuchungen und Experimente wurden über einen Zeitraum von zirka einem Jahr 66 Spermienproben von insgesamt drei Bullen (Tiere 1, 2 und 3) der Rasse Holstein-Friesian folgendermaßen behandelt (Tab. 2): 
Tab. 2: Übersicht des verwendeten Probenmaterials

\begin{tabular}{|c|c|c|c|c|c|c|c|c|c|c|c|}
\hline $\begin{array}{l}\text { Proben- } \\
\text { entnahmetag }\end{array}$ & ID1 & ID2 & ID3 & ID4 & ID5 & ID6 & ID7 & ID8 & ID9 & ID10 & ID11 \\
\hline 16. 06. 2008 & 1 & 1 & 1 & & & & & & & & \\
\hline 23. 06. 2008 & 1 & & & 1 & & & & & & & \\
\hline 30. 06. 2008 & 1 & & 1 & & 1 & & & & & & \\
\hline 14. 07. 2008 & 1 & & 1 & & & & 1 & 1 & & & \\
\hline 05. 08. 2008 & 1 & & 1 & & & 1 & & & & & \\
\hline 12. 08.2008 & 1 & & & & & & & & 1 & & \\
\hline 18. 08. 2008 & & & & & & & & & & 1 & 1 \\
\hline 11. 08.2008 & 2 & 2 & 2 & & & & & & & & \\
\hline 18. 08. 2008 & 2 & & & 2 & & & & & & & \\
\hline 25. 08. 2008 & 2 & & 2 & & 2 & & & & & & \\
\hline 09. 09. 2008 & 2 & & 2 & & & & & 2 & & & \\
\hline 23. 09. 2008 & 2 & & 2 & & & & 2 & & & & \\
\hline 07. 10. 2008 & 2 & & 2 & & & 2 & & & & & \\
\hline 08. 10. 2008 & 2 & & & & & & & & 2 & & \\
\hline 22. 10. 2008 & 2 & & & & & & & & & 2 & 2 \\
\hline 21. 04. 2009 & 3 & 3 & 3 & & & & & & & & \\
\hline 05. 05. 2009 & 3 & & & 3 & & & & 3 & & & \\
\hline 26. 05. 2009 & 3 & & $3^{\mathrm{a}}$ & & 3 & & & & & & \\
\hline 02. 06. 2009 & 3 & & 3 & 3 & & & 3 & & & & \\
\hline 09. 06. 2009 & 3 & & 3 & & & 3 & & & & & \\
\hline 16. 06. 2009 & 3 & & & & & & & & 3 & & \\
\hline 23. 06. 2009 & 3 & & & & & & & & & 3 & 3 \\
\hline 07. 07. 2009 & 3 & & 3 & 3 & & & 3 & & & & \\
\hline
\end{tabular}

\section{5 Probenaufarbeitung für die Transmissionselektronenmikroskopie}

Unabhängig von der Behandlung der Spermienproben (Tab. 1) erfolgte die Fixierung des Untersuchungsmaterials über Nacht in einer Lösung aus 1,5 Prozent Glutaraldehyd (SERVA Electrophoresis GmbH, Heidelberg, Deutschland) und 1,5 Prozent Paraformaldehyd (Merck KGaA, Darmstadt, Deutschland) in 0,1 M Phosphatpuffer, $\mathrm{pH}$ 7,3 (77 mM di-Natriumhydrogenphosphat-Dihydrat; 23 mM Natriumhydrogenphosphat-Monohydrat) bei Raumtemperatur. Das dabei verwendete Volumen der Fixierlösung betrug das 10fache des Volumens der Spermiensuspension mit $15 \times 10^{6}$ Spermien. Anschließend wurde die Spermiensuspension zentrifugiert (5 min, 1000x g), der Überstand verworfen. Das resultierende Pellet wurde in einem Reaktionsgefäß 5 min mit 0,1 M Phosphatpuffer gewa- 
schen (Pellet hierfür in zirka 10fachem Volumen gelöst). Die Suspension wurde nun erneut zentrifugiert (5 min, 1000x g). Der Überstand wurde verworfen und das Pellet durch vorsichtiges Schütteln wieder in Lösung gebracht. Dann wurde die Zellsuspension im Verhältnis 1:1 mit einer 2-prozentigen SeaPrep Agarose-Lösung (Lonza GmbH, Wuppertal, Deutschland; in 0,1 M Phosphatpuffer) gemischt und in eine 0,3-ml-Hartgelatine-Leer-Kapsel (Küpper-PRIMAX GmbH, Troisdorf, Deutschland) eingefüllt. Diese Kapsel wurde in ein Eppendorf-Reaktionsgefäß eingebracht und zentrifugiert (5 min, 1000x g). Anschließend wurde die Agarose auf Eis ausgehärtet (30 min). Danach wurde das Pellet mit einem Skalpell aus der Kapsel ausgeschnitten.

Die Nachfixierung $(1 \mathrm{~h})$ erfolgte in einer 1-prozentigen Osmiumtetroxidlösung (SERVA Electrophoresis) in $0,1 \mathrm{M}$ Phosphatpuffer. Anschließend wurden die Proben in 0,1 M Phosphatpuffer gewaschen (3x5 min), in einer aufsteigenden Alkoholreihe entwässert (70, 80 und 90 Prozent für je 10 min; 100 Prozent für 2x15 min und 1x30 min) und nacheinander in Propylenoxid (SERVA Electrophoresis; 2x5 min) sowie in Gemische aus Propylenoxid und Araldit (SERVA Electrophoresis) eingebracht, und zwar zunächst im Verhältnis 1:1 für $1 \mathrm{~h}$, dann 1:3 über Nacht. Anschließend wurde das Pellet in reines Araldit eingebracht (zunächst für 45 min bei Raumtemperatur, dann 45 min bei $60{ }^{\circ} \mathrm{C}$ ) und abschließend in Kautschukförmchen aus Elastosil M4601 (Kahmann \& Ellerbrock, Bielefeld, Deutschland) wiederum in reinem Araldit eingebettet und ausgehärtet (3 Tage, $\left.60{ }^{\circ} \mathrm{C}\right)$.

\section{6 Herstellung von Dünnschnitten für die Licht- und Elektronenmikroskopie}

Die aus den Kautschukförmchen entnommenen Aralditblöckchen wurden mit einem Blocktrimmer (Modell TM60, Reichert-Jung, Heidelberg, Deutschland) angefräst, so dass die Spitze des eingebetteten Spermienpellets offenlag. Danach wurden die Blöckchen, ausgehend von der freiliegenden Schnittfläche, an allen vier Kanten pyramidenförmig ,zugetrimmt“.

Für die orientierende Untersuchung der Proben am Lichtmikroskop wurden zunächst $1 \mu \mathrm{m}$ dünne Schnitte hergestellt (Reichert-Jung Ultracut E, Diamantmesser DIATOME Histo, Leica Mikrosysteme Vertrieb GmbH, Wetzlar, Deutschland). Zwei bis zehn solcher Schnitte wurden auf einen Glasobjektträger aufgebracht, auf einer Wärmeplatte getrocknet, mit Methylenblau (in Borat mit 1 Prozent Azur II (1:1)) für zirka 20 s gefärbt, gespült, getrocknet und mit DePeX (SERVA Electrophoresis) und einem Deckgläschen eingedeckt.

Zur Herstellung von Dünnschnitten für die Transmissionselektronenmikroskopie wurde der pyramidenförmig getrimmte Aralditblock erneut verkleinert, um die Gewinnung von Schnitten mit einer Dicke von nur 50 bis $90 \mathrm{~nm}$ zu erleichtern. Diese Schnitte wurden mit einem Diamantmesser (DIA- 
TOME Ultra, Leica) hergestellt, anschließend durch kurzzeitige Chloroformbedampfung gestreckt und auf mit Formvar (SERVA Electrophoresis) beschichtete Ein-Loch-Blenden (Leica) übertragen. Die Kontrastierung der Schnitte (0,5 Prozent Uranylazetat, 3 Prozent Bleizitrat, Leica) erfolgte mit dem Kontrastiergerät EM AC20 (Leica). Die kontrastierten Schnitte wurden in Reichert-Gridboxen (Leica) von Dritten archiviert und verblindet, so dass für den Untersucher weder Datum, Tier noch die Identifikationsnummer der Spermienbehandlung (Tab. 1) aus der Position der Blende in der Gridbox ersichtlich waren.

\section{7 Bildakquisition im Transmissionselektronenmikroskop}

Für die transmissionselektronenmikroskopische Auswertung der Schnitte stand ein EM 900 (Leo GmbH, Oberkochen, Deutschland) zur Verfügung. Die Analysen wurden bei einer Betriebsspannung von 50 Kiloelektronenvolt unter Stickstoffkühlung durchgeführt. Ziel der Bildakquisition war es, von jeder Probe Aufnahmen von 100 Mittelstückanschnitten für die spätere Befundung und statistische Auswertung zu erstellen (MegaView III-Kamera; Auflösung: 1376 x 1032 Pixel; Soft Imaging System, Münster, Deutschland). Daher wurden von jeder Spermienprobe je nach Spermiendichte eine, zwei oder maximal drei Blenden benötigt und Photos in x12000-Vergrößerung aufgenommen. Mit der Bildakquisition wurde grundsätzlich in der linken oberen Ecke der jeweiligen Blende begonnen. Von hier ausgehend wurde das Präparat mäanderförmig mit überlappungsfreien Blickfeldern der Kamera durchmustert. Je nach Spermiendichte wurden dabei bis zu 85 Photos pro Spermienprobe aufgenommen, und zwar in ausgewürfelten Intervallen zwischen 1 und 6.

Die Bilder wurden als LZW-komprimierte Tiff (tagged-image-file-format)-Dateien in einer Farbtiefe von 8-Bit-Graustufen gespeichert und zur Nachbearbeitung mit PhotoPaint 11 (Corel GmbH, München, Deutschland) in 24-Bit-Farbbilder umgewandelt. Diese Nachbearbeitungen betrafen die Bildhelligkeit (Gamma-Korrektur), den Kontrast sowie die Bildschärfe (Unscharfmaske: Radius 5; 50 Prozent).

\section{8 Befundung der Spermienproben}

Die Befundung der Rinderspermien erfolgte am Monitor unter Verwendung von PhotoPaint 11 (Corel) und parallel am Ausdruck. Die untersuchten ultrastrukturellen Merkmalsausprägungen, beispielsweise verschiedene Mitochondrienkonformationen, wurden dabei farblich unterschiedlich codiert. 


\section{8.1 Methodische Überlegungen}

Aus Gründen, die in der Einleitung sowie im Ergebnisteil spezifiziert werden, haben wir uns auf die Analyse der Mittelstück-Mitochondrien der Rinderspermien konzentriert. Um Mehrfachzählungen individueller Mitochondrien möglichst zu vermeiden, muss ihre dreidimensionale Anordnung beachtet werden. Bei Rinderspermien sind die Mitochondrien in Form einer Helix End-zu-End um die Längsachse des Spermienmittelstückes aufgereiht, wobei strittig ist, ob es sich um eine linksgängige (Kojima 1966) oder eine rechtsgängige Helix (Bahr und Engler 1970) handelt. Nach Bahr und Engler (1970) windet sich jedes einzelne Mitochondrium genau einmal um die zentrale Spermienlängsachse. Sämtliche Schnittebenen, die senkrecht zur Längsachse des Spermienmittelstücks verlaufen, erfassen das zu untersuchende Mitochondrium genau ein einziges Mal (Abb. 3A). Daher können in Querschnitten durch das Mittelstück sämtliche Mitochondrienanschnitte gewertet werden, ohne dass Doppelzählungen eines Mitochondriums in großer Zahl auftreten. Dagegen besteht bei Längsschnitten durch das Spermienmittelstück die Gefahr, dass individuelle Mitochondrien mehrfach angeschnitten werden (Abb. 3B). Um Doppelbefundungen einzelner Mitochondrien möglichst zu vermeiden, wurde in Längsschnitten daher nur eine der beiden perlschnurartigen Reihen von Mitochondrien in die Auswertung einbezogen.

\section{8.2 Quantitative Auswertung}

Es wurden 100 Mittelstückanschnitte pro Spermienprobe analysiert. Die Befundungskriterien der jeweils untersuchten ultrastrukturellen Merkmale werden im Abschnitt „Ergebnisse“ (S. 19ff) erläutert. Mögliche Unterschiede zwischen Probenpaaren hinsichtlich des Auftretens ultrastruktureller Merkmale wurden mit Hilfe des nichtparametrischen Mann-Whitney-U-Tests auf statistische Signifikanz überprüft, da der Test für den Vergleich zweier unabhängiger, nicht normalverteilter Stichproben geeignet ist und die Testvoraussetzungen (mindestens ordinales Skalenniveau, stetige Verteilung der Daten) erfüllt sind (Rasch et al. 2006, Weiß 2010). Die statistischen Berechnungen sowie die Erstellung der Box-and-Whiskers-Plots erfolgte mit dem Programm Statistica Version 10 für Windows (StatSoft (Europe) GmbH, Hamburg, Deutschland). 


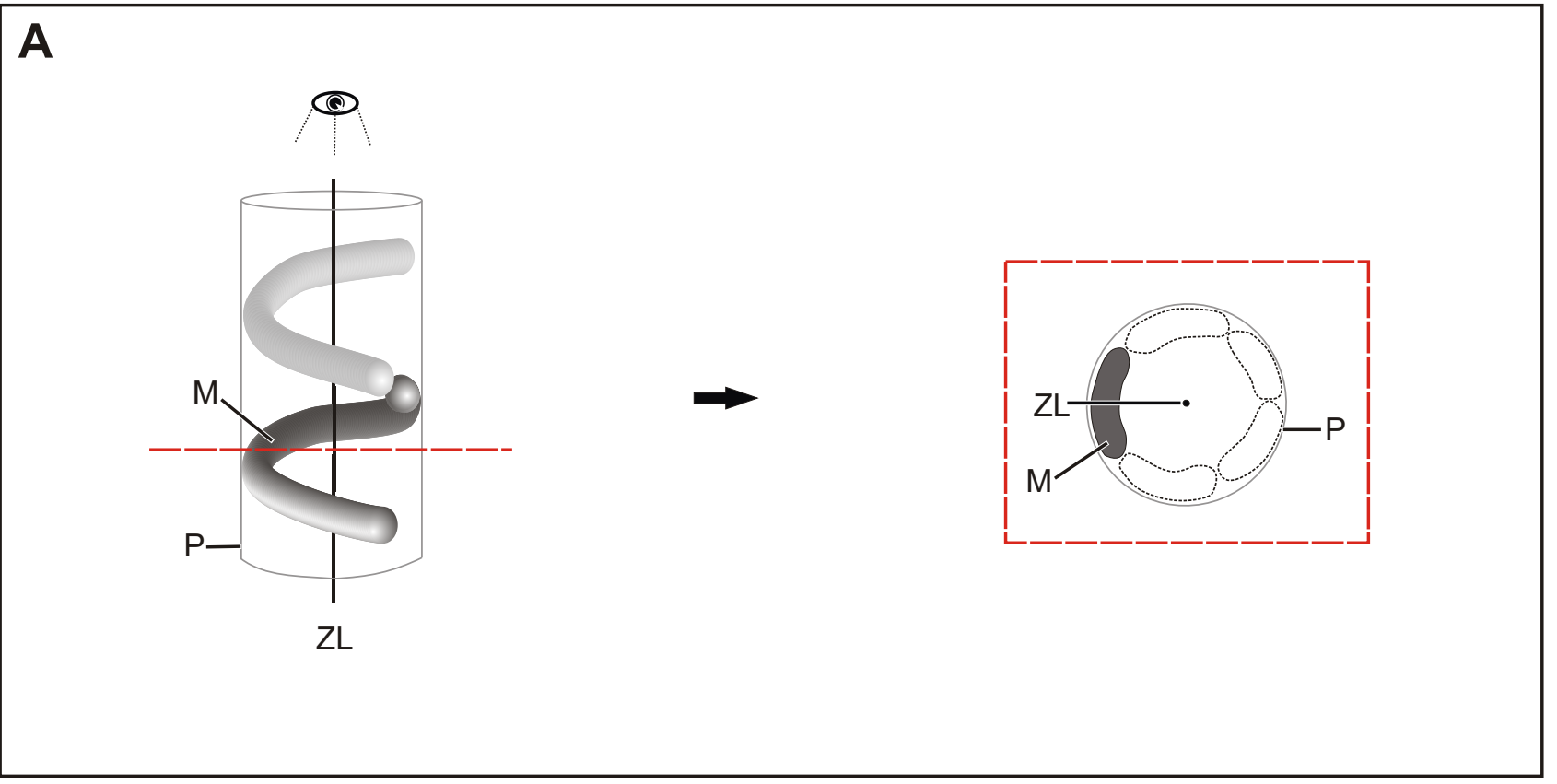

B

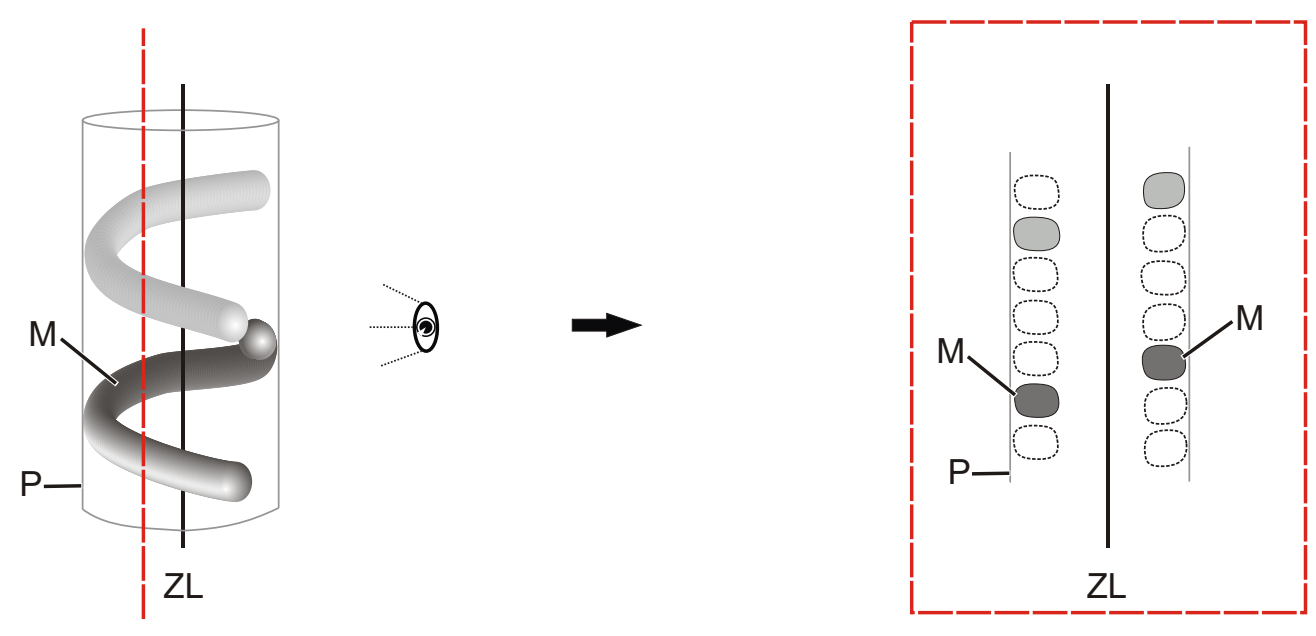

Abb. 3: Helikale Mitochondrienanordnung im Spermienmittelstück nach Befunden von Kojima 1965. Exemplarische Darstellung einer von mehreren Mitochondrienhelices (linke Bildseite) im transmissionselektronenmikroskopischen Schnitt (rechte Bildseite). A (Fall 1): Anschnittsebenen (rot) von senkrecht zur zentralen Längsachse (ZL) verlaufenden Querschnitten durch das Mittelstück erfassen jedes Mitochondrium (M) nur ein einziges Mal. P, Plasmamembran. B (Fall 2): Parallel zur Spermienlängsachse verlaufende Schnittebenen können ein Mitochondrium rechts und links der zentralen Spermienlängsachse erfassen. 


\section{ERGEBNISSE}

\section{1 Ultrastruktur der untersuchten Spermien}

\section{1.1 Normalbefunde}

Rinderspermien sind in den Spermienkopf sowie in Hals, Mittel-, Haupt- und Endstück untergliedert. Der im Spermienkopf lokalisierte Kern ist elektronendicht, im Längsschnitt zigarrenförmig, bis zu 7,5 $\mu \mathrm{m}$ lang und zirka 0,3 $\mu \mathrm{m}$ breit (Abb. 4A). Am vorderen Pol sowie an der Seitenfläche des von einer Doppelmembran umgebenen Kerns findet sich das Akrosom, dessen hinterer Abschnitt sich zum Äquatorialsegment verschmälert (Abb. 4B). Schon bei nichtsortierten, für die Elektronenmikroskopie aufgearbeiteten Spermien treten partielle oder sogar vollständige Ablösungen der Plasmamembran des Spermienkopfes auf (Abb. 4A, B). Basal besitzt der Spermienkern eine Mulde, in die sich die mäßig elektronendichte, dem Kern eng anliegende Basalplatte einschmiegt (Abb. 4C). Sie wird im Halsstück schwanzwärts vom gleichfalls moderat elektronendichten Kapitulum unterlagert. Dahinter schließen sich die segmentierten Säulen an, die am Übergang vom Hals zum Mittelstück mit den Außenfibrillen verschmelzen (Abb. 4C).

In Längsschnitten durch das Mittelstück zeigen sich beidseits lateral der Außenfibrillen perlschnurartig angeordnete, überwiegend rundlich-ovale Mitochondrienanschnitte (Abb. 4, 5). Abweichend hiervon sind die Mitochondrienanschnitte nahe des Spermienhalses oft länglich (Abb. 4C), was auf einen regional steileren Verlauf der Mitochondrienhelix zurückzuführen ist (Saacke und Almquist 1964). Die Matrix orthodox konformierter Mitochondrien ist mäßig elektronendicht und wird pro Mitochondrienanschnitt im Regelfall von ein bis drei Cristae mitochondriales mit schmalem intracristalem Spalt (Weite um $10 \mathrm{~nm}$ ) durchzogen (Abb. 5A, B). Die Cristae verlaufen gestreckt oder halbkreisförmig gebogen. Die Weite des Verbindungsstücks (Crista Junction, Perkins et al. 1997) zwischen einer Crista mitochondrialis und dem korrespondierenden Abschnitt der inneren Mitochondrienmembran kann die Weite des intracristalen Spaltes übertreffen, fortsetzen oder unterschreiten (Abb. 5A).

Zwischen den Außenfibrillen des Mittelstücks und den Außenmembranen der Mitochondrien finden sich elektronendichte bandförmige Strukturen (Abb. 5B), die höchstwahrscheinlich dem zunächst bei Hamsterspermien (Olson und Winfrey 1986), vor kurzem aber auch bei menschlichen Spermien (Kadam et al. 2007) beschriebenen submitochondrialen Reticulum entsprechen. Zwischen den Außenmembranen benachbarter Mitochondrien sind oft - im Einzelschnitt ein bis drei - kurze elektronendichte Verbindungsstreben nachweisbar (Abb. 5C). Sie ähneln den zuerst bei Spermien des Opossums beschriebenen intermitochondrialen Verbindungen (Olson und Hamilton 1976). Ähnliche 
Verbindungsstreben wurden später bei Hamsterspermien als studs charakterisiert (Olson und Winfrey 1992) und auch bei Spermien des Meerschweinchens als intermitochondriale thin filaments dokumentiert (Suzuki-Toyota et al. 2010). Intermitochondriale Verbindungsstreben könnten gemeinsam mit weiteren Verbindungsstreben zwischen Mitochondrien und Plasmamembran, die SuzukiToyota et al. (2010) bei Spermien des Meerschweinchens und wir bei Rinderspermien fanden (Abb. 5C), unter anderem für die mechanische Stabilisierung des Chondrioms bedeutungsvoll sein (siehe Diskussion).

Am Übergang vom Mittelstück zum Hauptstück liegt der im Längsschnitt dreieckige Jensen-Ring (Saacke und Almquist 1964). Dabei weist die Basis des Dreiecks auf den Spermienkopf, seine Spitze auf das Hauptstück (Abb. 6A). Innerhalb des Hauptstücks werden die Außenfibrillen von einer Faserscheide umgeben (Abb. 6A, B). Diese besteht aus zwei elektronendichten Längsfibrillen (Abb. 6B), die auf einander gegenüber liegenden Seiten des Spermienschwanzes lokalisiert sind. Verbunden werden diese beiden Stränge über Ringfasern, die quer zur Spermienlängsachse verlaufen (Abb. 6B).

\section{1.2 Vergleich nichtsortierter und geschlechtsspezifisch sortierter Spermien}

Geschlechtsspezifisch sortierte Spermien weisen Motilitätsminderungen auf (Grossfeld et al. 2005), die nach Auffassung von Piomboni et al. (2012) als Hinweis auf mitochondriale Schädigungen verstanden werden können. Deshalb haben wir unser Augenmerk auf die Ultrastruktur der MittelstückMitochondrien gerichtet. Wir fanden in den zunächst orientierend untersuchten Proben sortierter Spermien drei Klassen von ultrastrukturellen Auffälligkeiten (mitochondriale Gefügestörungen, Mitochondrienschwellungen und stark kondensiert konformierte Mitochondrien), deren Relevanz anschließend mit erheblich vergrößertem Probenaufkommen bei sortierten und nichtsortierten Spermien statistisch überprüft wurde. Hierzu wurden Spermienproben von insgesamt drei Tieren jeweils an mehreren Versuchstagen entnommen. Nichtsortierte Proben (ID1) wurden sofort nach der Entnahme für die elektronenmikroskopische Untersuchung aufgearbeitet. Dagegen wurden Proben der ID3 zuvor im Standardverfahren geschlechtsspezifisch sortiert. Anschließend wurden X- und Y-chromosomale Spermien wieder zusammengeführt, die im Abfallbehälter gesammelten geschädigten Spermien jedoch verworfen. Die statistische Auswertung erfolgte mittels des Mann-Whitney-UTests $(\mathrm{p}<0,05)$. 


\section{1.2.1 Gefügestörungen des Chondrioms}

Als mitochondriale Gefügestörung bezeichne ich Abweichungen von der für reife Rinderspermien im Längsschnitt typischerweise beschriebenen perlschnurartigen Anordnung der Mittelstück-Mitochondrien (Saacke und Almquist 1964, S. 168: „a column of small spheres“). Im einfachsten, als diskrete Gefügestörung definierten Fall sind lediglich einzelne Mitochondrienanschnitte aus der ansonsten ungestört wirkenden perlschnurartigen Reihung ausgebrochen und in Richtung auf die Plasmamembran verlagert (Abb. 7A). Alternativ finden wir punktuelle Aussparungen in der ansonsten lückenlosen Mitochondrienreihe, allerdings ohne Nachweis eines verlagerten Mitochondriums (Abb. 7B). Eine weitere Variante diskreter Gefügestörungen besteht darin, dass auch bei vollständig abgelöster Plasmamembran lediglich einzelne Mitochondrien aus der Mitochondrienkette nach auBen abgedrängt sind (Abb. 7C).

Massive mitochondriale Gefügestörungen sind dadurch charakterisiert, dass die perlschnurartige Aneinanderreihung der Mitochondrien streckenweise nahezu vollständig aufgehoben ist. Stattdessen finden sich mehrschichtig oder sogar gänzlich irregulär angeordnete Mitochondrienanschnitte (Abb. 7D). Die von der typischen helikalen Anordnung mit Sicherheit erheblich abweichende dreidimensionale Struktur massiv gestörter Mitochondriengefüge kann aus den analysierten Einzelschnitten nicht erschlossen werden.

Für die statistische Auswertung bezüglich des Vorkommens mitochondrialer Gefügestörungen sowie aller weiteren untersuchten strukturellen Merkmale wurden unter Zugrundelegung eines $\mathrm{Zu}$ fallsverfahrens (Material und Methoden) transmissionselektronenmikroskopische Aufnahmen (Vergrößerung: x12000) von je 100 Mittelstückanschnitten pro Spermienprobe angefertigt. Anschließend wurde für jede Spermienprobe die Gesamtzahl der in diesen 100 Anschnitten sichtbaren Gefügestörungen bestimmt. Hierbei wurden diskret oder massiv ausgeprägte Gefügestörungen (Abb. 7A-D) zu einer gemeinsamen Kategorie zusammengefasst. Bei Längsschnitten wurden Gefügestörungen in beiden Mitochondrienreihen eines Mittelstücks in die Auswertung einbezogen. Es stellte sich heraus, dass keines der drei untersuchten Tiere bezüglich der Häufigkeit des Auftretens mitochondrialer Gefügestörungen einen signifikanten Unterschied $(\mathrm{p}<0,05)$ zwischen nichtsortierten (ID1) und standardsortierten (ID3) Proben aufweist (Tab. 3). 
Tab. 3: Vergleich der Anzahl mitochondrialer Gefügestörungen in nichtsortierten (ID1) und in standardsortierten Rinderspermien (ID3). Angegeben ist die Anzahl von Gefügestörungen pro Probe (je 100 Mittelstückanschnitte). Verglichen (Mann-Whitney-U-Test) wurden pro Tier jeweils alle für ID1 mit allen für ID3 gewonnenen Zahlenwerte. Signifikanter Unterschied bei $\mathrm{p}<0,05$; ID, Identifikationsnummer der Spermienbehandlung.

\begin{tabular}{|c|c|c|c|c|}
\hline \multicolumn{5}{|c|}{$\begin{array}{l}\text { Anzahl Gefüge- } \\
\text { störungen je Probe }\end{array}$} \\
\hline Tier & $\begin{array}{l}\text { Proben- } \\
\text { entnahmetag }\end{array}$ & ID1 & ID3 & $\mathbf{p}$ \\
\hline \multirow[t]{4}{*}{1} & 16. 06. 2008 & 7 & 0 & \multirow{4}{*}{0,31} \\
\hline & 30. 06. 2008 & 8 & 2 & \\
\hline & 14. 07. 2008 & 6 & 9 & \\
\hline & 05. 08. 2008 & 4 & 1 & \\
\hline \multirow[t]{5}{*}{2} & 11. 08. 2008 & 1 & 0 & \multirow{5}{*}{0,46} \\
\hline & 25. 08. 2008 & 1 & 2 & \\
\hline & 09. 09. 2008 & 0 & 0 & \\
\hline & 23. 09. 2008 & 1 & 1 & \\
\hline & 07. 10. 2008 & 2 & 0 & \\
\hline \multirow[t]{4}{*}{3} & 21. 04. 2009 & 1 & 1 & \multirow{4}{*}{0,31} \\
\hline & 02. 06. 2009 & 0 & 1 & \\
\hline & 09. 06. 2009 & 0 & 0 & \\
\hline & 07. 07. 2009 & 0 & 1 & \\
\hline
\end{tabular}

\section{1.2.2 Mitochondriale Schwellung}

Bei den zuerst untersuchten Proben sortierter Spermien sind uns neben mitochondrialen Gefügestörungen auch geschwollene Mittelstück-Mitochondrien aufgefallen. Im Vergleich zu orthodox konformierten Mitochondrien ist die Anschnittsfläche stark geschwollener Mitochondrien vergrößert und die Matrix weniger elektronendicht (Abb. 8A). Weiterhin lassen sich in ihrem Innenraum kaum noch strukturell intakte Cristae, sondern häufig allenfalls Cristafragmente nachweisen. Wie in vielen anderen Veröffentlichungen über das Vorkommen mitochondrialer Schwellungen in ganz verschiedenartigen Zelltypen beschrieben (Szollosi 1965, Blondin und Green 1967, zur Übersicht: Kaasik et al. 2007), fanden wir auch bei den Rinderspermien erhebliche Unterschiede hinsichtlich des Schwellungsgrades der Mittelstück-Mitochondrien. Die Spannbreite reichte von einer eben erkennbaren Aufhellung der Mitochondrienmatrix bis zu einer zirka vierfachen Vergrößerung der elektronenhellen mitochondrialen Anschnittsfläche.

Im nächsten Arbeitsschritt haben wir orientierend den prozentualen Anteil stark geschwollener Mitochondrien am Chondriom nichtsortierter (ID1) und standardsortierter (ID3) Spermien miteinander verglichen. Hierbei wurden nur diejenigen Mitochondrien als geschwollen gewertet, die bereits in 
der Übersichtsaufnahme (Vergrößerung: x12000) auf Grund (1) ihrer Größenzunahme, (2) ihrer Armut an intakten Cristae sowie (3) wegen ihrer stark verminderten Elektronendichte unter der Mehrheit benachbarter, gleichförmig perlschnurartig angeordneter Mitochondrien hervorstachen (Abb. 8A). Diese stark geschwollenen Mitochondrien können unschwer sowohl gegen orthodox als auch gegen kondensiert konformierte Mitochondrien (siehe Kapitel III. 1.2.3) abgegrenzt werden.

Zunächst wurde für jeden einzelnen befundeten Mittelstückanschnitt (pro Probe: 100 Mittelstückanschnitte) der prozentuale Anteil stark geschwollener Mitochondrien ermittelt. Bei der statistischen Auswertung (Mann-Whitney-U-Test) wurden anschließend jeweils die Prozentwerte von 100 Mittelstücken einer nichtsortierten Spermienprobe (ID1) mit den Prozentwerten von 100 Mittelstücken der korrespondierenden sortierten Spermienprobe (ID3) vom selben Probenentnahmetag miteinander verglichen (Tab. 4). Hierbei stellte sich heraus, dass stark geschwollene Mitochondrien nur bei einem von 13 untersuchten Probenpaaren (Tiere 1, 2 und 3 mit jeweils 4, 5 und 4 Probenpaaren) signifikant häufiger bei sortierten Spermien auftraten (Tier 2, Probenentnahmetag: 25. 08. 2008). Bei allen anderen untersuchten Probenpaaren konnten wir dagegen keinen signifikanten Unterschied bezüglich des Merkmals „starke Mitochondrienschwellung“ nachweisen.

Zur weiteren Veranschaulichung der Ergebnisse wurde aus den pro Spermienprobe ermittelten 100 Prozentwerten (Anteil stark geschwollener Mitochondrien pro Mittelstückanschnitt) der arithmetische Mittelwert (AM) sowie der Median (MD) errechnet (Tab. 5). Hierbei zeigte sich, dass der arithmetische Mittelwert bei den Proben nichtsortierter Spermien (ID1) in engen Grenzen zwischen 0,0 Prozent und 1,5 Prozent schwankt. In den korrespondierenden Proben von Spermien, die den Sortierprozess nach Standardprotokoll durchlaufen haben (ID3), ist die Schwankungsbreite des arithmetischen Mittelwerts (zwischen 0,0 Prozent und 3,6 Prozent) nur wenig größer. Für den Median ergibt sich in allen Proben sortierter wie nichtsortierter Spermien der Wert 0. 
Tab. 4: Vergleich des prozentualen Anteils stark geschwollener Mitochondrien in den Proben nichtsortierter (ID1) und standardsortierter (ID3) Rinderspermien. Verglichen (Mann-Whitney-U-Test) wurden pro Probenentnahmetag jeweils die für ID1 gewonnenen Prozentwerte mit den für ID3 gewonnenen Prozentwerten. Signifikanter Unterschied (*) bei $\mathrm{p}<0,05$; ID, Identifikationsnummer der Spermienbehandlung.

\section{ID1 versus ID3}

\begin{tabular}{|c|c|c|}
\hline Tier & $\begin{array}{l}\text { Proben- } \\
\text { entnahmetag }\end{array}$ & $\mathbf{p}$ \\
\hline \multirow[t]{4}{*}{1} & 16. 06. 2008 & 0,47 \\
\hline & 30. 06. 2008 & 0,91 \\
\hline & 14. 07. 2008 & 0,90 \\
\hline & 05. 08. 2008 & 0,81 \\
\hline \multirow[t]{5}{*}{2} & 11. 08. 2008 & 1,00 \\
\hline & 25.08 .2008 & $0,02 *$ \\
\hline & 09.09 .2008 & 0,91 \\
\hline & 23. 09. 2008 & 0,71 \\
\hline & 07. 10. 2008 & 0,91 \\
\hline \multirow[t]{4}{*}{3} & 21. 04. 2009 & 0,90 \\
\hline & 02. 06. 2009 & 0,81 \\
\hline & 09. 06. 2009 & 0,71 \\
\hline & 07. 07. 2009 & 0,81 \\
\hline
\end{tabular}

Tab. 5: Vergleich des prozentualen Anteils (\%) stark geschwollener Mitochondrien in den Proben nichtsortierter (ID1) und standardsortierter (ID3) Rinderspermien. Angegeben ist der Median (MD) und der arithmetische Mittelwert (AM) aus den 100 Prozentwerten jeder Probe. ID, Identifikationsnummer der Spermienbehandlung.

\begin{tabular}{clccccc} 
& & \multicolumn{2}{c}{ MD (\%) } & \multicolumn{2}{c}{ AM (\%) } \\
\hline Tier & $\begin{array}{l}\text { Proben- } \\
\text { entnahmetag }\end{array}$ & ID1 & ID3 & ID1 & ID3 \\
\hline 1 & 16. 06. 2008 & 0,0 & 0,0 & 1,5 & 0,5 \\
& 30. 06. 2008 & 0,0 & 0,0 & 0,2 & 0,5 \\
& 14. 07. 2008 & 0,0 & 0,0 & 0,1 & 0,5 \\
& 05. 08. 2008 & 0,0 & 0,0 & 0,1 & 0,0 \\
\hline \multirow{2}{*}{2} & 11. 08. 2008 & 0,0 & 0,0 & 0,0 & 0,1 \\
& 25. 08. 2008 & 0,0 & 0,0 & 0,0 & 3,6 \\
& 09. 09. 2008 & 0,0 & 0,0 & 0,2 & 0,1 \\
& 23. 09. 2008 & 0,0 & 0,0 & 0,4 & 0,0 \\
& 07. 10. 2008 & 0,0 & 0,0 & 0,1 & 0,1 \\
\hline 3 & 21. 04. 2009 & 0,0 & 0,0 & 0,9 & 0,5 \\
& 02. 06. 2009 & 0,0 & 0,0 & 0,0 & 0,3 \\
& 09. 06. 2009 & 0,0 & 0,0 & 0,5 & 0,0 \\
& 07. 07. 2009 & 0,0 & 0,0 & 0,1 & 0,7
\end{tabular}




\section{1.2.3 Mitochondrienkonformation}

Die dritte ultrastrukturelle Auffälligkeit in den zu Studienbeginn untersuchten Proben bestand darin, dass standardsortierte wie nichtsortierte Proben offenbar sowohl Spermien mit einem hohen Anteil kondensierter Mitochondrien als auch Spermien mit zahlreichen orthodox konformierten Mitochondrien aufwiesen (Abb. 8B-F). Die mögliche Sequenz der Entstehung maximal kondensierter Mitochondrien ließ sich aus elektronenmikroskopischen Momentaufnahmen hypothetisch rekonstruieren. Demnach setzt die Entwicklung mit einer geringgradigen Dilatation einzelner oder mehrerer Cristae mitochondriales ein (Abb. 8B). Im weiteren Verlauf scheint sowohl die Weite des intracristalen Spalts als auch die Weite der Crista Junctions (Abb. 8C) ständig zuzunehmen, bis im Extremfall das gesamte Mitochondrium von einem elektronenhellen Zentrum ausgefüllt ist, das rundum von der erheblich verdichteten mitochondrialen Matrix umgeben wird (Abb. 8B, C).

Um den Anteil kondensierter Mitochondrien am Chondriom sortierter und nichtsortierter Spermien quantitativ zu erfassen, wurde das zuvor für die Quantifizierung von mitochondrialen Gefügestörungen sowie von stark geschwollenen Mitochondrien verwendete Bildmaterial erneut ausgewertet. Zur Vermeidung falsch positiver Bewertungen wurden nur solche Mitochondrienanschnitte als kondensiert klassifiziert, die einen extrem stark, wie ausgestanzt wirkenden elektronendichten randständigen Saum kondensierter Matrix zeigten, der um ein elektronenhelles, im Regelfall vollständig oder zumindest weitgehend strukturloses Zentrum gruppiert war (Abb. 8C, E, F). Um die Abgrenzung kondensierter Mitochondrien gegen beginnend geschwollene Mitochondrien, die gleichfalls über zentrale elektronenhelle Abschnitte und randständige, elektronendichte Mitochondrienmembranen verfügen, zu erleichtern, haben wir ein Zusatzkriterium festgelegt. Demnach ist bei stark kondensierten Mitochondrien der Anteil der kondensierten randständigen Matrix einschließlich der hiervon schwer oder gar nicht abtrennbaren elektronendichten Mitochondrienmembranen am Gesamtdurchmesser mindestens so hoch wie der Anteil des elektronenhellen Zentrums. Dieses Zusatzkriterium stößt lediglich bei extrem tangential angeschnittenen Mitochondrien an seine Grenzen. Eine Abgrenzung stark kondensierter gegen stark geschwollene Mitochondrien ist dagegen auf Grund der enormen Vergrößerung des Durchmessers stark geschwollener Mitochondrien jederzeit möglich.

Bei der quantitativen Auswertung wurde in Analogie zur vorhergehenden Untersuchung stark geschwollener Mitochondrien der prozentuale Anteil stark kondensierter Mitochondrienanschnitte für jeden der pro Spermienprobe befundeten 100 Mittelstückanschnitte bestimmt. In den nichtsortierten Proben (ID1) waren die Mitochondrien mit Häufigkeiten von 0,7 Prozent bis 10,4 Prozent (AM) stark kondensiert (Tab. 6). In den standardsortierten Proben (ID3) traten stark kondensierte Mitochondrienanschnitte erheblich häufiger auf (AM: 12,8 Prozent bis 76,6 Prozent). Beim Vergleich 
korrespondierender nichtsortierter und standardsortierter Spermienproben vom jeweils selben Probenentnahmetag (Tab. 7) fand sich in allen Fällen ein signifikant erhöhter Prozentsatz stark kondensierter Mitochondrien in den sortierten Spermienproben (Mann-Whitney-U-Test, $\mathrm{p}<0.05$ ). Die vorliegende Untersuchung weist demnach erstmals nach, dass die Mitochondrien von Rinderspermien beim geschlechtsspezifischen Sortieren in ganz erheblichem Umfang Konformationsänderungen durchlaufen.

Zusätzlich zur tabellarischen Darstellung wurden die bezüglich des Merkmals „stark kondensierte Mitochondrien“ erhobenen Ergebnisse als Box-and-Whiskers-Plots visualisiert (Tier 1: Abb. 9A-D, Tier 2: Abb. 10A-E, Tier 3: Abb. 11A-D). In solchen Plots beschreiben die horizontalen unteren beziehungsweise oberen Begrenzungen der Box das 25- beziehungsweise das 75-Prozent-Quantil. Der Median des pro Spermienprobe ermittelten Prozentsatzes stark kondensierter Mitochondrien in 100 Mittelstückanschnitten ist als kleines Quadrat innerhalb der Box markiert. Die von der Box nach unten und oben ausgehenden Antennen (whiskers) stellen die Minimal- und Maximalwerte der in den Mittelstückanschnitten der Spermienprobe ermittelten Prozentwerte dar (Weiß 2010).

Tab. 6: Vergleich des prozentualen Anteils (\%) stark kondensierter Mitochondrien in nichtsortierten (ID1) und standardsortierten (ID3) Rinderspermien. Angegeben ist der Median (MD) und der arithmetische Mittelwert (AM) aus den 100 Prozentwerten jeder Probe. ID, Identifikationsnummer der Spermienbehandlung.

\begin{tabular}{clccccc} 
& & \multicolumn{2}{c}{ MD $(\%)$} & \multicolumn{2}{c}{ AM $(\%)$} \\
\hline Tier & $\begin{array}{l}\text { Proben- } \\
\text { entnahmetag }\end{array}$ & ID1 & ID3 & ID1 & ID3 \\
\hline \multirow{2}{*}{1} & 16. 06. 2008 & 0,0 & 37,4 & 2,5 & 35,7 \\
& 30. 06. 2008 & 0,0 & 0,0 & 0,7 & 18,0 \\
& 14. 07. 2008 & 0,0 & 0,0 & 1,9 & 12,8 \\
& 05. 08. 2008 & 0,0 & 76,4 & 10,4 & 66,9 \\
\hline \multirow{2}{*}{2} & 11. 08. 2008 & 0,0 & 80,0 & 1,4 & 70,6 \\
& 25. 08. 2008 & 0,0 & 13,4 & 0,9 & 24,8 \\
& 09. 09. 2008 & 0,0 & 76,0 & 3,7 & 70,8 \\
& 23. 09. 2008 & 0,0 & 65,1 & 2,3 & 49,4 \\
& 07. 10. 2008 & 0,0 & 75,0 & 2,2 & 67,0 \\
\hline \multirow{2}{*}{3} & 21. 04. 2009 & 0,0 & 83,3 & 2,5 & 76,6 \\
& 02.06 .2009 & 0,0 & 82,8 & 7,1 & 70,0 \\
& 09.06 .2009 & 0,0 & 66,7 & 2,1 & 53,6 \\
& 07.07 .2009 & 0,0 & 68,3 & 3,9 & 56,7
\end{tabular}


Tab. 7: Vergleich des prozentualen Anteils stark kondensierter Mitochondrien in nichtsortierten (ID1) und standardsortierten (ID3) Rinderspermien. Verglichen (Mann-Whitney-U-Test) wurden jeweils pro Probenentnahmetag alle für die ID1 gewonnenen Prozentwerte mit den für ID3 gewonnenen Prozentwerten. Signifikanter Unterschied $(*)$ bei p<0,05; ID, Identifikationsnummer der Spermienbehandlung.

\section{ID1 versus ID3}

\begin{tabular}{|c|c|c|}
\hline Tier & $\begin{array}{l}\text { Proben- } \\
\text { entnahmetag }\end{array}$ & $\mathbf{p}$ \\
\hline \multirow[t]{4}{*}{1} & 16. 06. 2008 & $0,00^{*}$ \\
\hline & 30. 06. 2008 & $0,00 *$ \\
\hline & 14. 07. 2008 & $0,02 *$ \\
\hline & 05. 08. 2008 & $0,00 *$ \\
\hline \multirow[t]{5}{*}{2} & 11. 08. 2008 & $0,00 *$ \\
\hline & 25.08 .2008 & $0,00 *$ \\
\hline & 09.09 .2008 & $0,00 *$ \\
\hline & 23. 09. 2008 & $0,00 *$ \\
\hline & 07.10 .2008 & $0,00 *$ \\
\hline \multirow[t]{4}{*}{3} & 21. 04. 2009 & $0,00^{*}$ \\
\hline & 02. 06. 2009 & $0,00^{*}$ \\
\hline & 09. 06. 2009 & $0,00^{*}$ \\
\hline & 07. 07. 2009 & $0,00^{*}$ \\
\hline
\end{tabular}



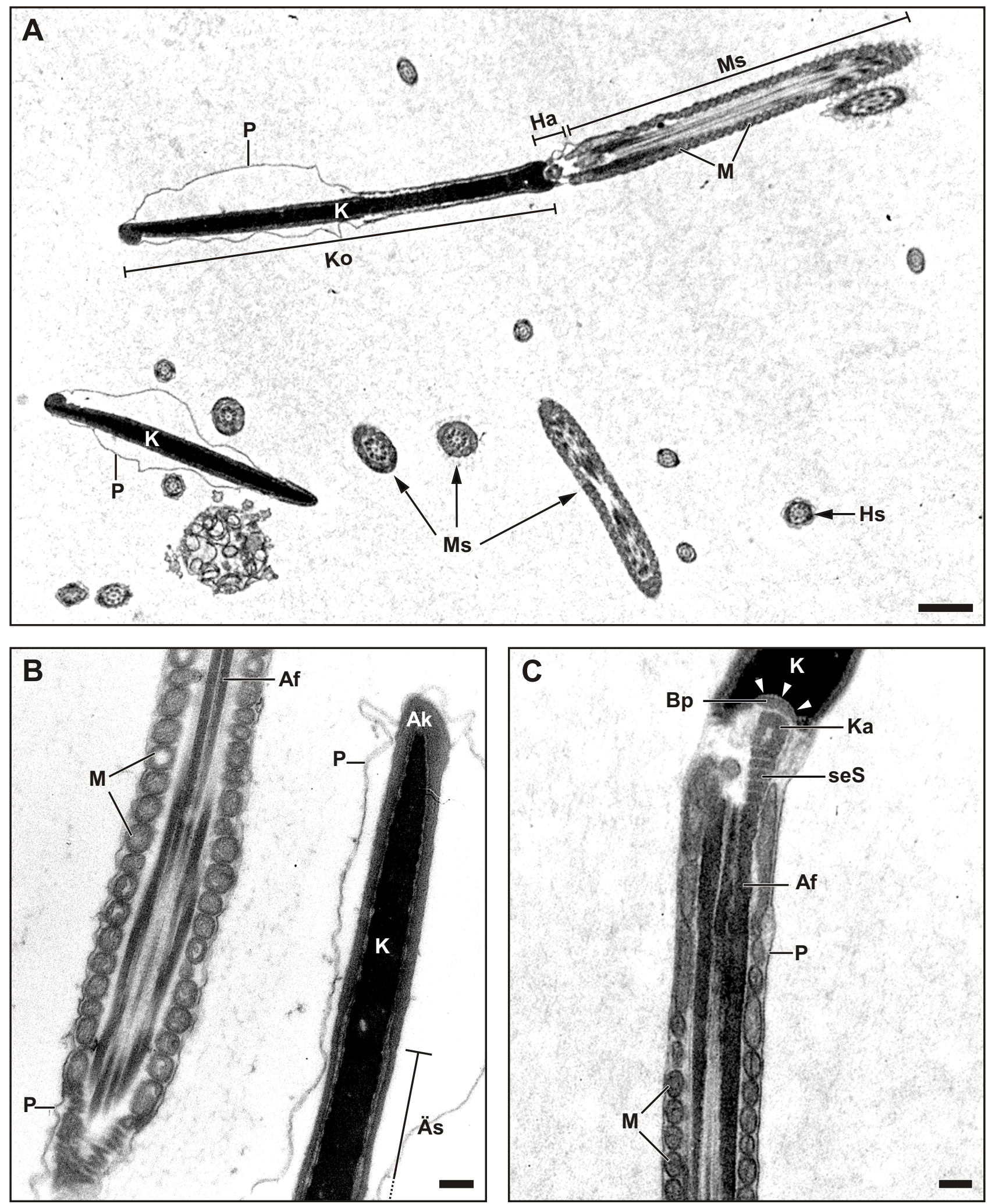

Abb. 4: Transmissionselektronenmikroskopische Aufnahmen von Kopf (Ko), Hals (Ha), Mittelstück (Ms) und Hauptstück (Hs) von Rinderspermien. A: Repräsentative Übersichtsaufnahme einer Spermaprobe (Tier 3, 23. 06. 2009, Aralditblock d, ID1: nichtsortiert). Die Plasmamembran (P) des Spermienkopfes ist häufig abgehoben. ID, Identifikationsnummer der Spermienbehandlung; M, Mitochondrium; K, Kern. B: Details von Spermienkopf und Spermienmittelstück. Af, Außenfibrillen; Ak, Akrosom; Äs, Äquatorialsegment (Tier 1, 05. 08. 2008, Aralditblock a, ID1: nichtsortiert). C: Die Außenfibrillen setzen sich über die segmentierten Säulen (seS) in das Kapitulum (Ka) fort. Dieses projiziert auf die Basalplatte (Bp), die sich in eine Konkavität des Kerns (Pfeilköpfe) einschmiegt (Tier 2, 22. 10. 2009, Aralditblock a, ID1: nichtsortiert). Maßstäbe: $\mathbf{A}=1 \mu \mathrm{m} ; \mathbf{B}, \mathbf{C}=0,2 \mu \mathrm{m}$. 

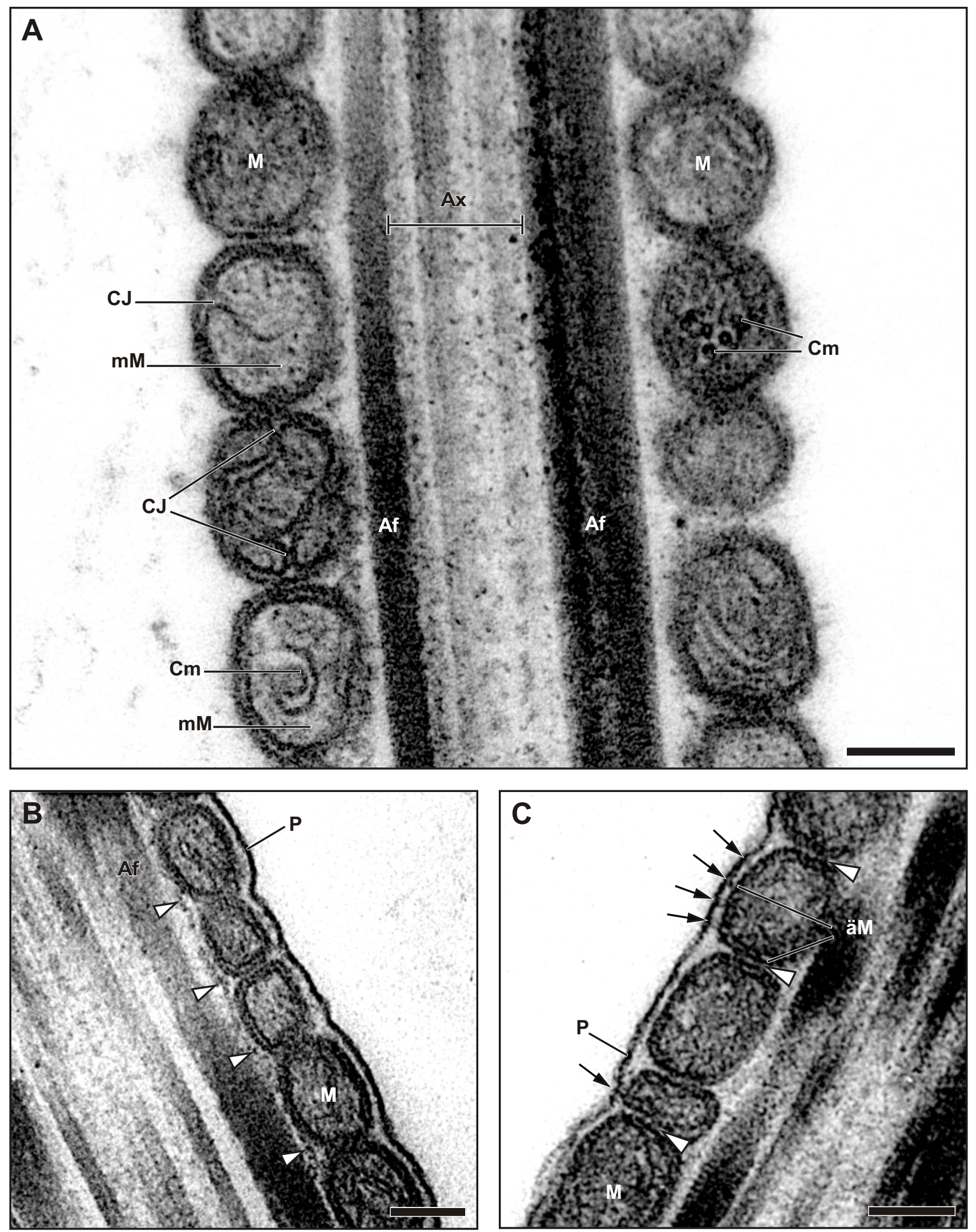

Abb. 5: Transmissionselektronenmikroskopische Aufnahmen von Mittelstücken von Rinderspermien, Längsschnitte. A: Perlschnurartige Aufreihung der Mitochondrien (M) lateral der Außenfibrillen (Af). Die mitochondriale Matrix (mM) ist mäßig elektronendicht. Beachte das Fehlen der Plasmamembran. Ax, Axonem; CJ, Crista Junction; Cm, Cristae mitochondriales; ID, Identifikationsnummer der Spermienbehandlung (Tier 1, 16. 06. 2008, Aralditblock a, ID2: Inkubation mit DNS-Farbstoff Hoechst 33342). B: Das elektronendichte Band (Pfeilköpfe) zwischen Mitochondrien und Außenfibrillen entspricht dem bei Hamsterspermien erstbeschriebenen submitochondrialen Reticulum (Olson und Winfrey 1986). P, Plasmamembran (Tier 3, 26. 05. 2009, Aralditblock a, ID1: nichtsortiert). C: Diskrete elektronendichte Verbindungsstreben zwischen den äußeren Membranen (äM) benachbarter Mitochondrien (Pfeilköpfe) sowie zwischen äußerer Mitochondrienmembran und Plasmamembran (Pfeile) (Tier 1, 05. 08. 2008, Aralditblock a, ID1: nichtsortiert). Maßstäbe $=0,1 \mu \mathrm{m}$. 

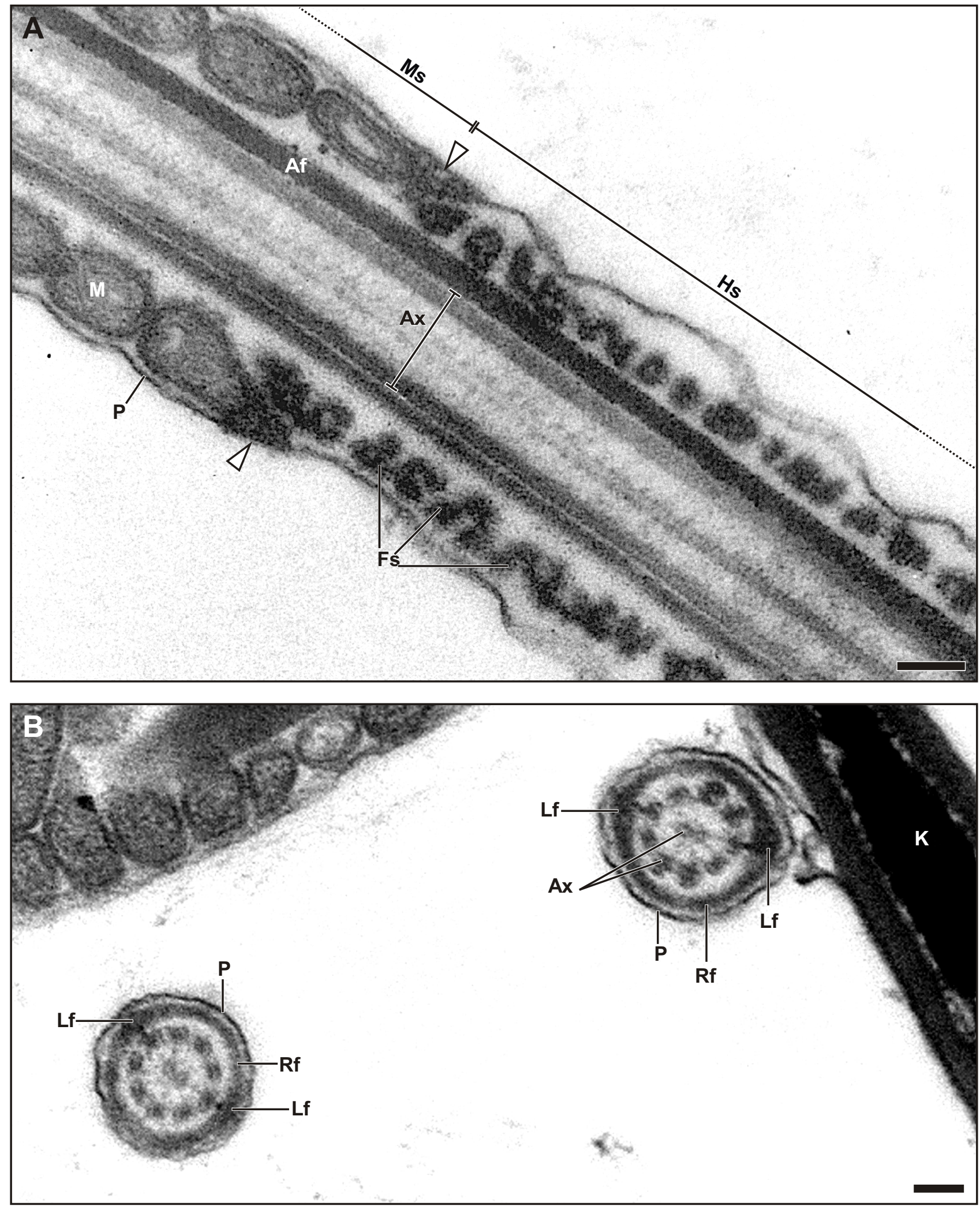

Abb. 6: Transmissionselektronenmikroskopische Aufnahmen vom Übergang zwischen Mittelstück (Ms) und Hauptstück (Hs) von Rinderspermien. A: Der dreieckige elektronendichte Jensen-Ring (Pfeilköpfe) bildet die Grenze zwischen Mittel- und Hauptstück. Im Hauptstück werden Außenfibrillen (Af) und Axonem (Ax) von einer Faserscheide (Fs) umgeben. M, Mitochondrium; P, Plasmamembran; ID, Identifikationsnummer der Spermienbehandlung (Tier 1, 05. 08. 2008, Aralditblock a, ID1: nichtsortiert). B: Die Faserscheide des Hauptstücks besteht aus elektronendichten Längsfibrillen (Lf), die durch Ringfasern (Rf) miteinander verbunden sind (Tier 1, 16. 06. 2008, Aralditblock a, ID1: nichtsortiert). Maßstäbe $=0,1 \mu \mathrm{m}$. 

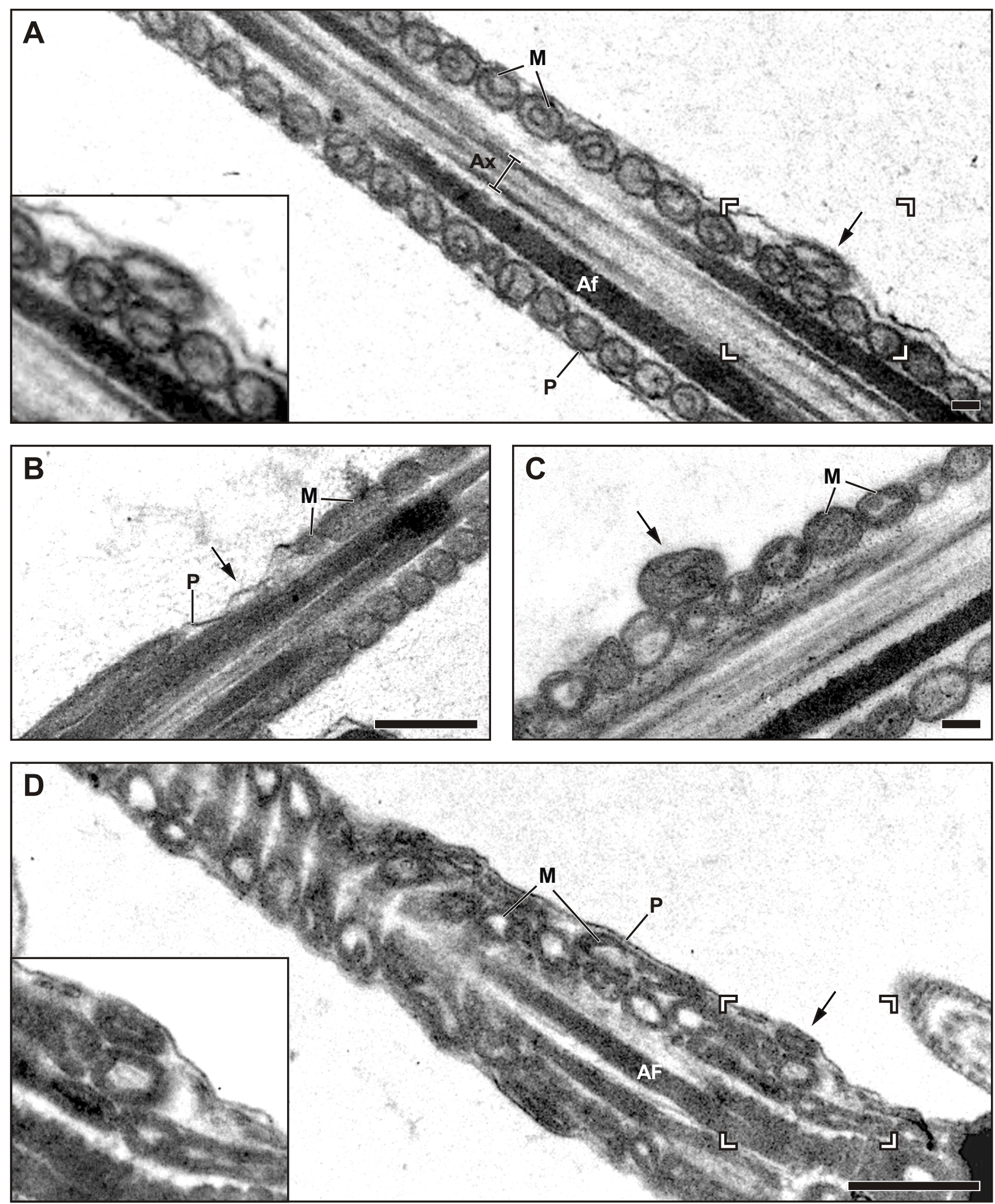

Abb. 7: Transmissionselektronenmikroskopische Aufnahmen von Gefügestörungen des Chondrioms in Rinderspermien, Längsschnitte. A: Diskrete Gefügestörung: unter den Mittelstück-Mitochondrien (M) ist ein einziges irregulär positioniert (Pfeil und Ausschnittsvergrößerung). Af, Außenfibrillen; Ax, Axonem; ID, Identifikationsnummer der Spermienbehandlung; P, Plasmamembran (Tier 3, 23. 06. 2009, Aralditblock a, ID10: Durchgang durch das Sortiergerät, Einfrieren und Wiederauftauen). B: Lücke (Pfeil) in der Mitochondrienreihe (Tier 3, 26. 05. 2009, Aralditblock a, ID1: nichtsortiert). C: Ein aus der Reihe verschobener Mitochondrienanschnitt (Pfeil) bei abgelöster Plasmamembran (Tier 2, 25. 08. 2008, Aralditblock b, ID5: Durchgang durch das Sortiergerät bei ausgeschaltetem Laser). D: Massive Gefügestörung: zwei bis drei "Schichten" (Pfeil und Ausschnittsvergrößerung) irregulär positionierter Mitochondrien (Tier 3, 21.04. 2009, Aralditblock a, ID3: standardsortiert). Maßstäbe: A, C =0,1 $\mu \mathrm{m} ; \mathbf{B}, \mathbf{D}=0,5 \mu \mathrm{m}$. 

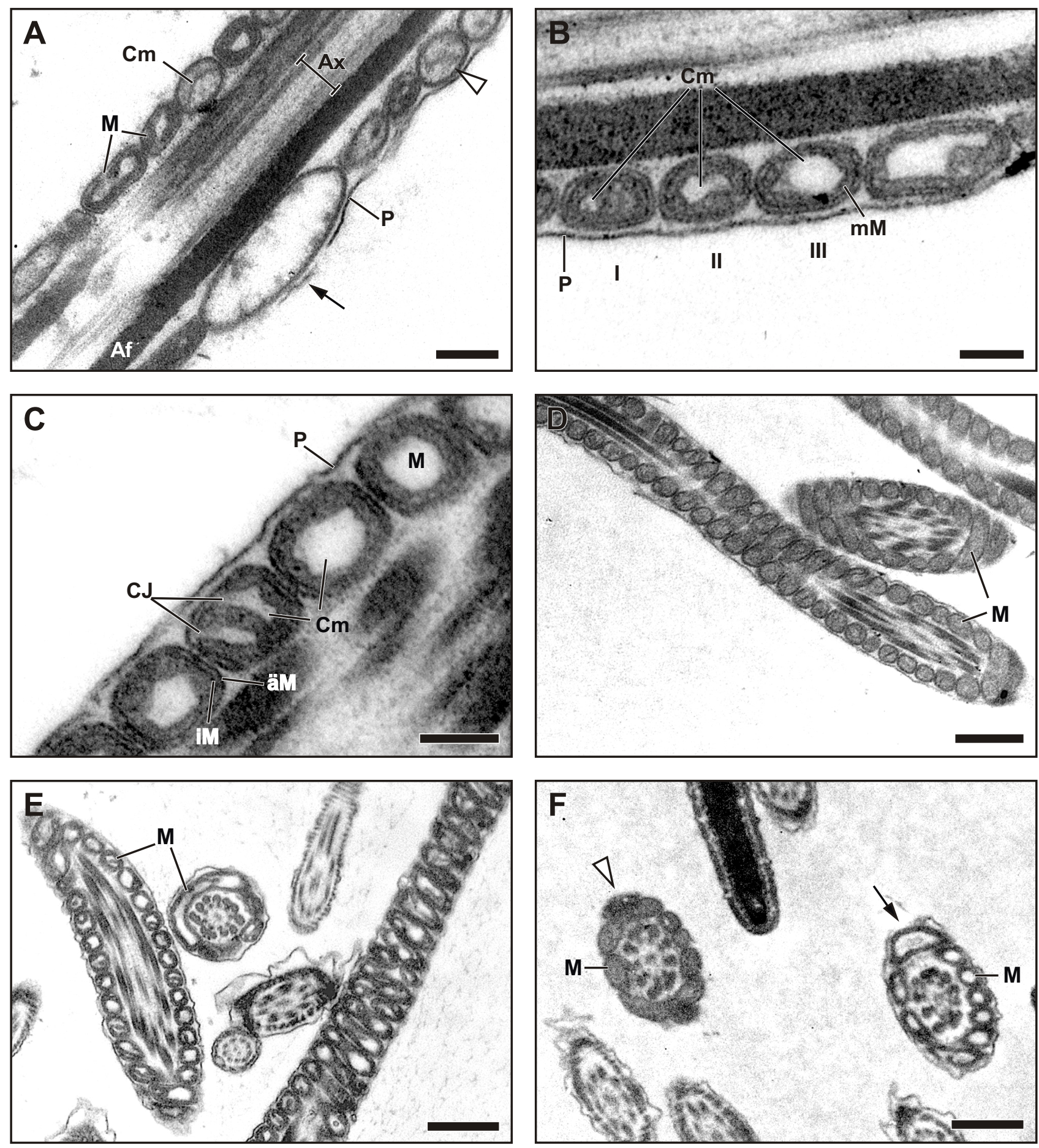

Abb. 8: Transmissionselektronenmikroskopische Aufnahmen von geschwollenen sowie unterschiedlich konformierten Mitochondrien in Rinderspermien. A: Beginnende (Pfeilkopf) und starke (Pfeil) mitochondriale Schwellung. Af, Außenfibrillen; Ax, Axonem; Cm, Crista mitochondrialis; ID, Identifikationsnummer der Spermienbehandlung; M, Mitochondrien; P, Plasmamembran (Tier 1, 30. 06. 2008, Aralditblock b, ID3: standardsortiert). B: Kondensierte Mitochondrienkonformation: hypothetische Entstehungssequenz (I bis III) mit zunehmender Dilatation der Cristae mitochondriales und Marginalisation der elektronendichten mitochondrialen Matrix (mM) (Tier 2, 11. 08. 2008, Aralditblock a, ID3: standardsortiert). C: Kondensierte Mitochondrien mit erweiterten Crista Junctions (CJ); iM, innere Mitochondrienmembran; äM, äußere Mitochondrienmembran (Tier 1, 05. 08. 2008, Aralditblock c, ID3: standardsortiert). D: Fast alle Mitochondrien zeigen orthodoxe Konformation (Tier 1, 16. 06. 2008, Aralditblock a, ID1: nichtsortiert). E: Zahlreiche Mitochondrien mit stark kondensierter Konformation (Tier 1, 05. 08. 2008, Aralditblock c, ID3: standardsortiert). F: Mittelstückanschnitte, bei denen sämtliche Mitochondrienanschnitte entweder kondensierte (Pfeil) oder orthodoxe (Pfeilkopf) Konformation aufweisen (Tier 3, 09. 06. 2009, Aralditblock e, ID6: sortiert bei 5 Volt am Piezokristall). Maßstäbe: $\mathbf{A}=0,2 \mu \mathrm{m} ; \mathbf{B}, \mathbf{C}=0,1 \mu \mathrm{m} ; \mathbf{D}-\mathbf{F}=0,5 \mu \mathrm{m}$. 
A

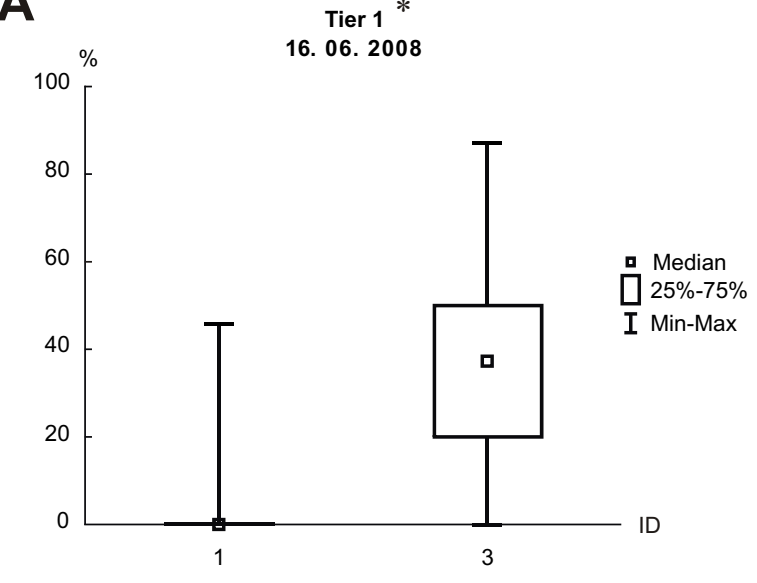

C

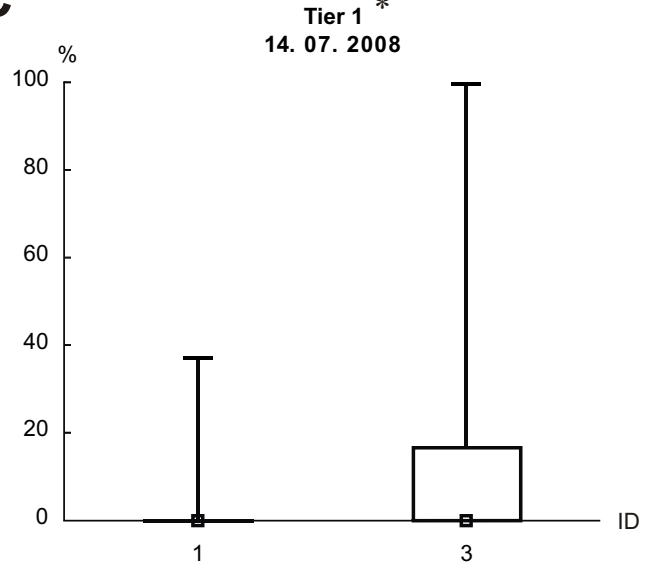

B

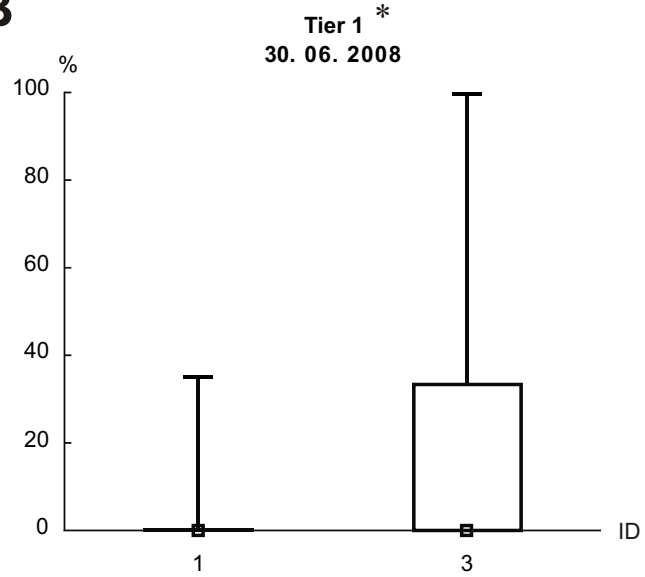

D

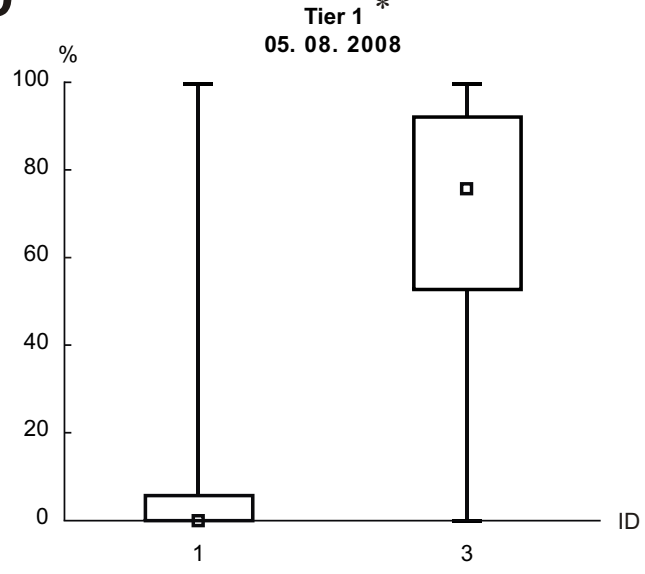

Abb. 9A-D: Prozentualer Anteil (\%) stark kondensierter Mitochondrien in 100 Mittelstückanschnitten pro Spermienprobe (Entnahmedatum angegeben). Bei allen Proben von Tier 1 besteht ein signifikanter Unterschied (*; $<<0,05$; Mann-Whitney-U-Test) zwischen jeweils korrespondierenden Proben nichtsortierter (ID1) und standardsortierter (ID3) Rinderspermien vom selben Probenentnahmetag. ID, Identifikationsnummer der Spermienbehandlung. 
A

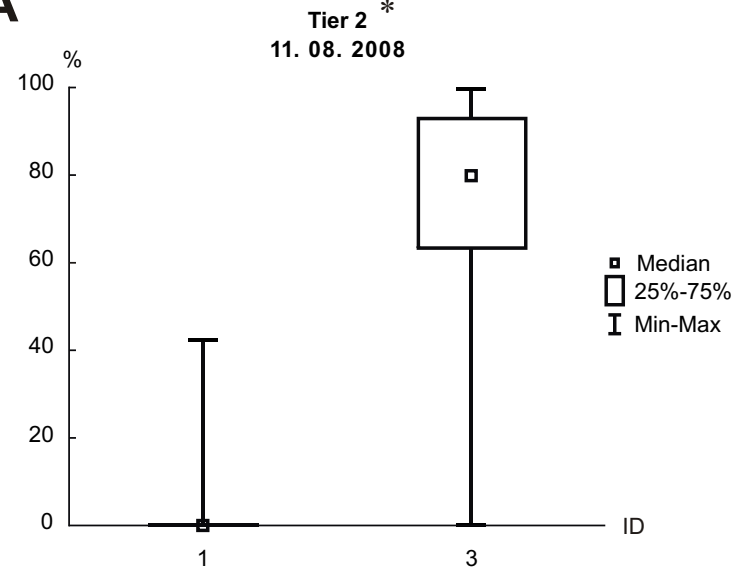

C

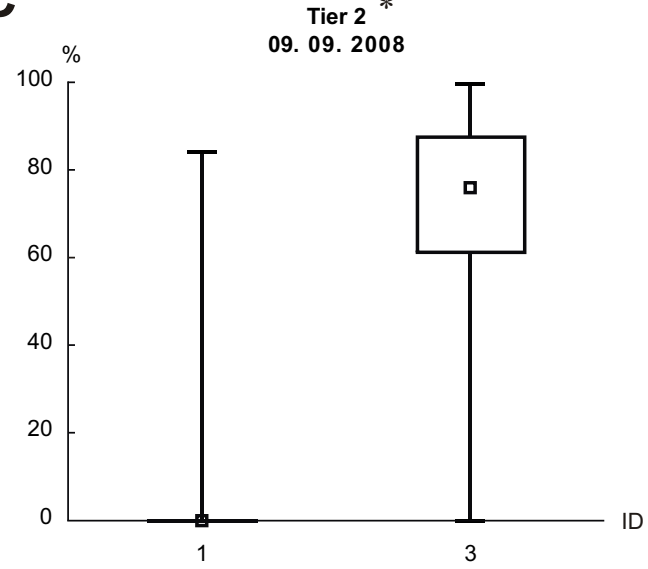

B
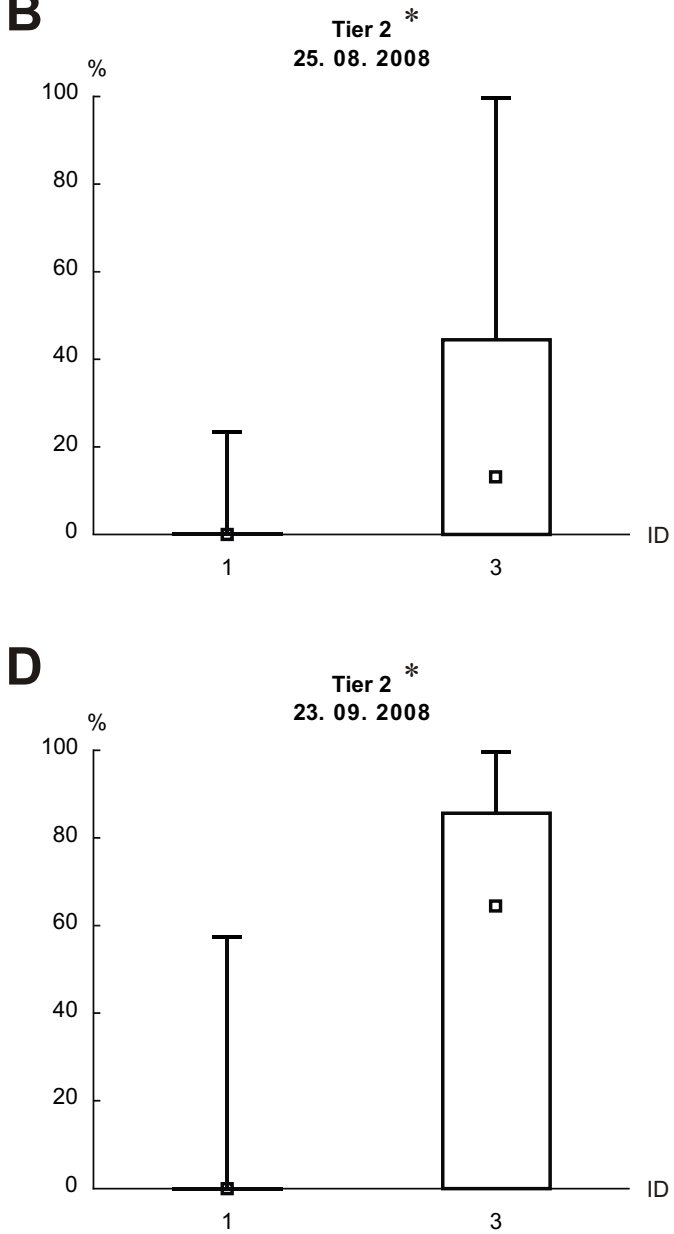

E
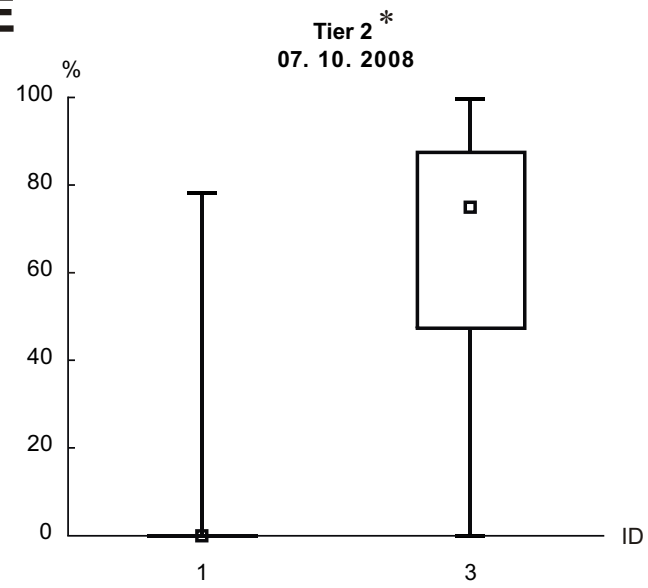

Abb. 10A-E: Prozentualer Anteil (\%) stark kondensierter Mitochondrien in 100 Mittelstückanschnitten pro Spermienprobe (Entnahmedatum angegeben). Bei allen Proben von Tier 2 besteht ein signifikanter Unterschied (*; $<<0,05$; Mann-Whitney-U-Test) zwischen jeweils korrespondierenden Proben nichtsortierter (ID1) und standardsortierter (ID3) Rinderspermien vom selben Probenentnahmetag. ID, Identifikationsnummer der Spermienbehandlung. 
A

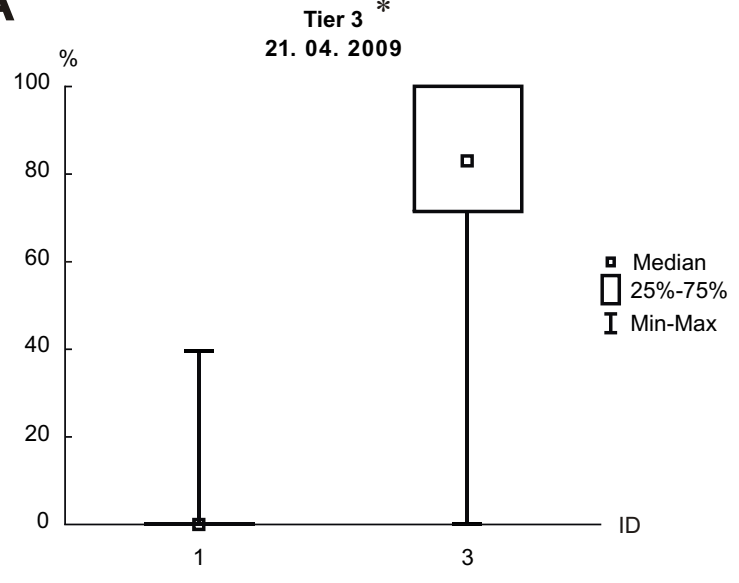

C

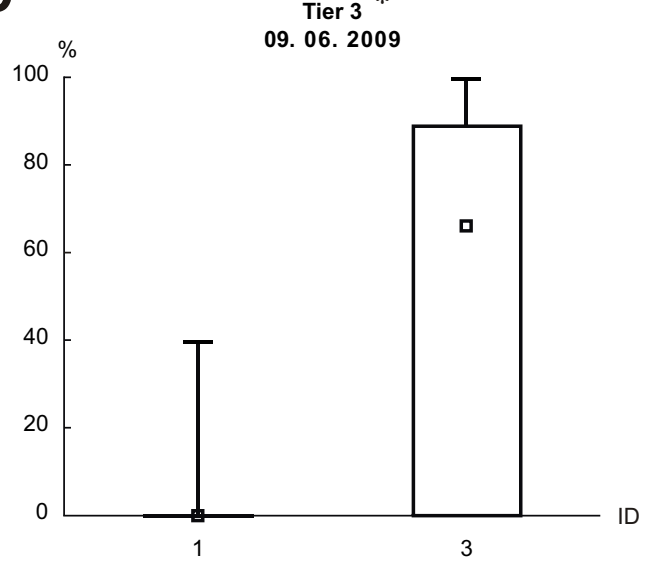

B

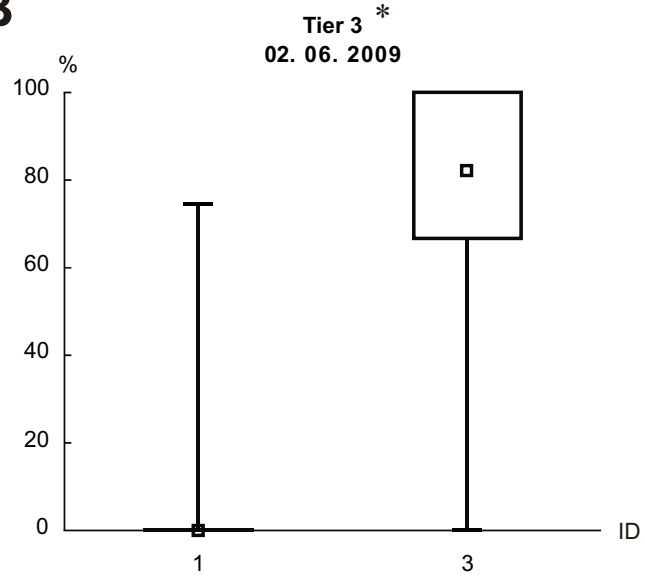

D

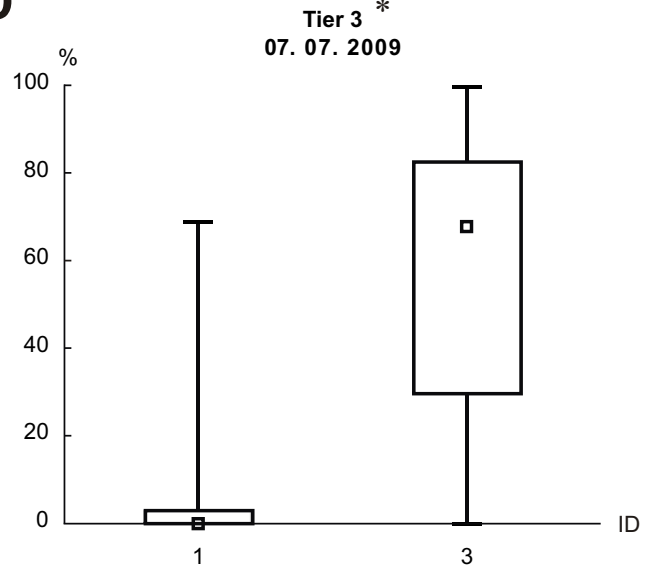

Abb. 11A-D: Prozentualer Anteil (\%) stark kondensierter Mitochondrien in 100 Mittelstückanschnitten pro Spermienprobe (Entnahmedatum angegeben). Bei allen Proben von Tier 3 besteht ein signifikanter Unterschied (*; $<<0,05$; Mann-Whitney-U-Test) zwischen jeweils korrespondierenden Proben nichtsortierter (ID1) und standardsortierter (ID3) Rinderspermien vom selben Probenentnahmetag. ID, Identifikationsnummer der Spermienbehandlung. 


\section{2 Einfluss individueller Komponenten des Sortierprozesses auf die Konformation von Spermienmitochondrien}

Im Anschluss haben wir untersucht, welche Komponenten des Sortierverfahrens dafür verantwortlich sein könnten, dass viele Spermienmitochondrien hierbei einen Konformationswechsel von orthodox zu kondensiert durchlaufen. Zu diesem Zweck wurden Spermienproben aus unterschiedlichen Phasen des Sortierprozesses entnommen und analysiert.

\section{2.1 DNS-Farbstoff Hoechst 33342}

Der DNS-Farbstoff Hoechst 33342 wurde den für die Sortierung vorgesehenen Spermienproben unmittelbar vor dem Einbringen in das Sortiergerät beigefügt (ID2). Verglichen wurden zunächst Spermienproben der ID2 und ID1 (nichtsortiert). Bei den Tieren 1 und 2 bestand hierbei kein signifikanter Unterschied hinsichtlich des Vorkommens stark kondensierter Mitochondrien (Tab. 8, 9; Abb. 12A, B). Im Gegensatz dazu war bei Tier 3 der Anteil stark kondensierter Mitochondrien in den Proben der ID2 signifikant höher als in den korrespondierenden Proben der ID1 (Tab. 8, 9; Abb. 12C). Stark kondensierte Mitochondrien entstehen demnach mindestens in einem Teil der Fälle bereits vor dem Durchlauf des Sortiergeräts unter Einwirkung des DNS-Farbstoffs Hoechst 33342.

Tab. 8: Vergleich des prozentualen Anteils (\%) stark kondensierter Mitochondrien in nichtsortierten (ID1) und in mit dem DNS-Farbstoff Hoechst 33342 inkubierten (ID2) Rinderspermien. Angegeben ist der Median (MD) und der arithmetische Mittelwert (AM) aus den 100 Prozentwerten jeder Probe. ID, Identifikationsnummer der Spermienbehandlung.

\begin{tabular}{clrrrr} 
& & MD $(\%)$ & \multicolumn{2}{c}{ AM (\%) } \\
\hline Tier & $\begin{array}{l}\text { Proben- } \\
\text { entnahmetag }\end{array}$ & ID1 & ID2 & ID1 & ID2 \\
\hline 1 & 16. 06. 2008 & 0,0 & 0,0 & 2,5 & 2,8 \\
2 & 11.08 .2008 & 0,0 & 0,0 & 1,4 & 2,2 \\
3 & 21.04 .2009 & 0,0 & 40,0 & 2,5 & 42,2
\end{tabular}

Tab. 9: Vergleich des prozentualen Anteils stark kondensierter Mitochondrien in nichtsortierten (ID1) und in mit dem DNS-Farbstoff Hoechst 33342 inkubierten (ID2) Rinderspermien. Verglichen (Mann-Whitney-U-Test) wurden jeweils pro Probenentnahmetag alle für die ID1 gewonnenen Prozentwerte mit den für ID2 gewonnenen Prozentwerten. Signifikanter Unterschied $(*)$ bei $\mathrm{p}<0,05$; ID, Identifikationsnummer der Spermienbehandlung.

ID1 versus ID2

\begin{tabular}{clc}
\hline Tier & $\begin{array}{l}\text { Proben- } \\
\text { entnahmetag }\end{array}$ & $\mathbf{p}$ \\
\hline 1 & 16.06 .2008 & 0,69 \\
2 & 11.08 .2008 & 0,53 \\
3 & 21.04 .2009 & $0,00^{*}$
\end{tabular}


Im nächsten Schritt wollten wir herausfinden, ob sich die Häufigkeit stark kondensierter Mitochondrien signifikant erhöht, wenn Spermien, die bereits mit Hoechst 33342 inkubiert waren (ID2), anschließend standardmäßig sortiert werden (ID3). Tatsächlich zeigte sich eine solche signifikante Erhöhung $(\mathrm{p}<0,05)$ des Anteils stark kondensierter Mitochondrien bei allen drei untersuchten Tieren (Tab. 10, 11; Abb. 13A-C).

Tab. 10: Vergleich des prozentualen Anteils (\%) stark kondensierter Mitochondrien in mit dem DNS-Farbstoff Hoechst 33342 inkubierten (ID2) und in standardsortierten (ID3) Rinderspermien. Angegeben ist der Median (MD) und der arithmetische Mittelwert (AM) aus den 100 Prozentwerten jeder Probe. ID, Identifikationsnummer der Spermienbehandlung.

\begin{tabular}{clrrrr} 
& & \multicolumn{2}{c}{ MD $(\%)$} & \multicolumn{2}{c}{ AM (\%) } \\
\hline Tier & $\begin{array}{l}\text { Proben- } \\
\text { entnahmetag }\end{array}$ & ID2 & ID3 & ID2 & ID3 \\
\hline 1 & 16.06 .2008 & 0,0 & 37,4 & 2,8 & 35,7 \\
2 & 11.08 .2008 & 0,0 & 80,0 & 2,2 & 70,6 \\
3 & 21.04 .2009 & 40,0 & 83,3 & 42,2 & 76,6
\end{tabular}

Tab. 11: Vergleich des prozentualen Anteils stark kondensierter Mitochondrien in mit dem DNS-Farbstoff Hoechst 33342 inkubierten (ID2) und in standardsortierten (ID3) Rinderspermien. Verglichen (Mann-Whitney-U-Test) wurden jeweils pro Probenentnahmetag die für ID1 gewonnenen Prozentwerte mit den für ID3 gewonnenen Prozentwerten. Signifikanter Unterschied (*) bei p<0,05; ID, Identifikationsnummer der Spermienbehandlung.

ID2 versus ID3

\begin{tabular}{clc}
\hline Tier & $\begin{array}{l}\text { Proben- } \\
\text { entnahmetag }\end{array}$ & $\mathbf{p}$ \\
\hline 1 & 16.06 .2008 & $0,00^{*}$ \\
2 & 11.08 .2008 & $0,00^{*}$ \\
3 & 21.04 .2009 & $0,00^{*}$
\end{tabular}

\section{2.2 Laser}

Im nächsten Arbeitsschritt wurde überprüft, ob das signifikant häufigere Auftreten von stark kondensierten Mitochondrien bei standardsortierten Spermien (ID3) verglichen mit nichtsortierten Spermien (ID1) vom Einfluss des Lasers, der in das Sortiergerät integriert ist, abhängt. Zu diesem Zweck wurden Spermienproben untersucht, die das Sortiergerät nach der Inkubation mit Hoechst 33342 bei ausgeschaltetem Laser durchlaufen haben (ID5). Bei der Analyse dieser Daten muss bedacht werden, dass das Ausschalten des Lasers komplexe Folgen hat (siehe auch Diskussion). Es entfällt nämlich hierdurch nicht nur der mögliche direkte Einfluss des Lasers, sondern auch die geschlechtsspezifische elektrische Aufladung der X- oder Y-chromosomalen Spermien. Folglich fallen bei ID5 alle Spermien unabgelenkt in den Abfallbehälter des Sortiergerätes, in dem auch die bereits vor der Sortierung geschädigten (und technisch auf andere Weise aussortierten Spermien: Material 
und Methoden) gesammelt werden. Im Gegensatz dazu bestehen die standardsortierten Proben der ID3 ausschließlich aus geschlechtsspezifisch sortierten und anschließend gepoolten Spermien.

Bei allen drei untersuchten Tieren zeigte sich, dass Spermienproben der ID5, verglichen mit korrespondierenden Kontrollproben der ID1 (nichtsortierte Spermien), einen signifikant höheren Anteil an Mitochondrien mit stark kondensierter Konformation aufweisen (Tab. 12, 13; Abb. 14A-C). Dieser Befund unterstützt die Auffassung, dass auch diejenigen Komponenten des Sortierprozesses, die nach Ausschaltung des Lasers sowie der folgenden elektrischen Aufladung der Spermien wirksam bleiben, an der Entstehung stark kondensierter Mitochondrien beteiligt sind.

Tab. 12: Vergleich des prozentualen Anteils (\%) stark kondensierter Mitochondrien in Proben nichtsortierter Rinderspermien (ID1) und in Proben, die das Sortiergerät bei ausgeschaltetem Laser durchlaufen haben (ID5). Angegeben ist der Median (MD) und der arithmetische Mittelwert (AM) aus den 100 Prozentwerten jeder Probe. ID, Identifikationsnummer der Spermienbehandlung.

\begin{tabular}{clccccc} 
& & \multicolumn{2}{c}{ MD (\%) } & \multicolumn{2}{c}{ AM (\%) } \\
\hline Tier & $\begin{array}{l}\text { Proben- } \\
\text { entnahmetag }\end{array}$ & ID1 & ID5 & ID1 & ID5 \\
\hline 1 & 30.06 .2008 & 0,0 & 3,9 & 0,7 & 25,2 \\
2 & 25.08 .2008 & 0,0 & 8,3 & 0,9 & 18,0 \\
3 & 26.05 .2009 & 0,0 & 25,0 & 4,3 & 31,9
\end{tabular}

Tab. 13: Vergleich des prozentualen Anteils stark kondensierter Mitochondrien in Proben nichtsortierter Rinderspermien (ID1) und in Proben, die das Sortiergerät bei ausgeschaltetem Laser durchlaufen haben (ID5). Verglichen (MannWhitney-U-Test) wurden pro Probenentnahmetag jeweils die für ID1 gewonnenen Prozentwerte mit den für ID5 gewonnenen Prozentwerten. Signifikanter Unterschied $(*)$ bei $\mathrm{p}<0,05$; ID, Identifikationsnummer der Spermienbehandlung.

\section{ID1 versus ID5}

\begin{tabular}{clc}
\hline Tier & $\begin{array}{l}\text { Proben- } \\
\text { entnahmetag }\end{array}$ & $\mathbf{p}$ \\
\hline 1 & 30.06 .2008 & $0,00^{*}$ \\
2 & 25.08 .2008 & $0,00^{*}$ \\
3 & 26.05 .2009 & $0,00^{*}$
\end{tabular}

Ein Vergleich zwischen ID5 und der „klassischen“ ID3 ist auf Grund der oben dargelegten Unterschiede in der Zusammensetzung der resultierenden Proben nicht optimal belastbar. Besser geeignet ist ein Vergleich zwischen Proben von Spermien, die bei ausgeschaltetem Laser durch das Sortiergerät hindurchgegangen sind (ID5) und Proben von standardsortierten gepoolten Spermien, denen nachträglich auch die primär geschädigten und deshalb in den Abfallbehälter des Sortiergerätes gelenkten Spermien hinzugegeben werden (ID3+). Für diesen Vergleich stand vorläufig lediglich ein 
einziges korrespondierendes Probenpaar des Tieres 3 zur Verfügung, dessen Analyse bezüglich des Vorkommens stark kondensierter Mitochondrien keinen signifikanten Unterschied zwischen ID3+ und ID5 zutage förderte (Tab. 14, 15; Abb. 15).

Tab. 14: Vergleich des prozentualen Anteils (\%) stark kondensierter Mitochondrien in einer Probe standardsortierter Rinderspermien, denen unabgelenkte Spermien aus dem Abfallbehälter hinzugefügt wurden (ID3+), und in einer Probe, die das Sortiergerät bei ausgeschaltetem Laser durchlaufen hat (ID5). Angegeben ist der Median (MD) und der arithmetische Mittelwert (AM) aus den 100 Prozentwerten jeder Probe. ID, Identifikationsnummer der Spermienbehandlung.

\begin{tabular}{clcccc} 
& & \multicolumn{2}{c}{ MD (\%) } & \multicolumn{2}{c}{ AM (\%) } \\
\hline Tier & $\begin{array}{l}\text { Proben- } \\
\text { entnahmetag }\end{array}$ & ID3+ & ID5 & ID3+ & ID5 \\
\hline 3 & 26. 05. 2009 & 26,8 & 25,0 & 33,6 & 31,9
\end{tabular}

Tab. 15: Vergleich des prozentualen Anteils stark kondensierter Mitochondrien in einer Probe standardsortierter Rinderspermien, denen unabgelenkte Spermien aus dem Abfallbehälter hinzugefügt wurden (ID3+), und in einer Probe, die das Sortiergerät bei ausgeschaltetem Laser durchlaufen hat (ID5). Verglichen (Mann-Whitney-U-Test) wurden die für ID3+ gewonnenen Prozentwerte mit den für ID5 gewonnenen Prozentwerten. Signifikanter Unterschied (*) bei p<0,05; ID, Identifikationsnummer der Spermienbehandlung.

\section{ID3+ versus ID5}

\begin{tabular}{clc}
\hline Tier & $\begin{array}{l}\text { Proben- } \\
\text { entnahmetag }\end{array}$ & $\mathbf{p}$ \\
\hline 3 & 26.05 .2009 & 0,98
\end{tabular}

\section{2.3 Spannung am Piezokristall}

Anschließend wollten wir herausfinden, ob die Höhe der elektrischen Spannung am Piezokristall des Sortiergerätes, der für die Vibration der Düse und somit für die Erzeugung des für die Sortierung unentbehrlichen Tropfenstroms verantwortlich ist, Einfluss auf die Mitochondrienkonformation hat. Deshalb haben wir die bei der Standardsortierung regulär verwendete Spannung von 25 oder 30 Volt (ID3) auf 5 Volt reduziert (ID6).

Zunächst wurde die Häufigkeit von Anschnitten stark kondensierter Mitochondrien in Proben der ID6 mit derjenigen verglichen, die bei nichtsortierten Kontrollproben (ID1) auftritt. Hierbei zeigte sich bei allen drei untersuchten Tieren ein signifikant höherer Anteil stark kondensierter Mitochondrien bei Proben der ID6 (Tab. 16, 17; Abb. 16A-C). 
Tab. 16: Vergleich des prozentualen Anteils (\%) stark kondensierter Mitochondrien in nichtsortierten (ID1) und in bei reduzierter Spannung am Piezokristall sortierten (ID6) Rinderspermien. Angegeben ist der Median (MD) und der arithmetische Mittelwert (AM) aus den 100 Prozentwerten jeder Probe. ID, Identifikationsnummer der Spermienbehandlung.

\begin{tabular}{clcccrc} 
& & \multicolumn{2}{c}{ MD (\%) } & \multicolumn{2}{c}{ AM (\%) } \\
\hline Tier & $\begin{array}{l}\text { Proben- } \\
\text { entnahmetag }\end{array}$ & ID1 & ID6 & ID1 & ID6 \\
\hline 1 & 05.08 .2008 & 0,0 & 73,5 & 10,4 & 61,2 \\
2 & 07.10 .2008 & 0,0 & 63,6 & 2,2 & 57,6 \\
3 & 09.06 .2009 & 0,0 & 71,4 & 2,1 & 59,8
\end{tabular}

Tab. 17: Vergleich des prozentualen Anteils stark kondensierter Mitochondrien in nichtsortierten (ID1) und in bei reduzierter Spannung am Piezokristall sortierten (ID6) Rinderspermien. Verglichen (Mann-Whitney-U-Test) wurden pro Probenentnahmetag jeweils die für ID1 gewonnenen Prozentwerte mit den für ID6 gewonnenen Prozentwerten. Signifikanter Unterschied (*) bei $\mathrm{p}<0,05$; ID, Identifikationsnummer der Spermienbehandlung.

\section{ID1 versus ID6}

\begin{tabular}{clc}
\hline Tier & $\begin{array}{l}\text { Proben- } \\
\text { entnahmetag }\end{array}$ & $\mathbf{p}$ \\
\hline 1 & 05.08 .2008 & $0,00^{*}$ \\
2 & 07.10 .2008 & $0,00^{*}$ \\
3 & 09.06 .2009 & $0,00^{*}$
\end{tabular}

Im nächsten Arbeitsschritt wurden Proben der ID6 mit Proben der ID3 (Standardsortierung mit 25 oder 30 Volt am Piezokristall) verglichen. Demnach führt die Applikation geringerer Spannungen am Piezokristall (ID6) zu uneinheitlichen Ergebnissen. Bei Tier 2 trat eine signifikante Verminderung des Anteils stark kondensierter Mitochondrien auf (Tab. 18, 19; Abb. 17B). Dagegen fand sich bei den Tieren 1 und 3 kein signifikanter Unterschied bezüglich des untersuchten Merkmals (Tab. 18, 19; Abb. 17A, C).

Tab. 18: Vergleich des prozentualen Anteils (\%) stark kondensierter Mitochondrien in standardsortierten (ID3) und in bei reduzierter Spannung am Piezokristall sortierten (ID6) Rinderspermien. Angegeben ist der Median (MD) und der arithmetische Mittelwert (AM) aus den 100 Prozentwerten jeder Probe. ID, Identifikationsnummer der Spermienbehandlung.

\begin{tabular}{clcccc} 
& & \multicolumn{2}{c}{ MD (\%) } & \multicolumn{2}{c}{ AM (\%) } \\
\hline Tier & $\begin{array}{l}\text { Proben- } \\
\text { entnahmetag }\end{array}$ & ID3 & ID6 & ID3 & ID6 \\
\hline 1 & 05.08 .2008 & 76,4 & 73,5 & 66,9 & 61,2 \\
2 & 07.10 .2008 & 75,0 & 63,6 & 67,0 & 57,6 \\
3 & 09.06 .2009 & 66,7 & 71,4 & 53,6 & 59,8
\end{tabular}


Tab. 19: Vergleich des prozentualen Anteils stark kondensierter Mitochondrien in standardsortierten (ID3) und in bei reduzierter Spannung am Piezokristall sortierten (ID6) Rinderspermien. Verglichen (Mann-Whitney-U-Test) wurden pro Probenentnahmetag jeweils die für ID3 gewonnenen Prozentwerte mit den für ID6 gewonnenen Prozentwerten. Signifikanter Unterschied (*) bei p<0,05; ID, Identifikationsnummer der Spermienbehandlung.

ID3 versus ID6

\begin{tabular}{clc}
\hline Tier & $\begin{array}{l}\text { Proben- } \\
\text { entnahmetag }\end{array}$ & $\mathbf{p}$ \\
\hline 1 & 05.08 .2008 & 0,27 \\
2 & 07.10 .2008 & $0,01^{*}$ \\
3 & 09.06 .2009 & 0,51
\end{tabular}

\section{2.4 Hochspannungsplatten}

Weiterhin wurde der Einfluss des durch die Hochspannungsplatten erzeugten elektrischen Feldes auf die Ultrastruktur der Spermienmitochondrien untersucht. Hierfür wurden Spermien wie üblich zunächst mit dem DNS-Farbstoff Hoechst 33342 inkubiert, passierten den Laserstrahl und wurden dann, je nach Geschlecht, positiv oder negativ geladen. Das im Standardsortierverfahren (ID3) anschließend zu durchlaufende elektrische Feld blieb jedoch in diesem Versuch ausgeschaltet, weshalb die geladenen Spermien nicht zu den Seiten abgelenkt, sondern - wie bei ID5 (Ausschaltung des Lasers) - geradewegs in den Abfallbehälter des Sortiergerätes geleitet wurden (ID7). Zunächst wurden Spermienproben der ID7 mit Kontrollproben nichtsortierter Spermien (ID1) verglichen. Hierbei zeigten die Proben der ID7 bei allen drei Tieren eine signifikant höhere Häufigkeit von Mitochondrien mit stark kondensierter Konformation (Tab. 20, 21; Abb. 18A-D).

Tab. 20: Vergleich des prozentualen Anteils (\%) stark kondensierter Mitochondrien in Proben nichtsortierter Rinderspermien (ID1) und in Proben, die das Sortiergerät bei ausgeschalteten Hochspannungsplatten durchlaufen haben (ID7). Angegeben ist der Median (MD) und der arithmetische Mittelwert (AM) aus den 100 Prozentwerten jeder Probe. ID, Identifikationsnummer der Spermienbehandlung.

\begin{tabular}{clcrrrr} 
& & \multicolumn{2}{c}{ MD (\%) } & \multicolumn{2}{c}{ AM (\%) } \\
\hline Tier & $\begin{array}{l}\text { Proben- } \\
\text { entnahmetag }\end{array}$ & ID1 & ID7 & ID1 & ID7 \\
\hline 1 & 14. 07. 2008 & 0,0 & 0,0 & 1,9 & 9,9 \\
2 & 23. 09. 2008 & 0,0 & 65,2 & 2,3 & 45,9 \\
3 & 02.06 .2009 & 0,0 & 70,2 & 7,1 & 59,8 \\
3 & 07.07 .2009 & 0,0 & 75,0 & 3,9 & 61,4
\end{tabular}


Tab. 21: Vergleich des prozentualen Anteils stark kondensierter Mitochondrien in Proben nichtsortierter Rinderspermien (ID1) und in Proben, die das Sortiergerät bei ausgeschalteten Hochspannungsplatten durchlaufen haben (ID7). Verglichen (Mann-Whitney-U-Test) wurden pro Probenentnahmetag jeweils die für ID1 gewonnenen Prozentwerte mit den für ID7 gewonnenen Prozentwerten. Signifikanter Unterschied (*) bei p<0,05; ID, Identifikationsnummer der Spermienbehandlung.

\section{ID1 versus ID7}

\begin{tabular}{clc}
\hline Tier & $\begin{array}{l}\text { Proben- } \\
\text { entnahmetag }\end{array}$ & $\mathbf{p}$ \\
\hline 1 & 14.07 .2008 & $0,03^{*}$ \\
2 & 23.09 .2008 & $0,00^{*}$ \\
3 & 02.06 .2009 & $0,00^{*}$ \\
3 & 07.07 .2009 & $0,00^{*}$
\end{tabular}

Anschließend wurden die Spermienproben der ID7 mit standardsortierten Spermienproben (ID3) verglichen, denen allerdings in diesem Fall, anders als bei den bereits geschilderten Versuchen mit dem Laser (ID5 versus ID3+), keine geschädigten Spermien aus dem Abfallbehälter zugesetzt wurden (siehe Diskussion). Wir wollten wissen, ob das Ausschalten des elektrischen Feldes, verglichen mit der Standardsortierung, eine Verringerung des Anteils kondensierter Mitochondrien herbeiführt. Tatsächlich fanden wir, ungeachtet der Tatsache, dass die Proben der ID7, im Gegensatz zu Proben der ID3, auch primär geschädigte Spermien enthalten, bei den Tieren 1 und 2 niedrigere arithmetische Mittelwerte für ID7, in beiden Fällen jedoch ohne statistische Signifikanz (Tab. 22, 23; Abb. 19A, B). Bei Tier 3 waren die Ergebnisse uneinheitlich. An einem der beiden Probenentnahmetage wiesen die Proben der ID7, verglichen mit den Proben der ID3, sogar signifikant geringere Häufigkeiten stark kondensierter Mitochondrienanschnitte auf. Überraschenderweise zeigte sich aber am zweiten Probenentnahmetag ein höherer arithmetischer Mittelwert bei ID7, dies allerdings ohne statistische Signifikanz (Tab. 22, 23; Abb. 19C, D).

Tab. 22: Vergleich des prozentualen Anteils (\%) stark kondensierter Mitochondrien in Proben standardsortierter Rinderspermien (ID3) und in Proben, die das Sortiergerät bei ausgeschalteten Hochspannungsplatten durchlaufen haben (ID7). Angegeben ist der Median (MD) und der arithmetische Mittelwert (AM) aus den 100 Prozentwerten jeder Probe. ID, Identifikationsnummer der Spermienbehandlung.

\begin{tabular}{rlrrrrr} 
& & \multicolumn{2}{c}{ MD (\%) } & \multicolumn{2}{c}{ AM (\%) } \\
\hline Tier & $\begin{array}{l}\text { Proben- } \\
\text { entnahmetag }\end{array}$ & ID3 & ID7 & ID3 & ID7 \\
\hline 1 & 14.07 .2008 & 0,0 & 0,0 & 12,8 & 9,9 \\
2 & 23.09 .2008 & 65,2 & 65,2 & 49,4 & 45,9 \\
3 & 02.06 .2009 & 82,8 & 70,2 & 70,0 & 59,8 \\
3 & 07.07 .2009 & 68,3 & 75,0 & 56,7 & 61,4
\end{tabular}


Tab. 23: Vergleich des prozentualen Anteils stark kondensierter Mitochondrien in Proben standardsortierter Rinderspermien (ID3) und in Proben, die das Sortiergerät bei ausgeschalteten Hochspannungsplatten durchlaufen haben (ID7). Verglichen (Mann-Whitney-U-Test) wurden pro Probenentnahmetag jeweils die für ID3 gewonnenen Prozentwerte mit den für ID7 gewonnenen Prozentwerten. Signifikanter Unterschied (*) bei p<0,05; ID, Identifikationsnummer der Spermienbehandlung.

\begin{tabular}{clc}
\multicolumn{3}{c}{ ID3 versus ID7 } \\
\hline Tier & $\begin{array}{l}\text { Proben- } \\
\text { entnahmetag }\end{array}$ & p \\
\hline 1 & 14.07 .2008 & 0,70 \\
2 & 23.09 .2008 & 0,44 \\
3 & 02.06 .2009 & $0,01^{*}$ \\
3 & 07.07 .2009 & 0,16
\end{tabular}

\section{2.5 Eidotter im Auffangmedium}

Bei der Sortierung nach Standardprotokoll (ID3) wird dem TEST-Medium, in dem die sortierten Spermien aufgefangen werden, zusätzlich Eidotter zugegeben, der unter anderem Beeinträchtigungen der Spermienqualität durch vorhergehende Verdünnungseffekte (Zugabe von Hoechst 33342, Lebensmittelfarbstoff FD\&C Rot Nr. 40, Mantelflüssigkeit und Auffangmedium) verhindern soll (Maxwell 1996, zur Übersicht: Johnson et al. 2005). Wir wollten wissen, ob das Weglassen des Eidotters (ID4) Einfluss auf die Häufigkeit stark kondensierter Mitochondrien hat. Zunächst stellte sich heraus, dass Spermienproben der ID4, verglichen mit ID1 (nichtsortiert), bei allen untersuchten Tieren signifikant höhere Anteile an Mitochondrien mit stark kondensierter Konformation aufweisen (Tab. 24, 25; Abb. 20A-E).

Tab. 24: Vergleich des prozentualen Anteils (\%) stark kondensierter Mitochondrien in nichtsortierten Rinderspermien (ID1) und in solchen sortierten Rinderspermien, die in Auffangmedien ohne Eidotter eingebracht wurden (ID4). Angegeben ist der Median (MD) und der arithmetische Mittelwert (AM) aus den 100 Prozentwerten jeder Probe. ID, Identifikationsnummer der Spermienbehandlung.

\begin{tabular}{clcrrrr} 
& & \multicolumn{2}{c}{ MD (\%) } & \multicolumn{2}{c}{ AM (\%) } \\
\hline Tier & $\begin{array}{l}\text { Proben- } \\
\text { entnahmetag }\end{array}$ & ID1 & ID4 & ID1 & ID4 \\
\hline 1 & 23. 06. 2008 & 0,0 & 66,7 & 0,2 & 58,5 \\
2 & 18. 08. 2008 & 0,0 & 0,0 & 1,8 & 14,8 \\
3 & 05. 05.2009 & 0,0 & 25,0 & 1,7 & 29,9 \\
3 & 02. 06. 2009 & 0,0 & 20,0 & 7,1 & 25,0 \\
3 & 07. 07.2009 & 0,0 & 33,3 & 3,9 & 38,2
\end{tabular}


Tab. 25: Vergleich des prozentualen Anteils stark kondensierter Mitochondrien in nichtsortierten Rinderspermien (ID1) und in solchen sortierten Rinderspermien, die in Auffangmedien ohne Eidotter eingebracht wurden (ID4). Verglichen (Mann-Whitney-U-Test) wurden pro Probenentnahmetag jeweils die für ID1 gewonnenen Prozentwerte mit den für ID4 gewonnenen Prozentwerten. Signifikanter Unterschied (*) bei $\mathrm{p}<0,05$; ID, Identifikationsnummer der Spermienbehandlung.

\section{ID1 versus ID4}

\begin{tabular}{clc}
\hline Tier & $\begin{array}{l}\text { Proben- } \\
\text { entnahmetag }\end{array}$ & $\mathbf{p}$ \\
\hline 1 & 23.06.2008 & $0,00^{*}$ \\
2 & 18.08 .2008 & $0,00^{*}$ \\
3 & 05.05 .2009 & $0,00^{*}$ \\
3 & 02.06 .2009 & $0,00^{*}$ \\
3 & 07.07 .2009 & $0,00^{*}$
\end{tabular}

Im folgenden Arbeitsschritt wollten wir wissen, ob der Vergleich der Proben von ID4 (kein Eidotter im Auffangmedium) mit ID3 (standardsortiert, Eidotter im Auffangmedium) signifikante Unterschiede hinsichtlich des Auftretens stark kondensierter Mitochondrien zeigt. Allerdings war für diesen Vergleich lediglich Probenmaterial von Tier 3 vorhanden. In den korrespondierenden zwei Probenpaaren zeigte sich ein signifikant geringerer Anteil stark kondensierter Mitochondrien in den Proben der ID4 (Tab. 26, 27; Abb. 21A, B).

Tab. 26: Vergleich des prozentualen Anteils (\%) stark kondensierter Mitochondrien in standardsortierten Rinderspermien (ID3) und in solchen sortierten Rinderspermien, die in Auffangmedien ohne Eidotter eingebracht wurden (ID4). Angegeben ist der Median (MD) und der arithmetische Mittelwert (AM) aus den 100 Prozentwerten jeder Probe. ID, Identifikationsnummer der Spermienbehandlung.

\begin{tabular}{clccccc} 
& & \multicolumn{2}{c}{ MD (\%) } & \multicolumn{2}{c}{ AM (\%) } \\
\hline Tier & $\begin{array}{l}\text { Proben- } \\
\text { entnahmetag }\end{array}$ & ID3 & ID4 & ID3 & ID4 \\
\hline 3 & 02.06 .2009 & 82,8 & 20,0 & 70,0 & 25,0 \\
3 & 07.07 .2009 & 68,3 & 33,3 & 56,7 & 38,2
\end{tabular}

Tab. 27: Vergleich des prozentualen Anteils stark kondensierter Mitochondrien in standardsortierten Rinderspermien (ID3) und in solchen sortierten Rinderspermien, die in Auffangmedien ohne Eidotter eingebracht wurden (ID4). Verglichen (Mann-Whitney-U-Test) wurden pro Probenentnahmetag jeweils die für ID3 gewonnenen Prozentwerte mit den für ID4 gewonnenen Prozentwerten. Signifikanter Unterschied (*) bei p<0,05; ID, Identifikationsnummer der Spermienbehandlung.

ID3 versus ID4

\begin{tabular}{clc}
\hline Tier & $\begin{array}{l}\text { Proben- } \\
\text { entnahmetag }\end{array}$ & $\mathbf{p}$ \\
\hline 3 & 02.06 .2009 & $0,00^{*}$ \\
3 & 07.07 .2009 & $0,00^{*}$
\end{tabular}




\section{2.6 Seminalplasma im Auffangmedium}

Anschließend haben wir Untersuchungen an Proben sortierter Spermien vorgenommen, die in einem TEST-Dotter-Medium aufgefangen wurden, das aber im Gegensatz zu standardsortierten Proben der ID3 kein Seminalplasma enthielt (ID8). Zunächst wurden Spermienproben der ID8 und ID1 (nichtsortierte Spermien) miteinander verglichen. Hierbei zeigte sich, dass stark kondensierte Mitochondrien bei allen drei untersuchten Tieren in Proben der ID8 signifikant häufiger auftreten als in den Kontrollproben der ID1 (Tab. 28, 29; Abb. 22A-C).

Tab. 28: Vergleich des prozentualen Anteils (\%) stark kondensierter Mitochondrien in nichtsortierten Rinderspermien (ID1) und in solchen sortierten Rinderspermien, die in Auffangmedien ohne Seminalplasma eingebracht wurden (ID8). Angegeben ist der Median (MD) und der arithmetische Mittelwert (AM) aus den 100 Prozentwerten jeder Probe. ID, Identifikationsnummer der Spermienbehandlung.

\begin{tabular}{clccccc} 
& & \multicolumn{2}{c}{ MD (\%) } & \multicolumn{2}{c}{ AM (\%) } \\
\hline Tier & $\begin{array}{l}\text { Proben- } \\
\text { entnahmetag }\end{array}$ & ID1 & ID8 & ID1 & ID8 \\
\hline 1 & 14.07 .2008 & 0,0 & 11,8 & 1,9 & 24,6 \\
2 & 09.09 .2008 & 0,0 & 80,0 & 3,7 & 71,3 \\
3 & 05.05 .2009 & 0,0 & 70,7 & 1,7 & 59,8
\end{tabular}

Tab. 29: Vergleich des prozentualen Anteils stark kondensierter Mitochondrien in nichtsortierten Rinderspermien (ID1) und in solchen sortierten Rinderspermien, die in Auffangmedien ohne Seminalplasma eingebracht wurden (ID8). Verglichen (Mann-Whitney-U-Test) wurden pro Probenentnahmetag jeweils die für ID1 gewonnenen Prozentwerte mit den für ID8 gewonnenen Prozentwerten. Signifikanter Unterschied (*) bei p<0,05; ID, Identifikationsnummer der Spermienbehandlung.

\section{ID1 versus ID8}

\begin{tabular}{clc}
\hline Tier & $\begin{array}{l}\text { Proben- } \\
\text { entnahmetag }\end{array}$ & $\mathbf{p}$ \\
\hline 1 & 14.07 .2008 & $0,00^{*}$ \\
2 & 09.09 .2008 & $0,00^{*}$ \\
3 & 05.05 .2009 & $0,00^{*}$
\end{tabular}

Beim anschließenden Vergleich von Spermienproben der ID8 mit Proben der ID3 (standardsortiert), für den je ein korrespondierendes Probenpaar der Tiere 1 und 2 zur Verfügung stand, zeigte sich ein uneinheitliches Bild. Bei Tier 1 fand sich ein signifikant höherer Anteil stark kondensierter Mitochondrien bei denjenigen Proben, die in einem Auffangmedium ohne Seminalplasma gesammelt wurden (Tab. 30, 31; Abb. 23A), während bei Tier 2 kein signifikanter Unterschied zwischen den Proben der ID3 und ID8 feststellbar war (Tab. 30, 31; Abb. 23B). 
Tab. 30: Vergleich des prozentualen Anteils (\%) stark kondensierter Mitochondrien in standardsortierten Rinderspermien (ID3) und in solchen sortierten Rinderspermien, die in Auffangmedien ohne Seminalplasma eingebracht wurden (ID8). Angegeben ist der Median (MD) und der arithmetische Mittelwert (AM) aus den 100 Prozentwerten jeder Probe. ID, Identifikationsnummer der Spermienbehandlung.

\begin{tabular}{clrrrrr} 
& & \multicolumn{2}{c}{ MD (\%) } & \multicolumn{2}{c}{ AM (\%) } \\
\hline Tier & $\begin{array}{l}\text { Proben- } \\
\text { entnahmetag }\end{array}$ & ID3 & ID8 & ID3 & ID8 \\
\hline 1 & 14.07 .2008 & 0,0 & 11,8 & 12,8 & 24,6 \\
2 & 09.09 .2008 & 76,0 & 80,0 & 70,8 & 71,3
\end{tabular}

Tab. 31: Vergleich des prozentualen Anteils stark kondensierter Mitochondrien in standardsortierten Rinderspermien (ID3) und in solchen sortierten Rinderspermien, die in Auffangmedien ohne Seminalplasma eingebracht wurden (ID8). Verglichen (Mann-Whitney-U-Test) wurden pro Probenentnahmetag jeweils die für ID3 gewonnenen Prozentwerte mit den für ID8 gewonnenen Prozentwerten. Signifikanter Unterschied $\left(^{*}\right)$ bei $\mathrm{p}<0,05$; ID, Identifikationsnummer der Spermienbehandlung.

ID3 versus ID8

\begin{tabular}{clc}
\hline Tier & $\begin{array}{l}\text { Proben- } \\
\text { entnahmetag }\end{array}$ & $\mathbf{p}$ \\
\hline 1 & 14.07 .2008 & $0,00^{*}$ \\
2 & 09.09 .2008 & 0,52
\end{tabular}

\section{3 Einfluss von Aufarbeitungsschritten und Thermoresistenztest auf die Konfor-} mation von Mitochondrien geschlechtsspezifisch sortierter Spermien

Im Anschluss an die Analyse individueller Komponenten des eigentlichen Sortierprozesses lag es nahe, auch wesentliche Schritte des unmittelbar hierauf folgenden Aufarbeitungsprozesses sortierter Spermien bezüglich ihres möglichen Einflusses auf die Konformation der Mittelstück-Mitochondrien zu untersuchen. Einige dieser Proben wurden vor der ultrastrukturellen Untersuchung zusätzlich einem Thermoresistenztest unterzogen.

\section{3.1 Kühlen auf $5{ }^{\circ} \mathrm{C}$}

Standardsortierte Spermien (ID3) werden im Routinebetrieb nach Zugabe eines ersten Tiefgefriermediums auf $5{ }^{\circ} \mathrm{C}$ abgekühlt (ID9). Wir haben zunächst überprüft, ob sich Spermienproben der ID9 hinsichtlich des Anteils an Mitochondrien mit stark kondensierter Konformation von Proben nichtsortierter Spermien (ID1) unterscheiden. Bei den Tieren 1 und 3 zeigten sich signifikant höhere Prozentsätze stark kondensierter Mitochondrien in Proben der ID9 (Tab. 32, 33; Abb. 24A, C), während die korrespondierenden Spermienproben (ID1, ID9) bei Tier 2 keinen signifikanten Unterschied aufwiesen (Tab. 32, 33; Abb. 24B). Stattdessen lagen die Werte für die nichtsortierte Probe hier auf einem ungewöhnlich hohen Niveau. 
Tab. 32: Vergleich des prozentualen Anteils (\%) stark kondensierter Mitochondrien in nichtsortierten Rinderspermien (ID1) und in sortierten, mit einem Tiefgefriermedium versetzten und auf $5{ }^{\circ} \mathrm{C}$ gekühlten Rinderspermien (ID9). Angegeben ist der Median (MD) und der arithmetische Mittelwert (AM) aus den 100 Prozentwerten jeder Probe. ID, Identifikationsnummer der Spermienbehandlung.

\begin{tabular}{rlrrrrr} 
& & \multicolumn{2}{c}{ MD (\%) } & \multicolumn{2}{c}{ AM (\%) } \\
\hline Tier & $\begin{array}{l}\text { Proben- } \\
\text { entnahmetag }\end{array}$ & ID1 & ID9 & ID1 & ID9 \\
\hline 1 & 12.08 .2008 & 0,0 & 47,2 & 7,1 & 42,7 \\
2 & 08.10 .2008 & 33,3 & 50,0 & 36,6 & 43,1 \\
3 & 16.06 .2009 & 0,0 & 42,9 & 2,8 & 42,3
\end{tabular}

Tab. 33: Vergleich des prozentualen Anteils stark kondensierter Mitochondrien in nichtsortierten Rinderspermien (ID1) und in sortierten, mit einem Tiefgefriermedium versetzten und auf $5{ }^{\circ} \mathrm{C}$ gekühlten Rinderspermien (ID9). Verglichen (Mann-Whitney-U-Test) wurden pro Probenentnahmetag jeweils die für ID1 gewonnenen Prozentwerte mit den für ID9 gewonnenen Prozentwerten. Signifikanter Unterschied $(*)$ bei $p<0,05$. ID, Identifikationsnummer der Spermienbehandlung.

\section{ID1 versus ID9}

\begin{tabular}{cll}
\hline Tier & $\begin{array}{l}\text { Proben- } \\
\text { entnahmetag }\end{array}$ & $\mathbf{p}$ \\
\hline 1 & 12.08 .2008 & $0,00^{*}$ \\
2 & 08.10 .2008 & 0,08 \\
3 & 16.06 .2009 & $0,00^{*}$
\end{tabular}

\section{3.2 Kühlen, Einfrieren und Wiederauftauen}

Standardmäßig sortierten Spermienproben (ID3) wird im Routineverfahren nach Zugabe des ersten Tiefgefriermediums und Abkühlen auf $5{ }^{\circ} \mathrm{C}$ (ID9) ein zweites Tiefgefriermedium zugegeben. Danach werden die Proben in flüssigem Stickstoff tiefgefroren und vor dem Einsatz zur Besamung wieder aufgetaut (ID10). Bei beiden untersuchten Tieren (2 und 3) stellte sich heraus, dass Proben der ID10 im Vergleich zu Proben der ID1 (nichtsortierte Spermien) keinen signifikant höheren Anteil stark kondensierter Mitochondrien aufweisen. Angesichts der Tatsache, dass die Spermienproben der ID10 den Sortiervorgang vollständig durchlaufen haben (vergleiche die durchgehend stark erhöhten Prozentsätze kondensierter Mitochondrien in Proben der ID3, Tab. 6), scheint der anschlieBende Vorgang des Einfrierens und Wiederauftauens zu einem Rückgang der Häufigkeit von Mitochondrien mit kondensierter Konformation zu führen (Tab. 34, 35; Abb. 25A, B). 
Tab. 34: Vergleich des prozentualen Anteils (\%) stark kondensierter Mitochondrien in nichtsortierten Rinderspermien (ID1) und in Proben der ID10 (Sortieren, Kühlen, Einfrieren und Wiederauftauen). Angegeben ist der Median (MD) und der arithmetische Mittelwert (AM) aus den 100 Prozentwerten jeder Probe. ID, Identifikationsnummer der Spermienbehandlung.

\begin{tabular}{clcccc} 
& & \multicolumn{2}{c}{ MD (\%) } & \multicolumn{2}{c}{ AM (\%) } \\
\hline Tier & $\begin{array}{l}\text { Proben- } \\
\text { entnahmetag }\end{array}$ & ID1 & ID10 & ID1 & ID10 \\
\hline 2 & 22. 10. 2008 & 0,0 & 0,0 & 0,7 & 2,7 \\
3 & 23. 06. 2009 & 0,0 & 0,0 & 3,9 & 3,4
\end{tabular}

Tab. 35: Vergleich des prozentualen Anteils stark kondensierter Mitochondrien in nichtsortierten (ID1) Rinderspermien und in Proben der ID10 (Sortieren, Kühlen, Einfrieren und Wiederauftauen). Verglichen (Mann-Whitney-U-Test) wurden pro Probenentnahmetag jeweils die für ID1 gewonnenen Prozentwerte mit den für ID10 gewonnenen Prozentwerten. Signifikanter Unterschied $(*)$ bei $p<0,05$; ID, Identifikationsnummer der Spermienbehandlung.

\section{ID1 versus ID10}

\begin{tabular}{clc}
\hline Tier & $\begin{array}{l}\text { Proben- } \\
\text { entnahmetag }\end{array}$ & $\mathbf{p}$ \\
\hline 2 & 22.10 .2008 & 0,39 \\
3 & 23.06 .2009 & 0,73
\end{tabular}

\section{3.3 Thermoresistenztest}

Schließlich wurde untersucht, wie sich Spermien bezüglich der Mitochondrienkonformation verhalten, die sortiert, nach Zugabe eines ersten Tiefgefriermediums gekühlt, mit einem zweiten Tiefgefriermedium versetzt und eingefroren, wieder aufgetaut und anschließend einem Thermoresistenztest unterzogen wurden (ID11). Bei diesem Test wurden die aufgetauten Spermienproben über sechs Stunden bei $37{ }^{\circ} \mathrm{C}$ aufbewahrt. Zunächst fand sich nur bei einem der beiden untersuchten Tiere (Tier 2), verglichen mit nichtsortierten Spermienproben der ID1, ein (eben) signifikant höherer Prozentsatz stark kondensierter Mitochondrien bei ID11 (Tab. 36, 37; Abb. 26A, B). Bemerkenswerterweise ist der Prozentsatz stark kondensierter Mitochondrien bei dieser Probe (ID11) erheblich niedriger als bei sämtlichen untersuchten Proben der ID3 (standardsortiert), aber im Trend sehr nahe an den allermeisten untersuchten Proben der ID1 (nichtsortiert, siehe Diskussion). Das zweite korrespondierende Probenpaar (ID1 versus ID11) wies keinen statistisch signifikanten Unterschied auf. 
Abb. 36: Vergleich des prozentualen Anteils (\%) stark kondensierter Mitochondrien in nichtsortierten (ID1) Rinderspermien und in Proben der ID11 (Sortieren, Kühlen, Einfrieren, Wiederauftauen, Thermoresistenztest). Angegeben ist der Median (MD) und der arithmetische Mittelwert (AM) aus den 100 Prozentwerten jeder Probe. ID, Identifikationsnummer der Spermienbehandlung.

\begin{tabular}{clcccr} 
& & \multicolumn{2}{c}{ MD (\%) } & \multicolumn{2}{c}{ AM (\%) } \\
\hline Tier & $\begin{array}{l}\text { Proben- } \\
\text { entnahmetag }\end{array}$ & ID1 & ID11 & ID1 & ID11 \\
\hline 2 & 22. 10. 2008 & 0,0 & 0,0 & 0,7 & 3,7 \\
3 & 23. 06. 2009 & 0,0 & 0,0 & 3,9 & 5,9
\end{tabular}

Tab. 37: Vergleich des prozentualen Anteils stark kondensierter Mitochondrien in nichtsortierten Rinderspermien (ID1) und in Proben der ID11 (Sortieren, Kühlen, Einfrieren, Wiederauftauen, Thermoresistenztest). Verglichen (Mann-Whitney-U-Test) wurden pro Probenentnahmetag jeweils die für ID1 gewonnenen Prozentwerte mit den für ID11 gewonnenen Prozentwerten. Signifikanter Unterschied $(*)$ bei $p<0,05$; ID, Identifikationsnummer der Spermienbehandlung.

\section{ID1 versus ID11}

\begin{tabular}{cll}
\hline Tier & $\begin{array}{l}\text { Proben- } \\
\text { entnahmetag }\end{array}$ & $\mathbf{p}$ \\
\hline 2 & 22.10 .2008 & $0,02 *$ \\
3 & 23.06 .2009 & 0,69
\end{tabular}

Abschließend wollten wir wissen, ob sich der Anteil stark kondensierter Mitochondrien verändert, wenn routinemäßig für die Befruchtung aufgearbeitete standardsortierte Spermien (ID10) einem Thermoresistenztest unterworfen werden (ID11). Nur bei einem der drei untersuchten Tiere (Tier 1) wiesen die Proben der ID11, verglichen mit den Proben der ID10, einen signifikant höheren Anteil an stark kondensierten Mitochondrien auf (Tab. 38, 39; Abb. 27A). Bei den übrigen beiden Tieren bestand dagegen kein signifikanter Unterschied zwischen den Proben der ID10 und ID11 (Tab. 39, Abb. 27B, C).

Tab. 38: Vergleich des prozentualen Anteils (\%) stark kondensierter Mitochondrien in Rinderspermien der ID10 (Sortieren, Kühlen, Einfrieren und Wiederauftauen) und der ID11 (Sortieren, Kühlen, Einfrieren, Wiederauftauen, Thermoresistenztest). Angegeben ist der Median (MD) und der arithmetische Mittelwert (AM) aus den 100 Prozentwerten jeder Probe. ID, Identifikationsnummer der Spermienbehandlung.

\begin{tabular}{clccrrr} 
& & \multicolumn{2}{c}{ MD (\%) } & \multicolumn{2}{c}{ AM (\%) } \\
\hline Tier & $\begin{array}{l}\text { Proben- } \\
\text { entnahmetag }\end{array}$ & ID10 & ID11 & ID10 & ID11 \\
\hline 1 & 18.08 .2008 & 0,0 & 0,0 & 6,0 & 17,8 \\
2 & 22.10 .2008 & 0,0 & 0,0 & 2,7 & 3,7 \\
3 & 23.06 .2009 & 0,0 & 0,0 & 3,4 & 5,9
\end{tabular}


Tab. 39: Vergleich des prozentualen Anteils stark kondensierter Mitochondrien in Rinderspermien der ID10 (Sortieren, Kühlen, Einfrieren und Wiederauftauen) und der ID11 (Sortieren, Kühlen, Einfrieren, Wiederauftauen, Thermoresistenztest). Verglichen (Mann-Whitney-U-Test) wurden pro Probenentnahmetag jeweils die für ID10 gewonnenen Prozentwerte mit den für ID11 gewonnenen Prozentwerten. Signifikanter Unterschied (*) bei p<0,05; ID, Identifikationsnummer der Spermienbehandlung.

\section{ID10 versus ID11}

\begin{tabular}{clc} 
Tier & $\begin{array}{l}\text { Proben- } \\
\text { entnahmetag }\end{array}$ & p \\
\hline 1 & 18.08 .2008 & $0,00^{*}$ \\
2 & 22.10 .2008 & 0,15 \\
3 & 23.06 .2009 & 0,91
\end{tabular}


A

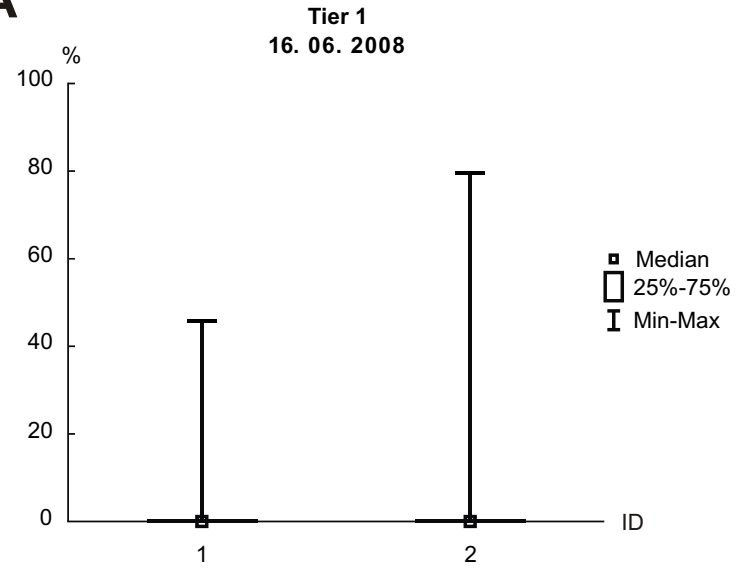

B

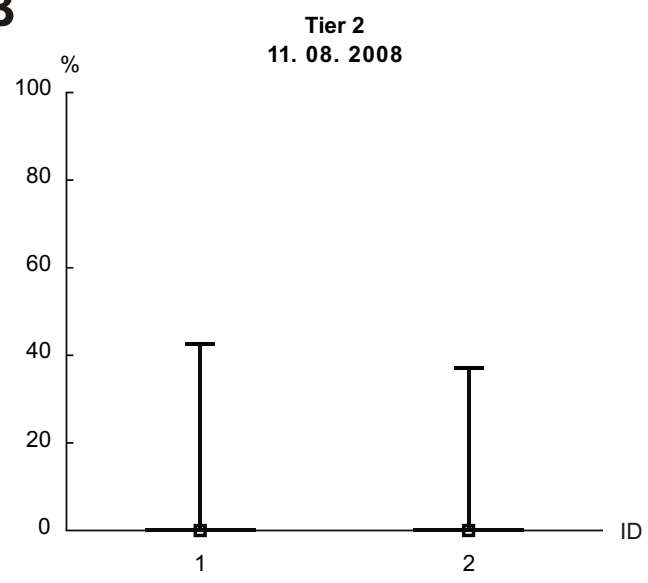

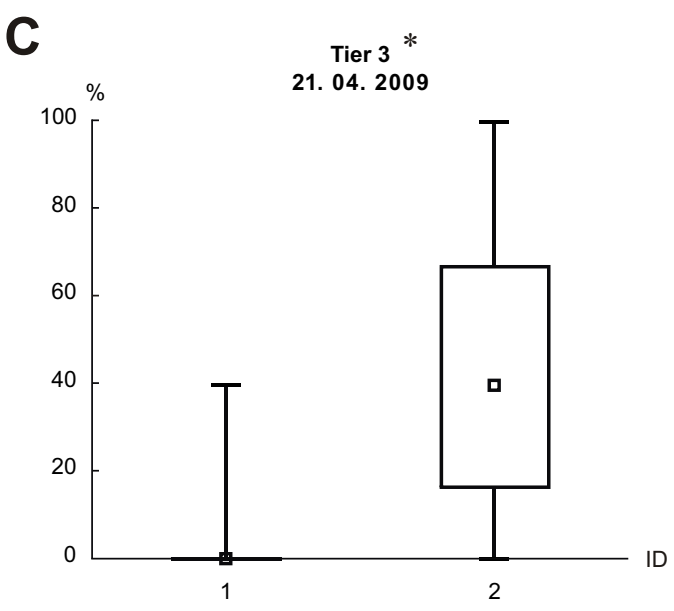

Abb. 12A-C: Prozentualer Anteil (\%) stark kondensierter Mitochondrien in 100 Mittelstückanschnitten pro Spermienprobe (Entnahmedatum angegeben). Lediglich bei einem von drei untersuchten Tieren (C: Tier 3) besteht ein signifikanter Unterschied (*; $<<0,05$; Mann-Whitney-U-Test) zwischen der Probe nichtsortierter Rinderspermien (ID1) und der korrespondierenden Probe vom selben Entnahmetag, die mit dem DNS-Farbstoff Hoechst 33342 inkubiert wurde (ID2). ID, Identifikationsnummer der Spermienbehandlung. 
A

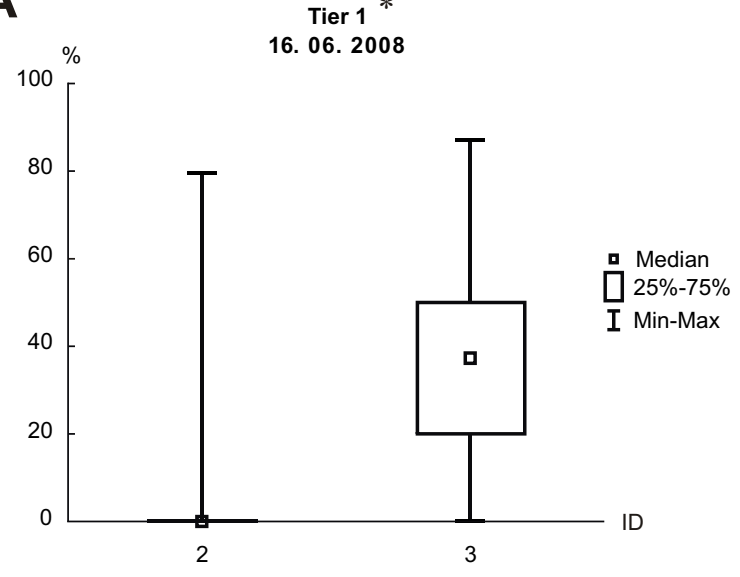

B

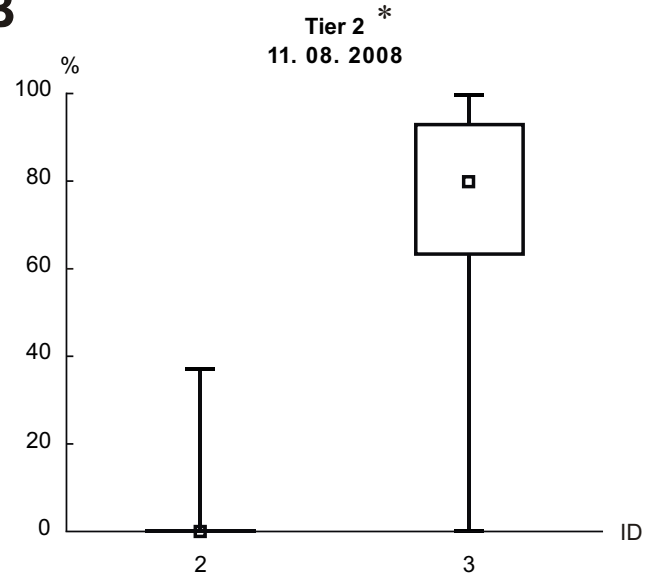

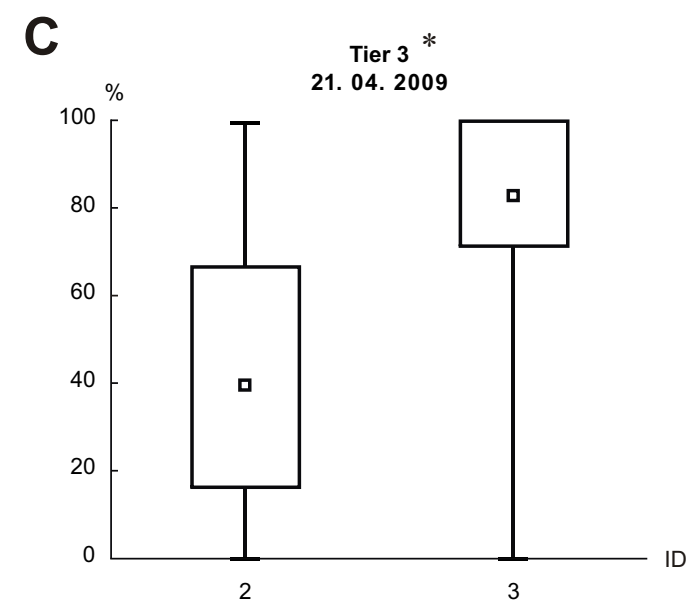

Abb. 13A-C: Prozentualer Anteil (\%) stark kondensierter Mitochondrien in 100 Mittelstückanschnitten pro Spermienprobe (Entnahmedatum angegeben). Bei allen drei untersuchten Tieren besteht ein signifikanter Unterschied $(* ; p<0,05$; Mann-Whitney-U-Test) zwischen jeweils korrespondierenden Proben von Rinderspermien, die mit dem DNS-Farbstoff Hoechst 33342 inkubiert wurden (ID2) und standardsortierten Rinderspermien (ID3) vom selben Entnahmetag. ID, Identifikationsnummer der Spermienbehandlung. 
A

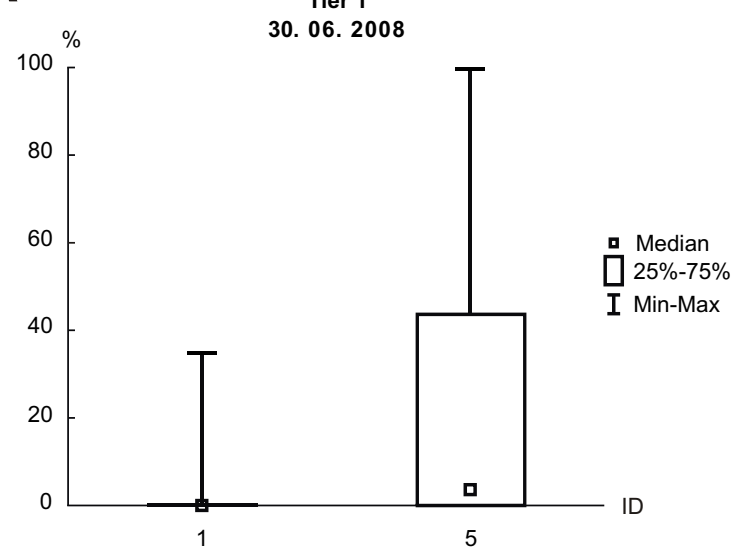

B

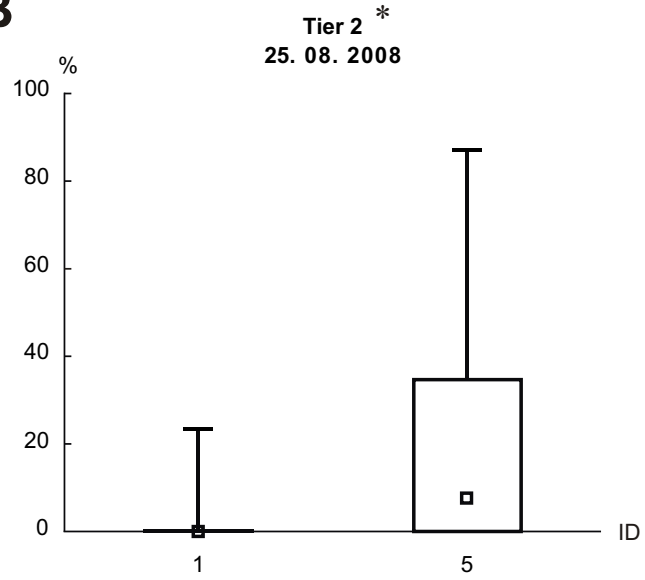

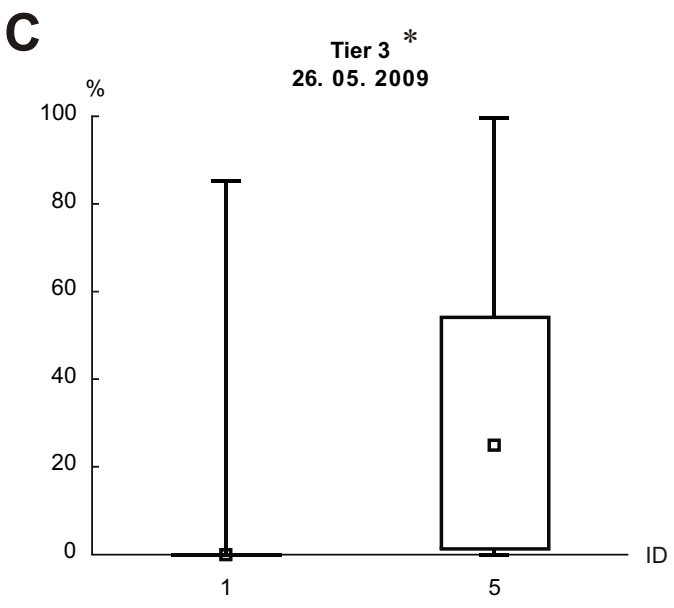

Abb. 14A-C: Prozentualer Anteil (\%) stark kondensierter Mitochondrien in 100 Mittelstückanschnitten pro Spermienprobe (Entnahmedatum angegeben). Bei allen drei untersuchten Tieren besteht ein signifikanter Unterschied $(* ; p<0,05$; Mann-Whitney-U-Test) zwischen jeweils korrespondierenden Proben nichtsortierter Rinderspermien (ID1) und solchen Proben vom selben Entnahmetag, die das Sortiergerät bei ausgeschaltetem Laser durchlaufen hatten (ID5). ID, Identifikationsnummer der Spermienbehandlung.

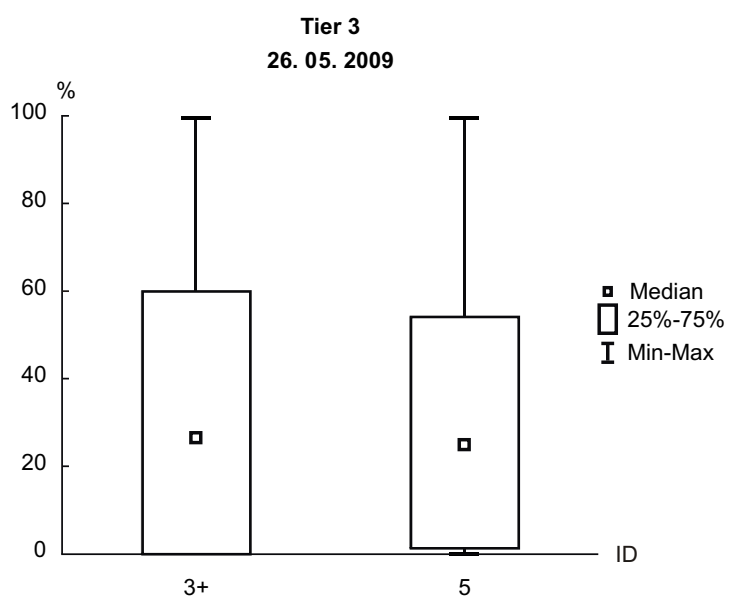

Abb. 15: Prozentualer Anteil (\%) stark kondensierter Mitochondrien in 100 Mittelstückanschnitten pro Spermienprobe (Entnahmedatum angegeben). Bei Tier 3 besteht kein signifikanter Unterschied (*; $<<0,05$; Mann-Whitney-U-Test) zwischen der Probe standardsortierter Rinderspermien, der zusätzlich unabgelenkte Spermien aus dem Abfallbehälter hinzugefügt worden waren (ID3+) und der korrespondierenden Probe vom selben Entnahmetag, die das Sortiergerät bei ausgeschaltetem Laser durchlaufen hatte (ID5). ID, Identifikationsnummer der Spermienbehandlung. 
A

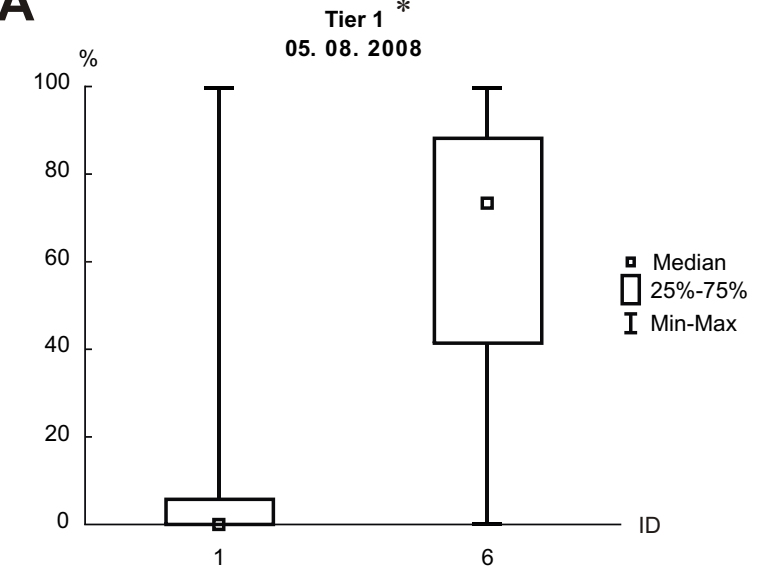

B

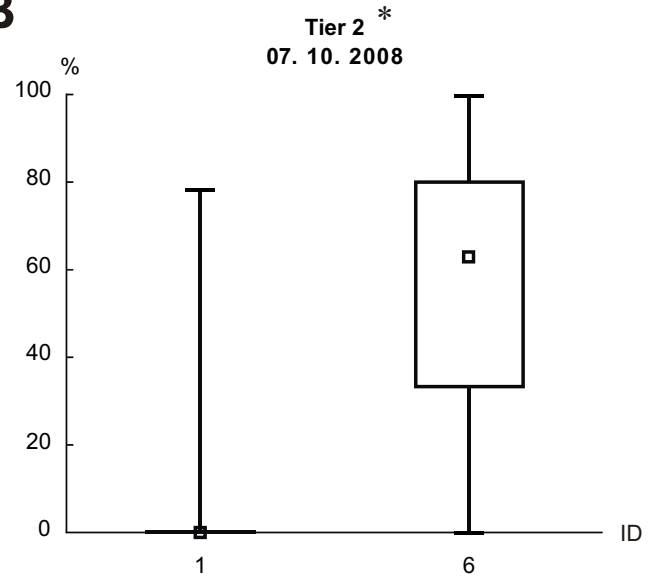

C

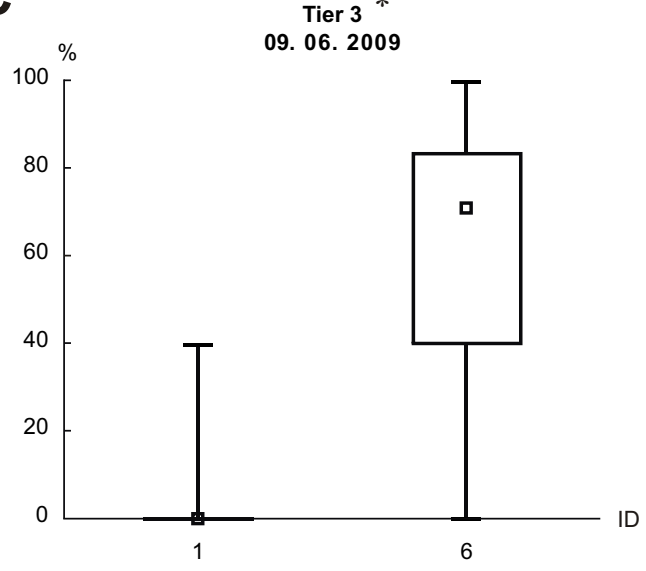

Abb. 16A-C: Prozentualer Anteil (\%) stark kondensierter Mitochondrien in 100 Mittelstückanschnitten pro Spermienprobe (Entnahmedatum angegeben). Bei allen drei untersuchten Tieren besteht ein signifikanter Unterschied $(* ; p<0,05$; Mann-Whitney-U-Test) zwischen jeweils korrespondierenden Proben nichtsortierter Rinderspermien (ID1) und solchen Proben vom selben Entnahmetag, die bei reduzierter Spannung am Piezokristall (5 Volt) sortiert wurden (ID6). ID, Identifikationsnummer der Spermienbehandlung. 
A

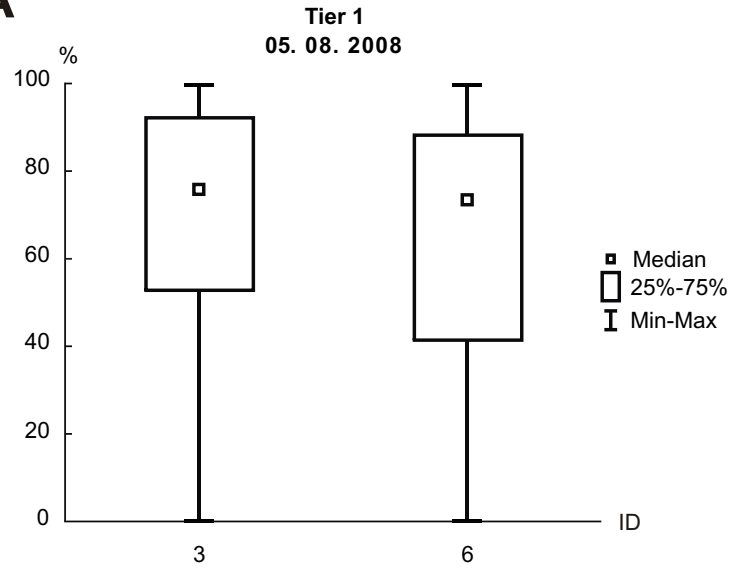

B

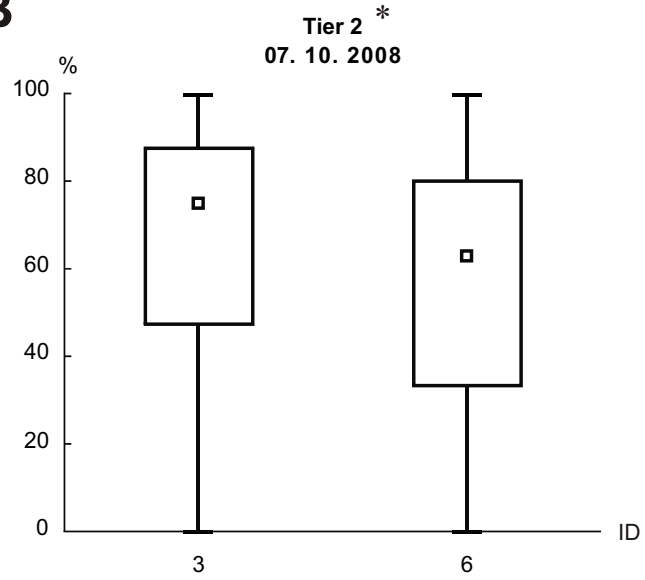

C

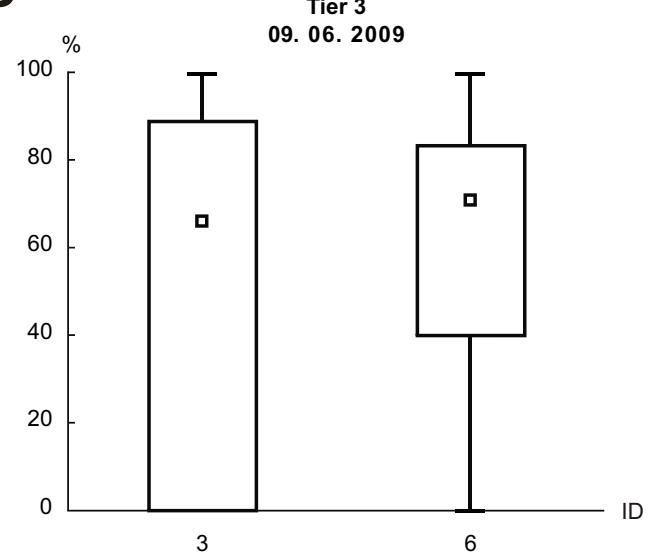

Abb. 17A-C: Prozentualer Anteil (\%) stark kondensierter Mitochondrien in 100 Mittelstückanschnitten pro Spermienprobe (Entnahmedatum angegeben). Lediglich bei einem von drei untersuchten Tieren (B: Tier 2) besteht ein signifikanter Unterschied (*; $<<0,05$, Mann-Whitney-U-Test) zwischen der Probe standardsortierter Rinderspermien (ID3) und der korrespondierenden Probe vom selben Entnahmetag, die bei reduzierter Spannung am Piezokristall (5 Volt) sortiert wurde (ID6). ID, Identifikationsnummer der Spermienbehandlung. 
A

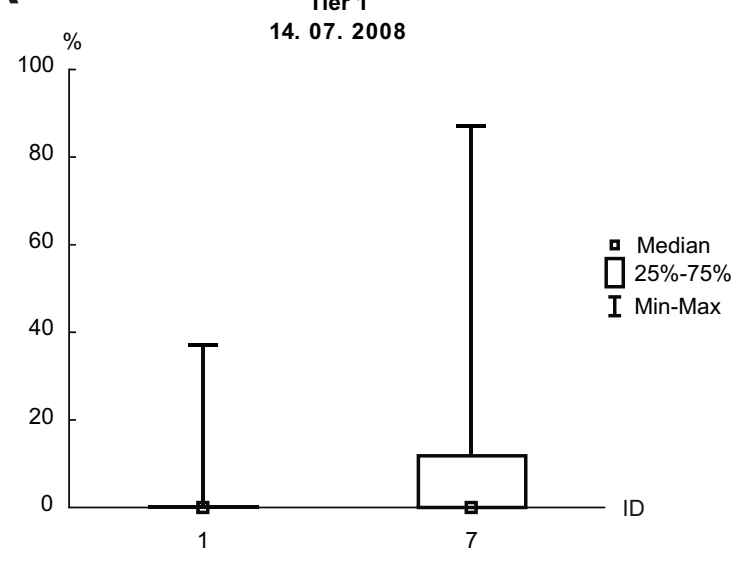

C

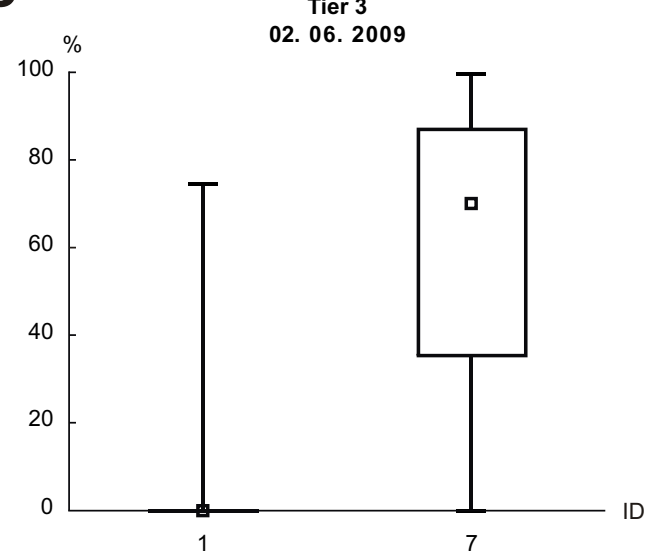

B

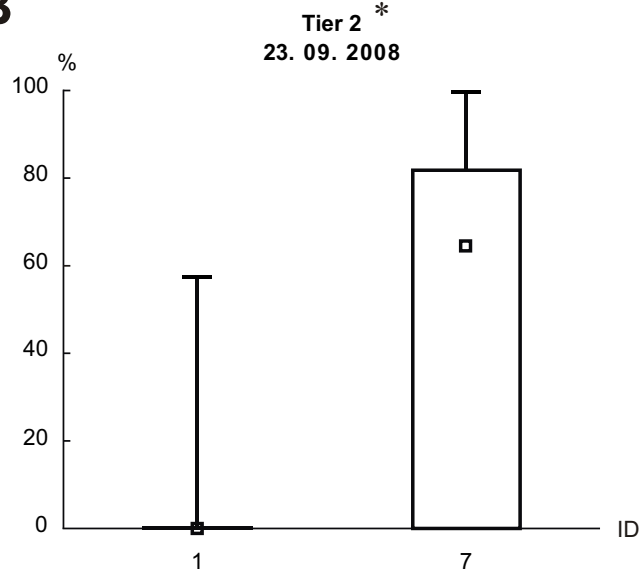

D

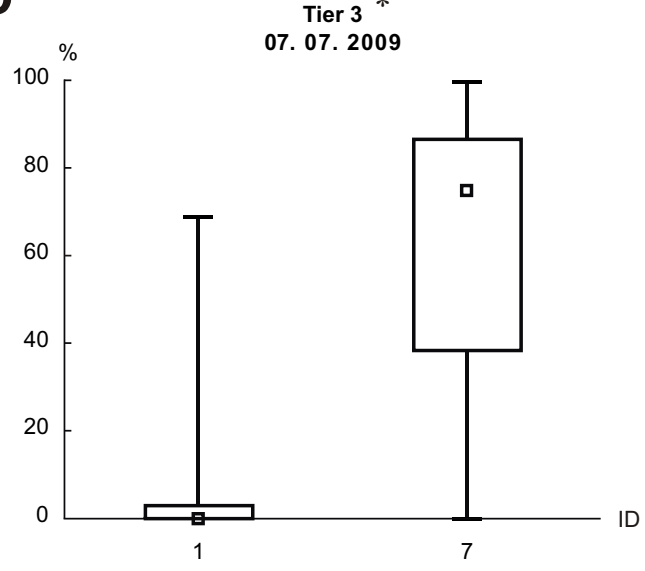

Abb. 18A-D: Prozentualer Anteil (\%) stark kondensierter Mitochondrien in 100 Mittelstückanschnitten pro Spermienprobe (Entnahmedatum angegeben). Bei allen drei untersuchten Tieren besteht ein signifikanter Unterschied (*; $<<0,05$; Mann-Whitney-U-Test) zwischen der Probe nichtsortierter Rinderspermien (ID1) und der korrespondierenden Probe vom selben Entnahmetag, die das Sortiergerät bei ausgeschalteten Hochspannungsplatten durchlaufen hatte (ID7). ID, Identifikationsnummer der Spermienbehandlung. 
A

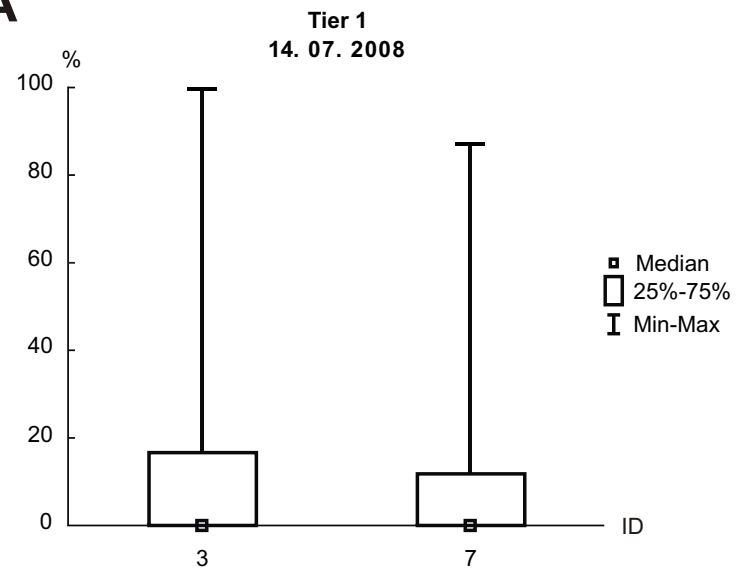

C

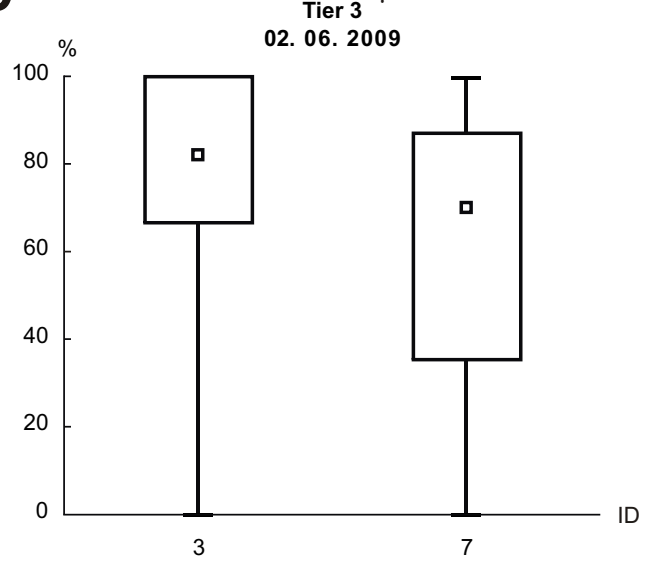

B

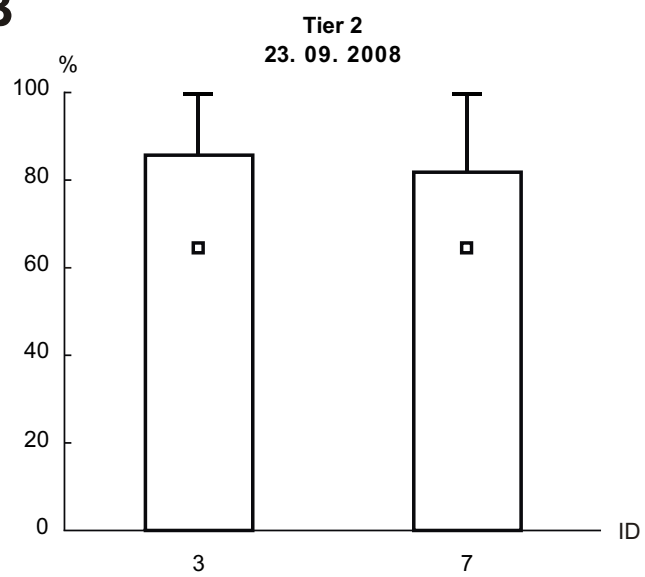

D

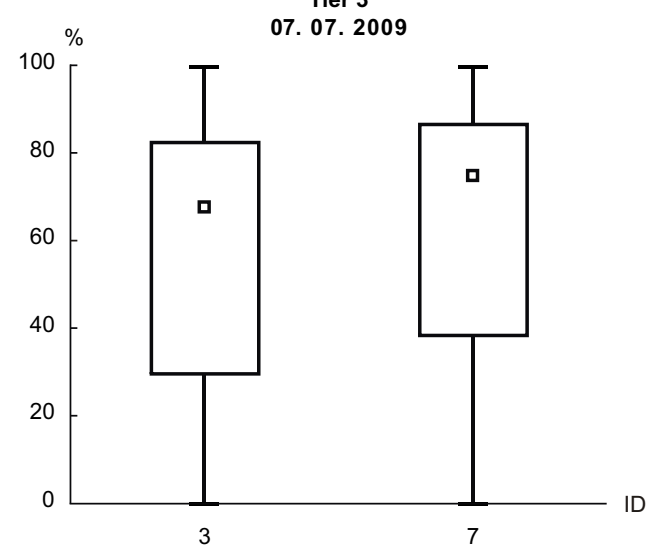

Abb. 19A-D: Prozentualer Anteil (\%) stark kondensierter Mitochondrien in 100 Mittelstückanschnitten pro Spermienprobe (Entnahmedatum angegeben). Lediglich bei einem von drei untersuchten Tieren (Tier 3) und hier lediglich bei einem von zwei untersuchten Probenpaaren (C) besteht ein signifikanter Unterschied (*; $<<0,05$; Mann-Whitney-U-Test) zwischen der Probe standardsortierter Rinderspermien (ID3) und der korrespondierenden Probe vom selben Entnahmetag, die bei ausgeschalteten Hochspannungsplatten das Sortiergerät durchlaufen hatte (ID7). ID, Identifikationsnummer der Spermienbehandlung. 
A

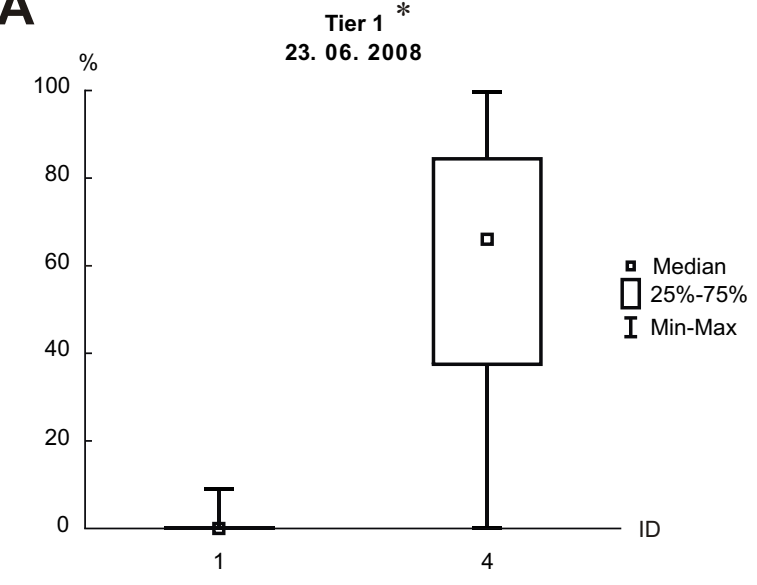

C

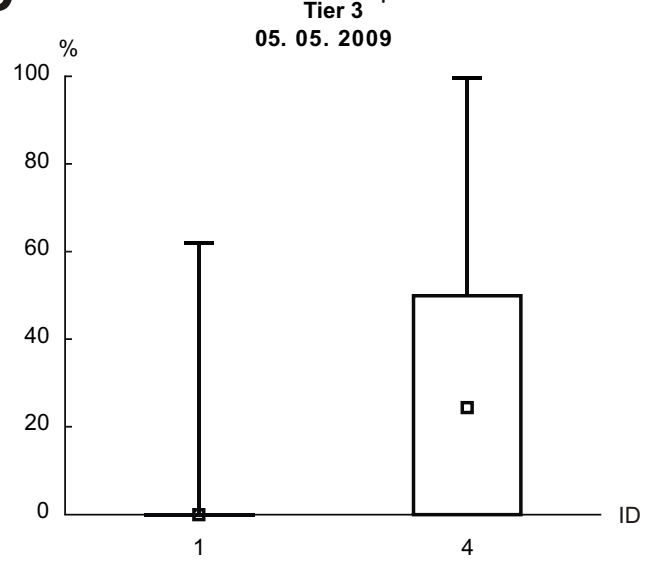

B

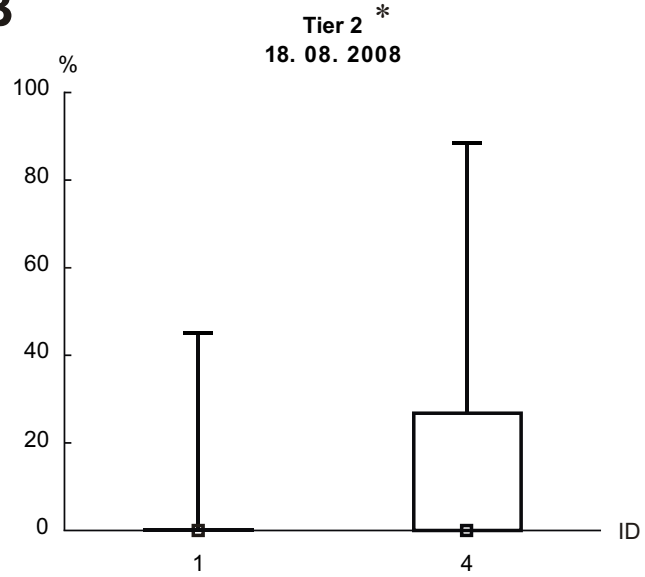

D

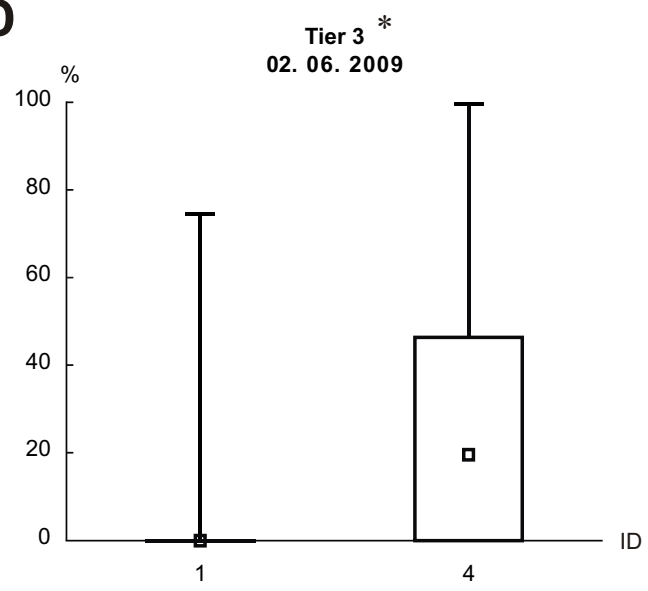

E

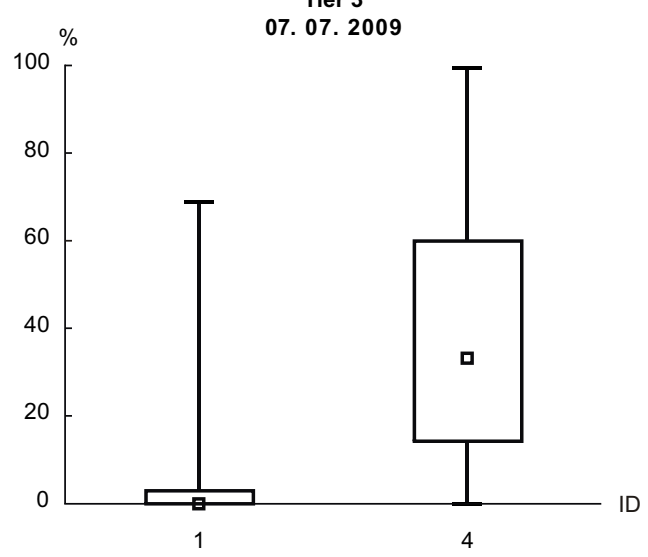

Abb. 20A-E: Prozentualer Anteil (\%) stark kondensierter Mitochondrien in 100 Mittelstückanschnitten pro Spermienprobe (Entnahmedatum angegeben). Bei allen drei untersuchten Tieren besteht ein signifikanter Unterschied $(* ; p<0,05$; Mann-Whitney-U-Test) zwischen jeweils korrespondierenden Proben nichtsortierter Rinderspermien (ID1) und Proben sortierter Rinderspermien vom selben Entnahmetag, die in Auffangmedien ohne Eidotter eingebracht wurden (ID4). ID, Identifikationsnummer der Spermienbehandlung. 
A

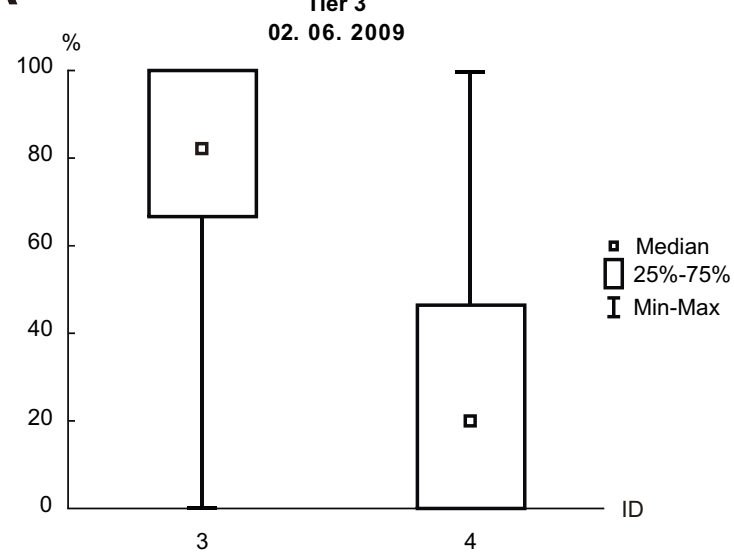

B

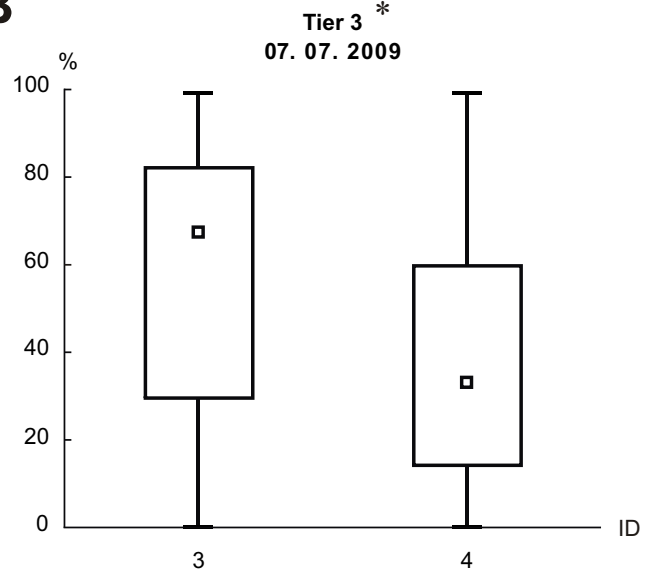

Abb. 21A, B: Prozentualer Anteil (\%) stark kondensierter Mitochondrien in 100 Mittelstückanschnitten pro Spermienprobe (Entnahmedatum angegeben). Bei Tier 3 besteht ein signifikanter Unterschied ( $*$; $<<0,05$; Mann-Whitney-UTest) zwischen jeweils korrespondierenden Proben standardsortierter Rinderspermien (ID3) und Proben sortierter Rinderspermien vom selben Entnahmetag, die in Auffangmedien ohne Eidotter eingebracht wurden (ID4). ID, Identifikationsnummer der Spermienbehandlung.

A

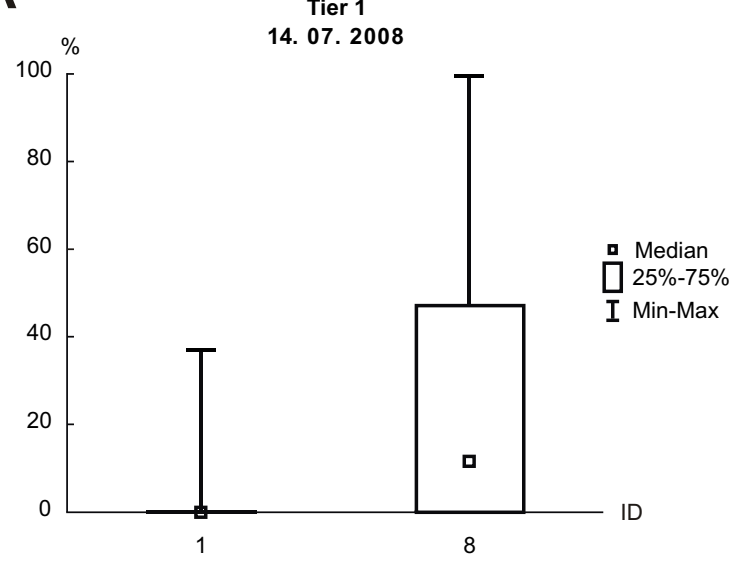

B

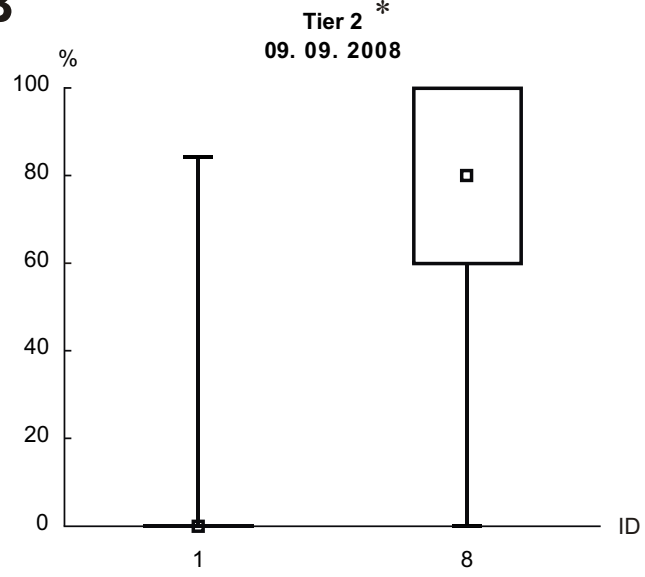

C

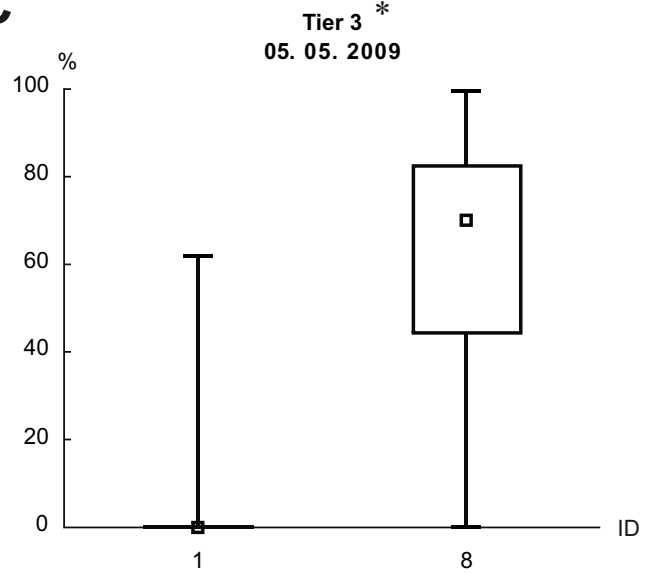

Abb. 22A-C: Prozentualer Anteil (\%) stark kondensierter Mitochondrien in 100 Mittelstückanschnitten pro Spermienprobe (Entnahmedatum angegeben). Bei allen drei untersuchten Tieren besteht ein signifikanter Unterschied $(* ; \mathrm{p}<0,05$; Mann-Whitney-U-Test) zwischen jeweils korrespondierenden Proben nichtsortierter Rinderspermien (ID1) und Proben sortierter Rinderspermien vom selben Entnahmetag, die in Auffangmedien ohne Seminalplasma eingebracht wurden (ID8). ID, Identifikationsnummer der Spermienbehandlung. 
A

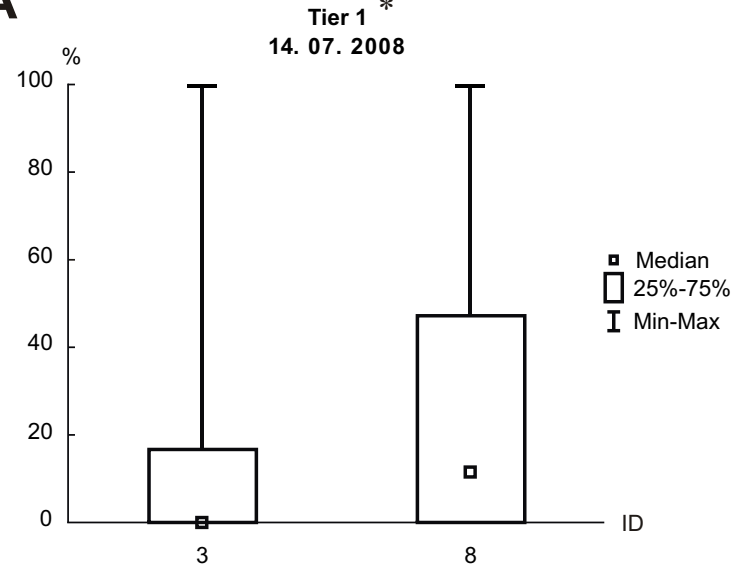

B

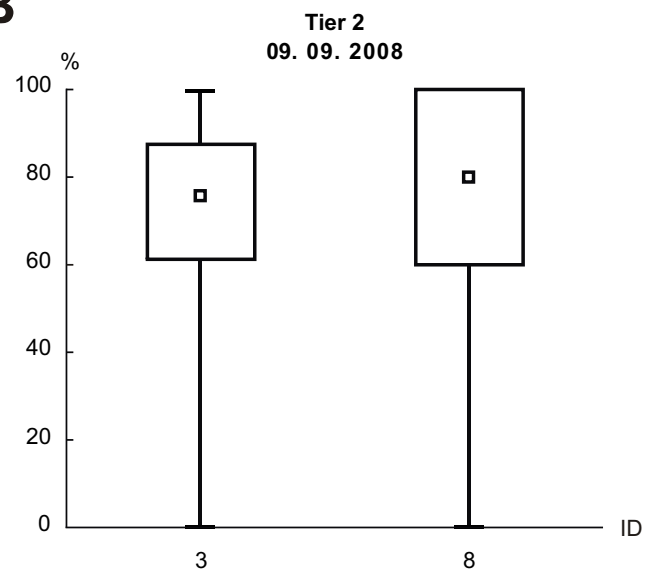

Abb. 23A, B: Prozentualer Anteil (\%) stark kondensierter Mitochondrien in 100 Mittelstückanschnitten pro Spermienprobe (Entnahmedatum angegeben). Ein signifikanter Unterschied (*; $<<0,05$; Mann-Whitney-U-Test) zwischen der Probe standardsortierter Rinderspermien (ID3) und der korrespondierenden Probe sortierter Rinderspermien vom selben Entnahmetag, die in einem Auffangmedium ohne Seminalplasma eingebracht wurde (ID8), besteht nur bei einem von zwei untersuchten Tieren (A: Tier 1). ID, Identifikationsnummer der Spermienbehandlung.

A

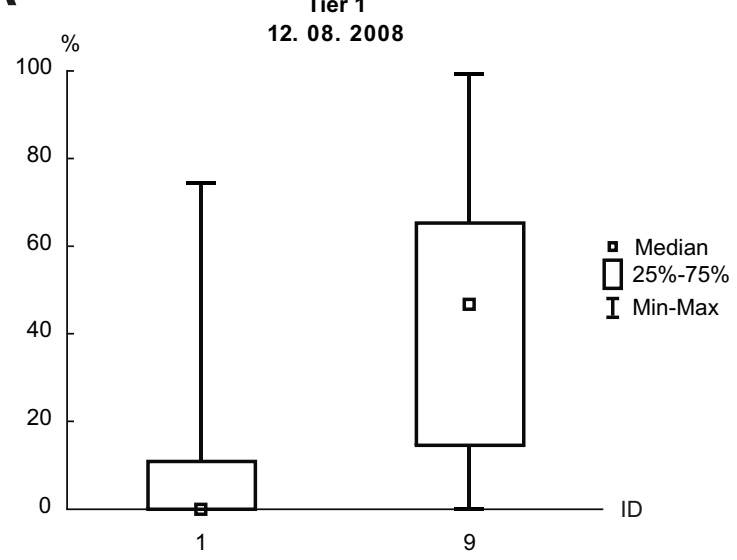

C

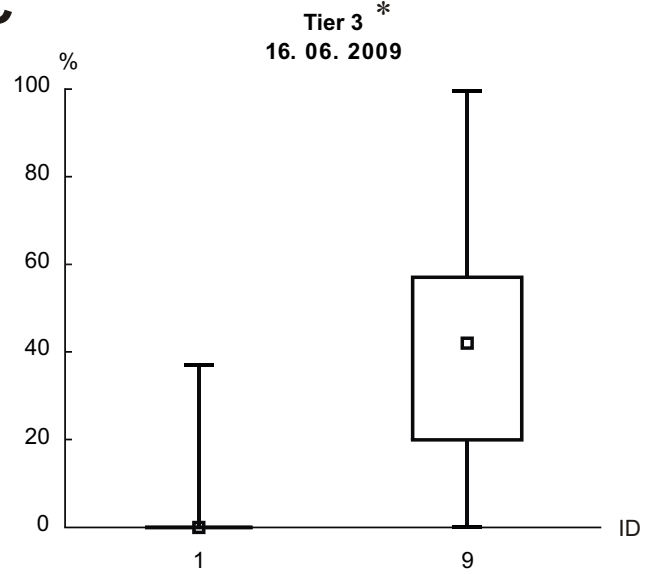

B

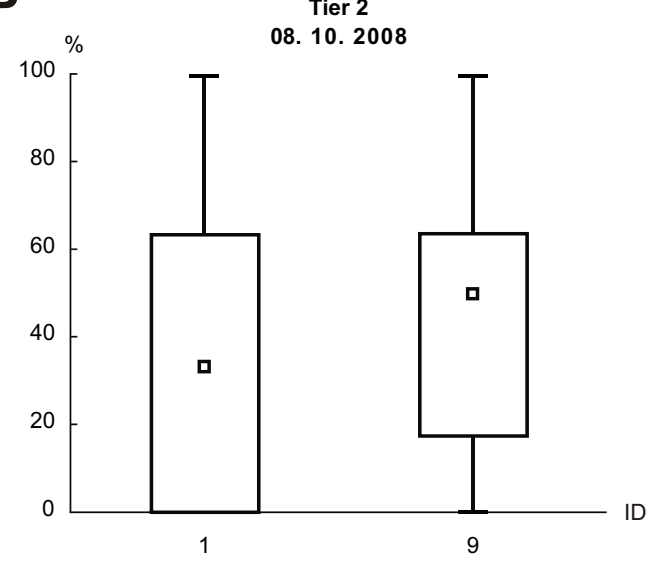

Abb. 24A-C: Prozentualer Anteil (\%) stark kondensierter Mitochondrien in 100 Mittelstückanschnitten pro Spermienprobe (Entnahmedatum angegeben). Ein signifikanter Unterschied ( $*$; $<0,05$; Mann-Whitney-U-Test) zwischen jeweils korrespondierenden Proben nichtsortierter Rinderspermien (ID1) und Proben vom selben Entnahmetag, die sortiert, mit einem Tiefgefriermedium versetzt und auf $5{ }^{\circ} \mathrm{C}$ gekühlt wurden (ID9), besteht bei zwei von drei untersuchten Tieren (A, C: Tiere 1, 3). ID, Identifikationsnummer der Spermienbehandlung. 
A

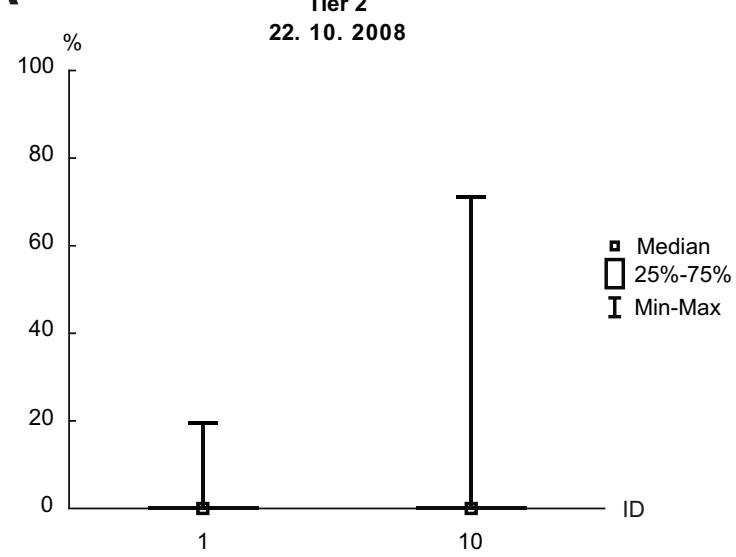

B

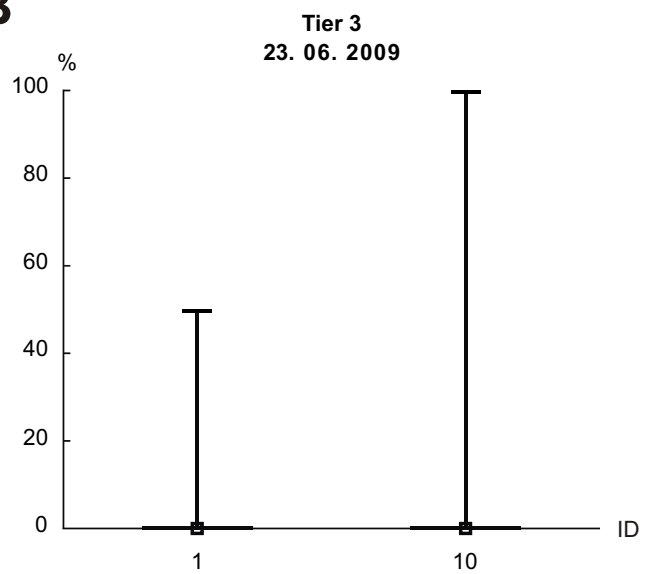

Abb. 25A, B: Prozentualer Anteil (\%) stark kondensierter Mitochondrien in 100 Mittelstückanschnitten pro Spermienprobe (Entnahmedatum angegeben). Ein signifikanter Unterschied (*; $p<0,05$; Mann-Whitney-U-Test) zwischen der Probe nichtsortierter Rinderspermien (ID1) und der korrespondierenden Probe der ID10 (Sortieren, Kühlen, Einfrieren und Wiederauftauen) vom selben Entnahmetag besteht bei keinem der beiden untersuchten Tiere. ID, Identifikationsnummer der Spermienbehandlung.

A

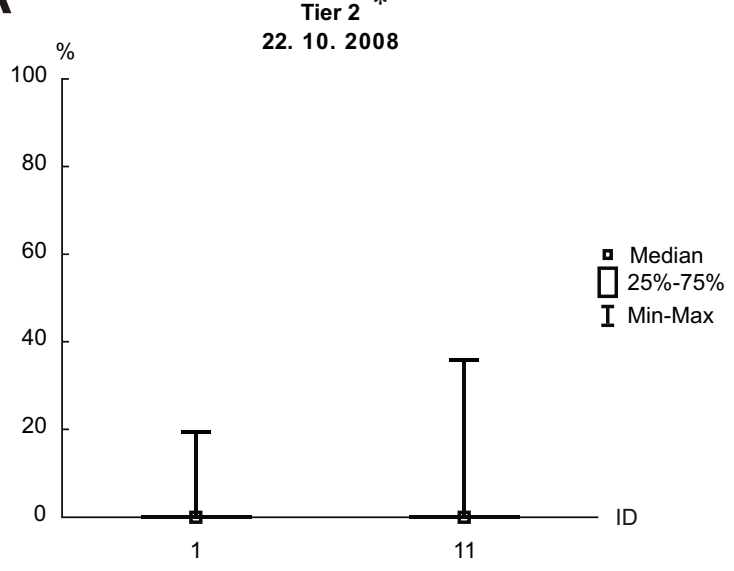

B

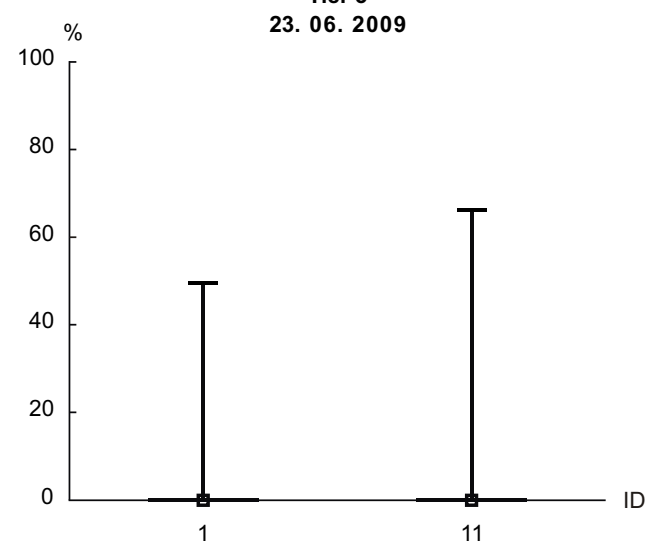

Abb. 26A, B: Prozentualer Anteil (\%) stark kondensierter Mitochondrien in 100 Mittelstückanschnitten pro Spermienprobe (Entnahmedatum angegeben). Lediglich bei einem von zwei untersuchten Tieren (A: Tier 2) besteht ein signifikanter Unterschied (*; $<<0,05$; Mann-Whitney-U-Test) zwischen der Probe nichtsortierter Rinderspermien (ID1) und der korrespondierenden Probe der ID11 (Sortieren, Kühlen, Einfrieren, Wiederauftauen, Thermoresistenztest) vom selben Entnahmetag. ID, Identifikationsnummer der Spermienbehandlung. 
A

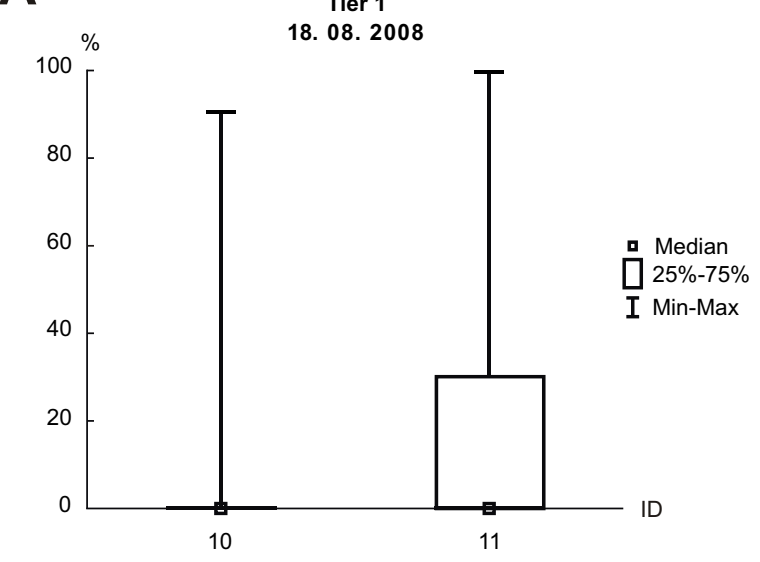

B

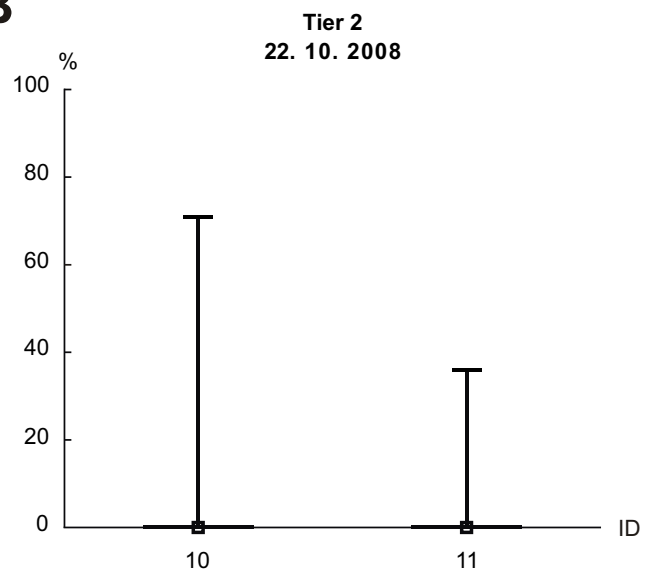

\section{C}

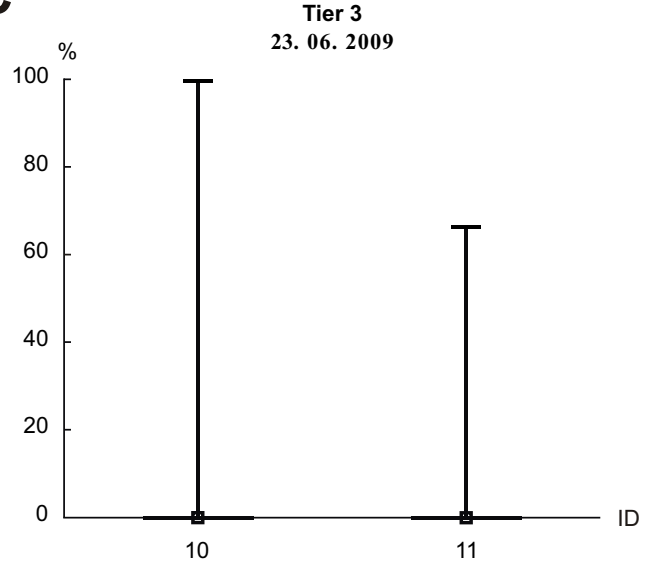

Abb. 27A-C: Prozentualer Anteil (\%) stark kondensierter Mitochondrien in 100 Mittelstückanschnitten pro Spermienprobe (Entnahmedatum angegeben). Ein signifikanter Unterschied (*; $<0,05$; Mann-Whitney-U-Test) zwischen korrespondierenden Proben der ID10 (Sortieren, Kühlen, Einfrieren und Wiederauftauen) und ID11 (Sortieren, Kühlen, Einfrieren, Wiederauftauen, Thermoresistenztest) vom selben Entnahmetag besteht lediglich bei einem von drei untersuchten Tieren (A: Tier 1). ID, Identifikationsnummer der Spermienbehandlung. 


\section{DISKUSSION}

\section{1 Ultrastruktur der Mitochondrien geschlechtsspezifisch sortierter Spermien}

Die Optimierung existierender sowie die Konzeption neuartiger Verfahren zur geschlechtsspezifischen Separierung von Spermien erfolgt im Interesse zahlreicher human- und veterinärmedizinischer Applikationen. Als anatomische Kooperationspartner innerhalb eines interdisziplinär ausgerichteten Forschungsverbunds hatten wir die Aufgabe übernommen, sortierte Rinderspermien auf ultrastrukturelle Veränderungen zu untersuchen, die die verminderte Beweglichkeit und Befruchtungsfähigkeit solcher sortierter Spermien erklären könnten.

Die im Rahmen der vorliegenden Dissertation erhobenen Befunde weisen erstmals nach, dass die Mitochondrien geschlechtsspezifisch sortierter Spermien signifikant häufiger in kondensierter Konformation vorliegen als die Mitochondrien nichtsortierter Spermien. Diese Aussage basiert auf der Untersuchung von 13 Proben standardsortierter Spermien sowie der jeweils korrespondierenden Proben nichtsortierter Spermien von insgesamt drei Tieren über einen Zeitraum von einem Jahr. Die arithmetischen Mittelwerte des in 100 Spermienmittelstücken pro Probe ermittelten Anteils kondensierter Mitochondrien bewegten sich bei sortierten Spermien weit überwiegend im (hohen) zweistelligen Prozentbereich (12,8 bis 76,6 Prozent). Dagegen erhoben sich die arithmetischen Mittelwerte in den korrespondierenden Proben nichtsortierter Spermien - mit Ausnahme einer einzigen Probe - niemals über den niedrigen einstelligen Prozentbereich. Demnach verursacht das Sortieren von Spermien einen gerichteten und quantitativ bedeutungsvollen Übergang der Mittelstück-Mitochondrien von einer orthodoxen in eine kondensierte Konformation.

Bei der Beurteilung des Konformationszustands der Mitochondrien standardsortierter und nichtsortierter Rinderspermien machten wir eine spannende Zusatzbeobachtung. Orthodox wie auch kondensiert konformierte Mitochondrien tendieren nämlich dazu, in Gruppen zusammenhängend - und nicht einzeln zufällig verteilt - im Mittelstück des Spermiums aufzutreten. Im Extremfall finden sich innerhalb eines Blickfelds der Kamera nebeneinander Spermien, in denen entweder alle Mitochondrien in kondensierter oder alle Mitochondrien in orthodoxer Konformation vorliegen (Abb. 8F). Angesichts der Tatsache, dass bestimmte Komponenten des Sortierprozesses die massive Erhöhung der Zahl kondensierter Mitochondrien „,von außen“ initiieren, wären Kontakte zwischen Plasmamembran und äußerer Mitochondrienmembran sowie zwischen den Außenmembranen benachbarter Mitochondrien ideal geeignet, um den offenbar zeitlich und räumlich koordiniert ablaufenden Konformationswechsel dieser Mitochondrien zu vermitteln. Strukturelle Korrelate für genau solche Kontakte werden in der vorliegenden Arbeit erstmals bei Rinderspermien nachgewiesen. Zusätzlich 
oder alternativ könnten solche elektronenmikroskopisch visualisierbaren intermitochondrialen Verbindungsstreben auch mechanisch stabilisierende Funktionen innehaben. Die physiologische perlschnurartige Mitochondrienanordnung bleibt nämlich in vielen Fällen auch dann erhalten, wenn extreme mechanische Belastungen, wie sie beim geschlechtsspezifischen Sortieren zweifellos auftreten (zur Übersicht: Seidel 2012), auf die Rinderspermien eingewirkt und eine vollständige Ablösung der Plasmamembran herbeigeführt haben (Abb. 7C).

Kontaktzonen zwischen den Mitochondrien des Spermienmittelstücks und Strukturen in ihrer unmittelbaren Umgebung existieren nicht nur beim Rind. So entdeckten Olson und Hamilton (1976) bei Opossumspermien punktartige Verbindungen zwischen benachbarten Mitochondrien, die später bei Hamsterspermien als Abschnitte eines zweidimensionalen Netzwerks elektronendichter Verbindungsstreben identifiziert werden konnten (Olson und Winfrey 1992: studs). In guter Übereinstimmung mit unseren aktuellen Befunden am Rinderspermium vermuteten auch diese Autoren, dass elektronendichte intermitochondriale Verbindungsstreben einerseits zur strukturellen Stabilisierung des Chondrioms beitragen, andererseits der Kommunikation zwischen benachbarten Mitochondrien dienen könnten. Ähnliche funktionelle Hypothesen äußerten Suzuki-Toyota et al. (2010), denen bei Meerschweinchenspermien der Nachweis elektronendichter thin filaments sowohl zwischen benachbarten Mitochondrien als auch zwischen äußerer Mitochondrienmembran und Plasmamembran gelang. Diese Filamente sollen einerseits die Etablierung der komplexen dreidimensionalen Anordnung der Mitochondrien unterstützen, andererseits die hypoosmotischen Belastungen im weiblichen Genitaltrakt kompensieren helfen. Nicht zuletzt könnten stabilisierende Wirkungen auf das Chondriom auch vom submitochondrialen Reticulum ausgehen, das Olson und Winfrey (1986, 1990, 1992) bei Hamsterspermien als gitterartig durchbrochenen Zylinder zwischen den Mitochondrien und den weiter innen im Mittelstück lokalisierten Außenfibrillen charakterisiert haben, und über das Rinderspermien, wie von uns gezeigt, gleichfalls verfügen (Abb. 5B).

Offenbar reichen die in der vorliegenden Arbeit am Beispiel von Rinderspermien beschriebenen punktuellen Kontakte zwischen den Außenmembranen benachbarter Mitochondrien sowie zwischen der äußeren Mitochondrienmembran und der Plasmamembran des Spermiums nicht in jedem Fall aus, um den Erhalt der korrekten helikalen Anordnung der Mitochondrien unter mechanischer Belastung sicherzustellen. Stattdessen fanden wir - zuerst bei geschlechtsspezifisch sortierten Spermien - Störungen des mitochondrialen Gefüges, die im diskretesten Fall lediglich darin bestanden, dass ein einziges Mitochondrium verschoben oder gänzlich aus dem helikal angeordneten Chondriom entfernt worden war. Am anderen Ende der Skala manifestierten sich aber auch massive Gefügestörungen des Chondrioms, bei denen die ursprünglich vorhandene mitochondriale Helix durch 
Gruppen anscheinend regellos aggregierter Mitochondrien ersetzt war. Natürlich vermuteten wir sofort, dass solche mitochondrialen Gefügestörungen durch den Sortierprozess hervorgerufen sein könnten. Entgegen dieser Annahme stellte sich jedoch heraus, dass mitochondriale Gefügestörungen in annähernd gleichem Maße sowohl bei standardsortierten als auch bei nichtsortierten Spermien auftreten. Folglich kommt als mögliche Ursache am ehesten die bei beiden Probenklassen gleichartig ablaufende Aufarbeitungsprozedur der Spermien für die elektronenmikroskopischen Untersuchungen in Betracht, die unter anderem mechanische Belastungen durch Zentrifugationsschritte einschließt.

Die ultrastrukturelle Unterscheidung zwischen orthodox oder kondensiert konformierten Mitochondrien geht auf Charles R. Hackenbrock zurück, der in der Pionierzeit der Transmissionselektronenmikroskopie am Beispiel der Leberzelle und an Aszites-Tumorzellen ein funktionsorientiertes, in seinen Grundzügen bis heute Maßstäbe setzendes Konzept entwickelt hat (Hackenbrock 1966, 1968, Hackenbrock und Caplan 1969, Hackenbrock et al. 1971, zur Übersicht: Scalettar et al. 1991). Nach Hackenbrock zeichnen sich kondensierte Mitochondrien gegenüber orthodox konformierten Mitochondrien durch eine Abnahme des Matrixvolumens sowie durch eine Zunahme der Elektronendichte der Matrix aus. Charakteristisch für kondensiert konformierte Mitochondrien ist weiterhin die Erweiterung des Raums zwischen innerer und äußerer Mitochondrienmembran sowie des intracristalen Raums (Hackenbrock 1966). In den folgenden Jahrzehnten konnten die von Hackenbrock erhobenen Befunde zur Ultrastruktur von Mitochondrien unter Zuhilfenahme optimierter elektronenmikroskopischer Techniken im Wesentlichen bestätigt werden (zur Übersicht: Mannella 2006). Allerdings stellte sich auch heraus, dass die zuvor als ,weit“ erachtete Übergangszone zwischen intracristalem Raum und dem zwischen innerer und äußerer Mitochondrienmembran lokalisierten Raum auf kurze und enge tubuläre Verbindungsstücke reduziert werden kann, die sich im Übrigen auch zwischen benachbarten Cristae nachweisen lassen. Die dramatischen Folgen, die solche strukturellen Veränderungen für die Leistungsfähigkeit von Mitochondrien haben können (,diffusional bottle neck for ADP“, Mannella et al. 2013, S. 52) unterstreichen die mögliche funktionelle Bedeutung des markanten Konformationswechsels, den wir bei zahlreichen Mitochondrien geschlechtsspezifisch sortierter Rinderspermien festgestellt haben.

Die von uns beobachteten und quantitativ ausgewerteten kondensierten Spermienmitochondrien erfüllen mit Ausnahme der bei uns selten markant auftretenden Erweiterung des Raumes zwischen innerer und äußerer Mitochondrienmembran durchgehend die von Hackenbrock (1966) aufgestellten ultrastrukturellen Kriterien. Darüber hinaus war es möglich, aus den befundeten Momentaufnahmen eine hypothetische „Sequenz“ der Entstehung maximal kondensierter Mitochondrien zusammenzu- 
stellen. Diese Sequenz nimmt ihren Ausgang von diskret dilatierten einzelnen Cristae. In den postulierten Folgestadien (Abb. 8B) vergrößert sich sowohl die Breite des intracristalen Raums als auch die Weite der Verbindung zwischen intracristalem und intermembranösem Raum. Schließlich ist die gesamte, jetzt stark elektronendichte Matrix ringförmig an die Peripherie des Mitochondriums gedrängt, wo sie selbst bei hoher Auflösung kaum mehr gegen die Hüllmembranen des Mitochondriums abgegrenzt werden kann. Der einheitlich elektronendichte, wie ausgestanzt wirkende Ring umgibt ein elektronenhelles, weitgehend oder vollständig strukturloses Zentrum, das letztlich dem verbliebenen, extrem dilatierten intracristalen Raum entspricht. Sofern ein markanter äußerer Matrixring bestand, wurden im Rahmen unserer Auswertung filigrane Reststrukturen innerhalb des elektronenhellen Zentrums „toleriert“. Um vermeidbare subjektive Fehleinschätzungen auszuschlieBen, wurde zusätzlich festgelegt, dass die Definition eines stark kondensierten Mitochondriums dann erfüllt ist, wenn der Anteil des elektronendichten Matrixrings am Gesamtdurchmesser des Mitochondriums mindestens ebenso groß ist wie der Anteil des elektronenhellen Zentrums. Unter Zuhilfenahme aller dieser Kriterien war es möglich, stark kondensierte Mitochondrien in praktisch allen Fällen von orthodox konformierten oder stark geschwollenen Mitochondrien zu unterscheiden.

Mitochondriale Schwellungen sind durch eine Volumenzunahme der Mitochondrien, durch das Auftreten einer elektronenhellen Matrix sowie durch die teilweise oder vollständige Fragmentierung der Cristae mitochondriales gekennzeichnet. Je nach Schweregrad können solche Schwellungen reversibel sein oder irreversibel zum Untergang des Organells beziehungsweise der gesamten Zelle führen (Szollosi 1965, zur Übersicht: Blondin und Green 1967, Kaasik et al. 2007). Angesichts der Tatsache, dass Mitochondrien ein relativ eingeschränktes Repertoire vorhalten, mit dem sie phänotypisch auf äußere Einflüsse reagieren können, wundert es nicht, dass mitochondriale Schwellungen unter ganz verschiedenen physiologischen oder pathophysiologischen Bedingungen beobachtet worden sind, beispielsweise von Schmiedl et al. (1990) am Hundeherz, von Sesso et al. (2012) an Phäochromozytomzellen und von Rivera et al. (2003) an befruchteten Eizellen des Rindes.

Um einen Hinweis darauf zu gewinnen, ob auch die Anwendung geschlechtsspezifischer Sortierungsverfahren eine möglicherweise schädigend auf die Spermien wirkende Schwellung ihrer Mitochondrien herbeiführt, haben wir sämtliche Proben aller drei Versuchstiere zunächst auf das Vorkommen stark geschwollener Mitochondrien untersucht, deren Volumenzunahme und Elektronenhelle derart ausgeprägt waren, dass sie schon in der Übersichtsaufnahme unter benachbarten, typischerweise einheitlich großen und perlschnurartig aufgereihten Mitochondrienanschnitten ,,herausfielen“. Es zeigte sich, dass das Sortieren bei 12 von 13 untersuchten Probenpaaren nicht zu einem statistisch signifikant vermehrten Auftreten stark geschwollener Mitochondrien führt. Ob auch mo- 
derat und/oder diskret geschwollene Mitochondrien gleich häufig in sortierten und nichtsortierten Rinderspermien vorkommen, soll in Folgearbeiten mittels geeigneter stereologischer Methoden untersucht werden.

\section{2 Vorkommen und Funktionen kondensierter Spermienmitochondrien}

Kondensierte Spermienmitochondrien sind einerseits physiologisch im Rahmen der Spermatogenese, andererseits experimentell unter Einwirkung verschiedener exogener Faktoren beobachtet worden. Phänotypisch stimmt unsere Charakterisierung stark kondensierter Mittelstïck-Mitochondrien („elektronendichter Matrixring um elektronenhelles Zentrum“) mit den Beschreibungen der Vorautoren überein. Allerdings ist die jeweils verwendete Terminologie bisweilen inkonsistent, wofür zwei wesentliche Gründe anzuführen sind. Einerseits nämlich wurden einige dieser Untersuchungen bereits vor Etablierung des Hackenbrock'schen Konzepts mitochondrialer Konformationswechsel durchgeführt. Andererseits meiden manche Autoren die von Hackenbrock eingeführte Begrifflichkeit, weil über die Struktur-Funktionsbeziehungen orthodox beziehungsweise kondensiert konformierter Mitochondrien noch immer nicht genügend bekannt ist (zur Übersicht: Perkins und Ellis$\operatorname{man} 2011)$.

Eines der frühesten grundlegenden Werke, in dem die Ultrastruktur von Mitochondrien während der Spermatogenese von Säugetieren umfassend dargestellt wurde, stammt von André (1962), der am Beispiel der Ratte demonstriert, dass Mitochondrien spätestens im Spermatozyten-Stadium beginnen, dilatierte Cristae zu entwickeln. Deren Aufweitung schreitet in den Folgestadien so lange voran, bis eine zusammenhängende zentrale elektronenhelle Zone von einem Ring elektronendichter Matrixkomponenten umgeben wird: „Mitochondrie fortement vésiculisée dont la matrice est réduite à une lame pariétale“ (André 1962, S. 36). Diese Beschreibung stimmt im Wesentlichen sowohl mit den Befunden jüngerer Arbeiten zur Entwicklung von Rattenspermien (de Martino et al. 1979, Meinhardt et al. 2000) als auch mit der von uns postulierten Entstehungssequenz stark kondensierter Mitochondrien in geschlechtsspezifisch sortierten Rinderspermien überein (Abb. 8B). Die von André (1962) im Rahmen der Spermatogenese beschriebene Dilatation der Cristae mitochondriales bleibt auch dann noch erhalten, wenn sich die Mitochondrien helikal um das entstehende Mittelstück entlang der Außenfibrillen des Rattenspermiums anordnen. Erst im reifen Rattenspermium ist ihre Konformation, wie im Falle der Mitochondrien nichtsortierter Rinderspermien, nach heutiger Terminologie überwiegend orthodox.

Auf die Frage, warum Mitochondrien während der Spermatogenese Konformationswechsel durchlaufen, gibt es bis heute keine im Detail befriedigende Antwort. Allerdings weisen der bei den kon- 
densierten Mitochondrien nachgewiesene hohe respiratorische Kontrollkoeffizient sowie ihre hohe Affinität zu ADP nach Auffassung von de Martino et al. (1979) darauf hin, dass sich die Mitochondrien heranreifender Spermien in einem aktiven Funktionszustand befinden. Meinhardt et al. (2000) befassen sich weniger mit der Funktion kondensierter Mitochondrien als mit den für ihre Entstehung in reifenden Spermien ursächlich verantwortlichen Faktoren. Diesen Untersuchungen ist die Erkenntnis zu verdanken, dass das von den Sertoli-Zellen physiologischerweise produzierte und sezernierte Activin A nach experimenteller Gabe dafür sorgt, dass die von den Spermienmitochondrien im Pachytän erreichte kondensierte Konformation länger als üblich beibehalten wird. Unter Würdigung der relevanten Literatur (Kumari et al. 1990, Meinhardt et al. 1995, Paranko et al. 1996) vertreten Meinhardt et al. (2000) außerdem die Arbeitshypothese, dass die Entstehung kondensierter Spermienmitochondrien zeitlich (und kausal) einerseits mit dem Verlust des zuvor in großer Menge vorhandenen Hitzeschockproteins 60, andererseits mit der Aktivität der zeitgleich in die Mitochondrien importierten Sulfhydryloxidase zusammenfällt, die den Kondensationsprozess der Mitochondrien durch Ausbildung von Disulfidbrücken zwischen Proteinen der mitochondrialen Matrix vorantreiben könnte.

Über die molekularen Mechanismen, die der Entstehung kondensierter Mitochondrien in geschlechtsspezifisch sortierten Rinderspermien zu Grunde liegen, können wir bisher keine Aussagen machen. Ein erster Schritt in diese Richtung könnte darin bestehen, den möglichen Einfluss der von Meinhardt et al. (2000) im Rahmen der Spermatogenese diskutierten Faktoren zu überprüfen. Mindestens ebenso spannend wird es sein, herauszufinden, inwieweit sich die von de Martino et al. (1979) bei den kondensierten Mitochondrien heranreifender Spermien nachgewiesenen funktionellen Eigenschaften (hoher respiratorischer Kontrollkoeffizient, hohe Affinität zu ADP) auch bei geschlechtsspezifisch sortierten Rinderspermien wiederfinden. Ein wichtiger dritter geplanter Forschungsansatz dient der Klärung der Frage, ob kondensiert konformierte Mitochondrien tatsächlich für die reduzierte Motilität sortierter Rinderspermien verantwortlich sind. Hierzu wollen wir komplementär zur strukturellen Analyse Messungen des mitochondrialen Membranpotenzials durchführen, dessen Höhe positiv mit der Motilität und Befruchtungsfähigkeit von Spermien korreliert (Kasai et al. 2002). Bei der Planung, Durchführung und Interpretation solcher Experimente ist allerdings zu bedenken, dass mindestens ein Teil der durch den Sortierprozess in eine kondensierte Konformation gedrängten Mitochondrien im Rahmen der „Aufarbeitung“ sortierter Spermien, die der künstlichen Befruchtung unmittelbar vorangeht, wieder in die orthodoxe Konformation zurückspringt (siehe Kapitel III. 3). Wie im Falle der heranreifenden Spermien (André 1962, de Martino et al. 1979, Meinhardt et al. 2000) stellt also das Erlangen einer kondensierten Konformation nicht das „letzte Wort“ dar. Ungeachtet der Tatsache, dass heranreifende Spermien, die vorübergehend über 
kondensierte Mitochondrien verfügen, mehrheitlich funktionell intakt sind, könnte jedoch das zwar gleichfalls temporäre, aber eben unphysiologische Auftreten kondensierter Mitochondrien in sortierten ausgereiften Spermien genügen, um funktionelle Einbußen herbeizuführen. Gestützt wird diese Arbeitshypothese unserer Auffassung nach auch dadurch, dass das Ausmaß der Matrixkondensation in sortierten Rinderspermien, anders als im Falle der heranreifenden Spermien (André 1962, de Martino et al. 1979, Meinhardt et al. 2000), derartig hoch ist, dass eine Unterscheidung zwischen peripher lokalisiertem Matrixring und den Hüllmembranen der Mitochondrien auch bei hoher elektronenmikroskopischer Auflösung kaum mehr möglich ist (Abb. 8B).

Exogen können kondensierte Spermienmitochondrien beispielsweise durch Verabreichung eines Kälteschocks erzeugt werden. Schafspermien, die man auf diese Weise behandelt, nehmen massiv Calcium auf (Simpson et al. 1986), und zwar in Abhängigkeit vom pH und unter erhöhter Sauerstoffaufnahme (Simpson et al. 1987). In beiden Experimentserien wurde ein weitgehender, zum Teil irreversibler Verlust der Spermienmotilität beobachtet. Interessanterweise führt auch die experimentell induzierte Calciumüberladung von Mäusespermien - hier erzeugt durch Ausschaltung ATP-abhängiger Calciumauswärtspumpen - einerseits zum vermehrten Auftreten kondensierter Mitochondrien, andererseits zur Reduktion der Fertilität (Okunade et al. 2004). Negativ bewerten auch Rahmy und Ayoub (2002) das vermehrte Auftreten kondensierter Mitochondrien bei Ziegenspermien, die mit Kobra-Gift behandelt wurden. Diese Autoren halten es für gesichert, dass die veränderte Mitochondrienkonformation (in ihrer Terminologie: Mitochondrien mit distorted cristae) kausal für die Reduktion der Motilität verantwortlich ist und mit einer reduzierten Lebensfähigkeit der betroffenen Spermien einhergeht. Schließlich wurden auch an menschlichen Spermien Befunde erhoben, die einen möglichen Zusammenhang zwischen strukturellen Veränderungen des Chondrioms und Fällen ungeklärter Asthenozoospermie in den Raum stellen (Pelliccione et al. 2011). Tatsächlich können diese Autoren gleich mehrere ultrastrukturelle Abweichungen von der Norm dingfest machen: (1) mitochondriale Gefügestörungen, (2) Mitochondrien mit „disaggregated inner structure“ (Pelliccione et al. 2011, S. 644), die in unserer Terminologie als ,anfänglich geschwollen“ bezeichnet werden würden, sowie (3) Mitochondrien mit erheblich aufgeweiteten intracristalen Räumen (,dilated intermembrane spaces“, Pelliccione et al. 2011, S. 644), die strukturell frühen Stadien der bei den sortierten Rinderspermien in großer Zahl entdeckten kondensierten Mitochondrien entsprechen (Abb. 8B). Zusammenfassend existieren demnach zahlreiche weitere (indirekte) Hinweise darauf, dass sich das Vorhandensein kondensierter Mitochondrien negativ auf die Leistungsfähigkeit geschlechtsspezifisch sortierter Spermien auswirken könnte. Bewiesen und im Detail ausgeführt wurde ein solcher kausaler Zusammenhang in den skizzierten experimentellen Arbeiten jedoch nicht. 


\section{3 Einfluss individueller Komponenten des Sortierprozesses auf die Mitochondrien- konformation von Spermien}

\section{3.1 Methodenkritische Vorbemerkung}

Hauptziel der vorliegenden Arbeit war es, ultrastrukturelle Veränderungen zu identifizieren, die Rinderspermien bei der geschlechtsspezifischen Sortierung erfahren. Dieses Ziel wurde durch den Nachweis deutlich vermehrt auftretender kondensierter Mittelstück-Mitochondrien erreicht. Insofern war es sinnvoll zu versuchen, diejenigen Komponenten des Sortierprozesses zu entlarven, die das explosionsartige Ansteigen der Zahl kondensierter Mitochondrien in erster Linie hervorrufen. Dies gilt umso mehr, als andere Teilprojekte unseres Forschungsverbunds sich intensiv mit der Frage auseinandergesetzt haben, wie man neue und bessere Sortiergeräte konstruieren muss, um mit den sortierten Spermien höhere Befruchtungsraten zu erzielen (Rath et al. 2013). Einschränkend muss jedoch hinzugefügt werden, dass eine vollkommene Isolierung individueller Komponenten des Sortierprozesses aus technischen Gründen nicht immer möglich war. Dennoch fanden wir spannende zusätzliche Hinweise, die den Hauptbefund ergänzen, mögliche Gefahrenquellen aufzeigen und deshalb bei der Entwicklung neuer Sortierverfahren Berücksichtigung finden sollten.

\section{3.2 DNS-Farbstoff Hoechst 33342}

Schon der erste Versuchsansatz brachte eine Überraschung. Es zeigte sich nämlich bei immerhin einem von drei analysierten Probenpaaren, dass bereits Spermienproben, die in Vorbereitung auf den eigentlichen Sortiervorgang mit dem DNS-Farbstoff Hoechst 33342 inkubiert worden waren, einen signifikant höheren Prozentsatz kondensierter Mitochondrien aufwiesen als unbehandelte Spermien. Unter der Voraussetzung, dass kondensierte Mitochondrien sich in Nachfolgeuntersuchungen tatsächlich als „schädlich“ herausstellen sollten, müsste deshalb über den Einsatz alternativer DNSFarbstoffe nachgedacht werden. Vorbehalte gegen die Verwendung von Hoechst 33342 wurden auch von anderer Seite vorgebracht. So nimmt beispielsweise die Schlagfrequenz des Spermienschwanzes nach Inkubation mit Hoechst 33342 konzentrationsabhängig ab (Watkins et al. 1996). Andere Autoren berichten über eine durch Hoechst 33342 ausgelöste signifikante Abnahme des Anteils membranintakter Spermien sowie des mitochondrialen Membranpotenzials (Spinaci et al. 2005), was die von uns geplante komplementäre Analyse von Mitochondrienkonformation und mitochondrialem Membranpotenzial umso notwendiger erscheinen lässt. Außerdem löst Hoechst 33342 eine Umverteilung des Hitzeschockproteins 70 (HSP70) aus, die offenbar mit dem Eintritt des Spermiums in Kapazitations-ähnliche Prozesse einhergeht (Spinaci et al. 2006). Schließlich ist zu bedenken, dass die Inkubation mit Hoechst 33342 ( $1 \mathrm{~h}$ bei $34{ }^{\circ} \mathrm{C}$ : Klinc und Rath 2007, vorliegende Arbeit) die Rate der spontanen Lipidperoxidation erhöht - mit negativen Auswirkungen auf die 
Spermienmotilität, wobei unklar ist, ob die Erhöhung der Lipidperoxidation vom Farbstoff, von der Temperatur, oder von einer Kombination aus beiden Faktoren abhängt (zur Übersicht: Klinc und Rath 2007). Optimierungsvorschläge aus unserem Forschungsverbund betreffen zunächst die Verkürzung der Inkubationszeit mit Hoechst 33342, die Mancini et al. (2013) durch Einsatz modifizierter Puffer erreichen konnten. Um darüber hinaus möglicherweise gänzlich auf den Einsatz „klassischer“ DNS-Farbstoffe verzichten zu können, untersuchten Taylor et al. (2013), wie man die DNS von Spermien mit Hilfe von Goldnanopartikeln markieren kann.

Unsere Befunde erlauben noch weitergehende Aussagen. Es stellte sich nämlich heraus, dass die durch Hoechst 33342 gegenüber unbehandelten Spermien in einem von drei untersuchten Fällen signifikant erhöhte Zahl stark kondensierter Mitochondrien nochmals signifikant ansteigt, wenn Hoechst 33342-gefärbte Spermien (ID2) im Standardverfahren sortiert werden (ID3). Von einer alleinigen Verursachung kondensierter Mitochondrien durch das Sortiergerät kann also nicht die Rede sein. Stattdessen trugen DNS-Färbung und Sortiergerät in diesem Fall etwa 50:50 zu der enormen Erhöhung des prozentualen Anteils kondensierter Mitochondrien bei. Interessanterweise beruhen auch die Umverteilung von HSP70 sowie die Abnahme der Zahl membranintakter Spermien sequenziell auf Beiträgen von Hoechst 33342 und Sortiergerät (Spinaci et al. 2006).

\section{3.3 Laser}

Spermienproben, die das Sortiergerät bei ausgeschaltetem Laser durchlaufen hatten, wiesen bei allen drei untersuchten Tieren noch immer einen signifikant höheren Anteil kondensierter Mitochondrien auf als die Kontrollproben nichtsortierter Spermien (ID1). Unter Berücksichtigung der bisher diskutierten Befunde lässt diese Beobachtung den Schluss zu, dass andere Gerätekomponenten und/oder der DNS-Farbstoff Hoechst 33342 für diesen massiven Anstieg der Zahl kondensierter Mitochondrien gesorgt haben. Eine tragfähige Differenzialdiagnose zwischen diesen beiden potenziell ursächlichen Faktoren(gruppen) ist jedoch auf der Basis der bisher vorliegenden Daten nicht möglich.

Auch der Vergleich von Spermien, die das Sortiergerät bei ausgeschaltetem Laser passiert haben (ID5), mit den nach dem Standardverfahren sortierten Spermien (ID3) ist nicht unproblematisch. Hierbei kommt nämlich zum Tragen, dass sich die Proben der ID3 aus den zunächst in getrennten Gefäßen aufgefangenen und dann gepoolten X- und Y-chromosomalen Spermien rekrutieren. Konträr sorgt die Ausschaltung des Lasers (ID5) dafür, dass sämtliche Spermien ungeladen und daher auch unabgelenkt von den Hochspannungsplatten in den Abfallbehälter verbracht werden. Wenn man also im Anschluss an den Vergleich von Proben der ID1 und ID5 wissen möchte, ob sich auch 
Proben der ID3 und ID5 bezüglich des untersuchten Merkmals signifikant unterscheiden, muss man den Proben der ID3 im Idealfall alle im Abfallbehälter gesammelten Spermien hinzugeben (ID3+). Beim Vergleich von Proben der ID3+ und ID5, der bisher allerdings lediglich auf einem einzigen korrespondierenden Probenpaar beruht, ließ sich kein signifikanter Unterschied bezüglich des Auftretens kondensierter Mitochondrien feststellen. Demnach scheint der Laser nicht in erster Linie für die Entstehung kondensierter Mitochondrien verantwortlich zu sein. Passend hierzu konnten Spinaci et al. (2006) nachweisen, dass auch das Verteilungsmuster von HSP70 nicht vom Einfluss des Lasers abhängt. Klärungsbedürftig bleibt unter anderem, inwieweit das Zustandekommen des hohen prozentualen Anteils kondensierter Mitochondrien in Proben der ID3 und ID3+ von potenzierenden Interaktionen zwischen dem DNS-Farbstoff Hoechst 33342 und dem Laser abhängt. Dass solche Interaktionen tatsächlich auftreten können, belegen die von Smith (1993) publizierten Befunde, denen zufolge UV-Bestrahlung in Kombination mit Hoechst 33342 die Aktivität von Oozytenmitochondrien deutlich senkt. In Analogie zu diesen Befunden halten es Carvalho et al. (2010) für wahrscheinlich, dass auch die von ihnen festgestellten Motilitätsstörungen geschlechtsspezifisch sortierter Spermien auf mitochondrialen Schäden beruhen könnten, die durch die kombinierte Einwirkung von Hoechst 33342 und Laser gesetzt werden.

\section{3.4 Spannung am Piezokristall}

Sämtliche Spermienproben der ID6, bei denen die Spannung am Piezokristall von den standardmäBig verwendeten 25 oder 30 Volt auf 5 Volt gesenkt wurde, wiesen im Vergleich mit Proben nichtsortierter Rinderspermien (ID1) signifikant höhere prozentuale Anteile kondensierter Mitochondrien auf. Weiterhin zeichnete sich eine dieser drei Spermienproben (ID6) - verglichen mit standardsortierten Spermien (ID3) - durch ein signifikant niedrigeres Vorkommen kondensierter Mitochondrien aus. Hieraus ist zu schließen, dass die Reduktion der Spannung am Piezokristall, die mit einer Reduktion des Drucks auf die Plasmamembran der Spermien einhergeht (mündliche Mitteilung von D. Rath, Institut für Nutztiergenetik, am 05. 12. 2013), zwar in einzelnen Fällen, aber nicht generell verhindern kann, dass Spermienmitochondrien beim geschlechtsspezifischen Sortieren von einer orthodoxen in eine kondensierte Konformation übergehen. Unter der auf der Grundlage unserer Befunde möglichen, aber keineswegs bewiesenen Voraussetzung, dass kondensierte Mittelstück-Mitochondrien einen negativen Einfluss auf die Motilität von Spermien haben, existiert eine publizierte Parallelbeobachtung an Rinderspermien bezüglich der Eigenschaften des Piezokristalls. Suh et al. (2005) haben nämlich herausgefunden, dass sich standardsortierte Spermienproben und Proben, die das Sortiergerät bei ausgeschaltetem Piezokristall durchlaufen haben, hinsichtlich ihrer Motilität kaum unterscheiden. Überraschend ist dieser Befund deshalb, weil Spermien, die nicht durch den Piezokristall in den Tröpfchenstrom integriert werden, weder geladen noch abgelenkt werden kön- 
nen, sondern gemeinsam mit den zuvor bereits abgestorbenen Spermien in den Abfallbehälter des Sortiergeräts fallen. Wenn, so argumentieren Suh et al. (2005), der Prozentsatz motiler Spermien in solchen aus dem Abfallbehälter gewonnenen Proben nicht, wie eigentlich zu erwarten, niedriger ist als bei standardsortierten Spermien, denen im Regelfall keine Spermien aus dem Abfallbehälter zugesetzt werden, so müsse dies letztlich daran liegen, dass sich der schädigende Einfluss des Piezokristalls auf die aus dem Abfallbehälter entnommenen Spermien nicht auswirken konnte. Nichtsdestoweniger lässt dieser Erklärungsversuch offen, ob der postulierte relative Zugewinn an Motilität unmittelbar auf die Ausschaltung des Piezokristalls zurückzuführen ist, oder ob sich auch die konsekutive Nichtzuteilung einer Ladung sowie die aus diesem Grund gleichfalls fehlende Ablenkung der Spermien im elektrischen Feld der Hochspannungsplatten positiv ausgewirkt haben.

\section{3.5 Hochspannungsplatten}

Zur Klärung der Frage, ob die Hochspannungsplatten, die im Normalfall geladene Spermien ablenken, einen übergeordneten Beitrag zur Entstehung kondensierter Mitochondrien liefern, standen von drei Tieren insgesamt vier Proben zur Verfügung, die das Sortiergerät bei ausgeschalteten Hochspannungsplatten durchlaufen hatten (ID7). Alle vier Proben wiesen im Vergleich mit den Kontrollproben nichtsortierter Spermien (ID1) signifikant höhere prozentuale Anteile kondensierter Mitochondrien auf, die offenbar durch andere Komponenten des Sortiergeräts und/oder durch den DNSFarbstoff Hoechst 33342 erzeugt worden sind. Der Vergleich zwischen Proben der ID7, die wegen der fehlenden elektrischen Ablenkung der Spermien aus dem Abfallbehälter des Sortiergeräts entnommen werden müssen, und Proben der ID3, denen in dieser Testreihe keine „kompensatorischen“ Spermien aus dem Abfallbehälter zugesetzt worden sind, förderte zutage, dass die Zahl kondensierter Mitochondrien nach Ausschalten der Hochspannungsplatten in einem Fall statistisch signifikant und in zwei weiteren Fällen immerhin tendenziell sinkt. Lediglich bei einem der vier analysierten Probenpaare fanden sich, allerdings ohne statistische Signifikanz, umgekehrte Verhältnisse. Angesichts dieser Befundlage ist ein hervorgehobener Beitrag der Hochspannungsplatten zur Entstehung kondensierter Mitochondrien in geschlechtsspezifisch sortierten Spermien eher wahrscheinlich.

In der Literatur wird das beim geschlechtsspezifischen Sortieren von den Hochspannungsplatten ausgehende Gefährdungspotenzial kontrovers diskutiert. So schließen de Ambrogi et al. (2006) zwar nicht aus, dass ein schädigender Einfluss auf die Spermien besteht, heben aber auf der Grundlage ihrer Untersuchungsergebnisse hervor, dass selbst diejenigen Spermienproben, die das Sortiergerät nach Ausschaltung von Hochspannungsplatten und Laser durchlaufen, noch immer, verglichen mit nichtsortierten Spermien, einen signifikant höheren Prozentsatz membrangeschädigter Spermien 
und auch einen signifikant höheren Grad an DNS-Fragmentierung aufweisen. Dagegen fanden Spinaci et al. (2006) Hinweise darauf, dass die bereits mehrfach diskutierte (und unter funktionellen Aspekten negativ bewertete) Umverteilung von HSP70 ganz wesentlich auf den Einfluss der elektrischen Ladung sowie des von den Hochspannungsplatten erzeugten elektrischen Feldes zurückzuführen ist. Außerdem gibt es Anhaltspunkte dafür, dass die Hochspannungsplatten an der Generierung reaktiver Sauerstoffradikale teilhaben (zur Übersicht: Rath et al. 2013), deren Auftreten bei menschlichen Spermien mit einer Senkung des mitochondrialen Membranpotenzials korreliert ist (Wang et al. 2003), und unter deren Einfluss die Spermienmotilität abnimmt (Klinc und Rath 2007). Auf ultrastruktureller Ebene bewirken reaktive Sauerstoffradikale, wie am Beispiel der Flugmuskeln von Drosophila melanogaster gezeigt, eine massive Dilatation der Cristae mitochondriales (Walker und Benzer 2004), die auch, wie hier gezeigt, bei geschlechtsspezifisch sortierten Rinderspermien auftritt. Die gleichfalls von uns beobachtete Kondensation der mitochondrialen Matrix findet sich auch bei der hämatopoetischen Zelllinie FL 5.12, und zwar als Folge eines erniedrigten mitochondrialen Membranpotenzials (Gottlieb et al. 2003), das bei menschlichen Spermien möglicherweise kausal mit dem Auftreten reaktiver Sauerstoffradikale zusammenhängt (Wang et al. 2003). Hypothetisch wäre es demnach denkbar, dass unter dem Einfluss der Hochspannungsplatten Sauerstoffradikale gebildet werden, die bei geschlechtsspezifisch sortierten Rinderspermien mittels Erniedrigung des mitochondrialen Membranpotenzials ein vermehrtes Auftreten kondensierter Mitochondrien hervorrufen.

\section{3.6 Eidotter im Auffangmedium}

Im Rahmen der Analyse des Auffangmediums für geschlechtsspezifisch sortierte Rinderspermien wurde zunächst die Komponente „Eidotter“ eliminiert (ID4). Im Routinebetrieb wird Eidotter zugesetzt, um (1) beispielsweise durch den Zusatz des DNS-Farbstoffs Hoechst 33342 eingetretene Verdünnungseffekte zu kompensieren, (2) einen Schutzfilm um die Spermien zu bilden, und (3) geschädigte Phospholipide in der Plasmamembran der Spermien zu ersetzen (zur Übersicht: Bergeron und Manjunath 2006). Der Vergleich zwischen Proben der ID4 und nichtsortierten Kontrollproben (ID1) förderte bei allen drei untersuchten Tieren einen signifikant höheren Anteil kondensierter Mitochondrien in den Proben der ID4 zutage. Dagegen zeigten Proben der ID4 (Tier 3, zwei Probenpaare) im Vergleich zu Proben der ID3 (Standardsortierung mit Standardauffangmedium: TESTDotter) einen signifikant niedrigeren Anteil kondensierter Mitochondrien. Angesichts der Tatsache, dass wir die funktionellen Eigenschaften kondensierter Mitochondrien in sortierten Rinderspermien noch nicht kennen, ist die Aufstellung von Hypothesen bezüglich der Frage, ob sich die Anwesenheit von Eidotter im Auffangmedium eher förderlich oder eher abträglich auf die Spermien auswirkt, verfrüht. 


\section{3.7 Seminalplasma im Auffangmedium}

Im Rahmen geschlechtsspezifischer Sortierungsprozesse von Spermien treten Verdünnungseffekte auf, die unter anderem die Konzentration der physiologischerweise im Seminalplasma enthaltenen Antioxidantien herabsetzen. Nicht zuletzt deshalb fügen viele Anwender dem TEST-Dotter-Auffangmedium Seminalplasma hinzu, um den Anteil motiler und membranintakter Spermien zu erhöhen (Maxwell et al. 1996). Unumstritten ist diese Maßnahme aber nicht, weil, je nach Tierart und Dosis, auch negative Einflüsse von Seminalplasma auf sortierte Spermien beschrieben worden sind (zur Übersicht: de Graaf et al. 2008). Insofern lag es nahe zu überprüfen, wie sich die An- oder Abwesenheit von Seminalplasma auf die Häufigkeit des Auftretens kondensierter Mittelstück-Mitochondrien auswirkt.

Zunächst stellte sich heraus, dass sämtliche Spermienproben, die nach dem Sortieren in einem Auffangmedium ohne Seminalplasma aufgefangen worden waren (ID8, 3 Tiere), verglichen mit den Kontrollproben nichtsortierter Spermien (ID1), einen signifikant höheren Anteil kondensierter Mitochondrien aufwiesen. Anschließend zeigte sich, dass der Prozentsatz kondensierter Mitochondrien in Spermienproben der ID8 (Tiere 1 und 2), verglichen mit standardsortierten Proben (ID3: Seminalplasma im Auffangmedium enthalten), in einem Fall signifikant erhöht war, während im zweiten Fall kein signifikanter Unterschied zwischen den Proben der ID8 und ID3 festgestellt werden konnte. Auch hier gilt angesichts der Tatsache, dass über die funktionellen Eigenschaften kondensierter Mitochondrien in geschlechtsspezifisch sortierten Rinderspermien bisher nichts bekannt ist, dass unsere Ergebnisse aktuell keine Entscheidung bezüglich der Frage herbeiführen können, ob sich das Seminalplasma eventuell nicht ausschließlich positiv auf die aufgefangenen Spermien auswirkt. Im Rahmen von Folgearbeiten zur Klärung dieser Frage wird unter anderem zu untersuchen sein, ob und wie sich die kombinierte An- oder Abwesenheit von Seminalplasma, das den Anteil kondensierter Mitochondrien tendenziell erniedrigt, und von Eidotter, der ihn tendenziell erhöht, auf die Konformation der Mittelstück-Mitochondrien auswirkt. Dass solche die Spermienqualität betreffende Interaktionen prinzipiell bestehen, geht beispielsweise daraus hervor, dass die im Eidotter enthaltenen Lipoproteine genau diejenigen Proteine des Seminalplasmas binden, die ihrerseits „,schützendes“ Cholesterin aus der Plasmamembran der Spermien herauslösen können (zur Übersicht: Bergeron und Manjunath 2006).

\section{3.8 Zusammenfassende Einschätzung}

Die Analyse der Einzelkomponenten des Sortierprozesses bezüglich ihres Beitrags zur Entstehung signifikant erhöhter prozentualer Anteile kondensierter Mitochondrien in geschlechtsspezifisch sortierten Rinderspermien lässt eine generelle Unterscheidung zwischen fördernden, neutralen und ge- 
genläufig agierenden Komponenten zu. Fördernde Komponenten sind der DNS-Farbstoff Hoechst 33342, die Hochspannungsplatten sowie der im Auffangmedium enthaltene Eidotter. Dagegen sinkt die Zahl kondensierter Mitochondrien tendenziell unter dem Einfluss des im Auffangmedium enthaltenen Seminalplasmas sowie bei Erniedrigung der Spannung am Piezokristall. Unter den gewählten Versuchsbedingungen neutral verhält sich lediglich der Laser des Sortiergeräts.

Unter der Voraussetzung, dass sich die beim geschlechtsspezifischen Sortieren beobachtete Zunahme der Zahl kondensierter Mitochondrien tatsächlich als Ausdruck oder Ursache einer verminderten Spermienqualität herausstellen sollte, müssten zukünftige Optimierungsversuche am Sortierverfahren am ehesten danach trachten, den DNS-Farbstoff Hoechst 33342 sowie die Hochspannungsplatten zu ersetzen, die beide auch aus anderen, oben bereits dargelegten Gründen kritisch hinterfragt werden. Als weitere Option böte sich die Reduktion der Spannung am Piezokristall an. Bezüglich einer möglichen Optimierung der Zusammensetzung des Auffangmediums sind unsere Befunde präliminär und bedürfen, wie auch die den Laser des Sortiergeräts betreffenden Tests, einer Überprüfung mit verfeinerter Methodik.

\section{4 Einfluss von Aufbereitungsschritten und Thermoresistenztest auf die Konforma- tion von Mitochondrien geschlechtsspezifisch sortierter Spermien}

\section{4.1 Kühlen auf $5{ }^{\circ} \mathrm{C}$}

Zunächst wollten wir in Erfahrung bringen, ob die Aufbereitung bereits sortierter Spermien, die zunächst in Form der Zugabe eines Tiefgefriermediums sowie einer einleitenden Kühlung auf $5{ }^{\circ} \mathrm{C}$ erfolgt (ID9), Einfluss auf die Mitochondrienkonformation hat. Die Anzahl der für diesen Test zur Verfügung stehenden Proben war auf drei korrespondierende Paare der ID1 (nichtsortierte Spermien) und ID9 beschränkt. In zwei von drei Fällen fanden wir einen signifikant höheren Anteil kondensierter Mitochondrien bei ID9. Im dritten Fall irritiert bei der nichtsortierten Spermienprobe (ID1) ein extrem hoher Prozentsatz kondensierter Mitochondrien, der aus dem Feld sämtlicher analysierter Spermienproben der ID1 heraussticht. Nichtsdestoweniger liegt auch in diesem Fall der für ID9 ermittelte Prozentwert noch immer über demjenigen von ID1, erreicht aber keine statistische Signifikanz.

Auf der Grundlage dieser Befunde kann nicht entschieden werden, ob und in welchem Ausmaß das Tiefgefriermedium und/oder die anschließende, in einem Zeitraum von etwa zwei Stunden ablaufende Kühlung auf $5{ }^{\circ} \mathrm{C}$ ursächlich an der Entwicklung kondensierter Mitochondrien beteiligt sind. Allerdings zählten Jones und Stewart (1979) bei nichtsortierten Rinderspermien, die unter Zusatz 
eines Tiefgefriermediums sechs Stunden lang bei $5{ }^{\circ} \mathrm{C}$ gelagert wurden, einen Anteil kondensierter Mitochondrien von nur 7 Prozent, der in guter Näherung den von uns in den Kontrollproben nichtsortierter Spermien (ID1) errechneten arithmetischen Mittelwerten entspricht. Unter dem Vorbehalt, dass sich beide Experimente sowohl hinsichtlich der Zusammensetzung der verwendeten Tiefgefriermedien als auch bezüglich der Dauer der Kälteexposition unterscheiden, vermuten wir deshalb, dass die in den Spermienproben der ID9 festgestellte hohe Zahl kondensierter Mitochondrien (arithmetische Mittelwerte zwischen 42 und 43 Prozent) überwiegend durch Komponenten des Sortierprozesses und nicht durch die nachfolgende Kühlung verursacht wurde.

\section{4.2 Kühlen, Einfrieren und Wiederauftauen}

Nichtsortierte Rinderspermien überstehen zwar, wie oben diskutiert, die Zugabe eines Tiefgefriermediums sowie die nachfolgende Abkühlung auf $5{ }^{\circ} \mathrm{C}$ für sechs Stunden, ohne gravierende ultrastrukturelle Auffälligkeiten auszubilden, erleiden aber durch anschließendes Einfrieren und Wiederauftauen einerseits Defekte der Plasmamembran, andererseits Matrixverluste ihrer Mittelstuick-Mitochondrien. Zusätzlich sinkt der bereits nach Abkühlung auf $5{ }^{\circ} \mathrm{C}$ ohnehin niedrige Anteil kondensierter Mitochondrien (8 Prozent) unter dem Einfluss des Einfrierens und Wiederauftauens auf 2 Prozent ab (Jones und Stewart 1979). Unsere Untersuchungen belegen, dass auch Proben sortierter Rinderspermien, die sich nach Zugabe des Tiefgefriermediums und Abkühlung auf $5{ }^{\circ} \mathrm{C}$ bezüglich ihres Gehalts an kondensierten Mitochondrien signifikant von nichtsortierten Spermien unterschieden, dieses Unterscheidungsmerkmal nach dem anschließenden Einfrieren und Wiederauftauen in allen untersuchten Probenpaaren verlieren.

Wäre es so einfach, dass kondensierte Mitochondrien sich eindeutig negativ auf die Qualität der Spermien auswirkten, so würde nach dem zuvor Gesagten das durch den Sortierprozess ausgelöste „Übel“ durch den nachfolgenden Aufarbeitungsprozess der sortierten Spermien umgehend wieder beseitigt werden. Tatsächlich jedoch bewirkt auch das Einfrieren nichtsortierter menschlicher Spermien eine Senkung des mitochondrialen Membranpotenzials sowie eine verminderte Motilität und Lebensfähigkeit der Spermien (O’Connell et al. 2002). Wir werden also in Folgearbeiten untersuchen müssen, welches Membranpotenzial die Mitochondrien geschlechtsspezifisch sortierter Rinderspermien in jeder der beschriebenen experimentellen Situationen haben, und wie mitochondriale Konformation, mitochondriales Membranpotenzial und Motilität der Spermien jeweils miteinander korreliert sind. In der hämatopoietischen Zelllinie FL5.12 ist ein direkter Zusammenhang zwischen der Abnahme des mitochondrialen Membranpotenzials und der Zunahme der Zahl kondensierter Mitochondrien bereits nachgewiesen worden (Gottlieb et al. 2003). 
Mögliche Hinweise darauf, dass „Qualitätsmängel“ sortierter Spermien durch Komponenten der auf die Sortierung folgenden Aufarbeitungsprozedur abgeschwächt werden, finden sich in der relevanten Literatur gleich mehrfach. Beispielsweise beobachteten Parrilla et al. (2005), dass sortierte Schweinespermien, die unmittelbar nach dem Sortieren für eine In-vitro-Fertilisation verwendet wurden, geringere Befruchtungsraten erzielten als solche, die nach dem Sortieren zunächst zwei Stunden bei $20^{\circ} \mathrm{C}$ gelagert worden waren. Hierzu passend beobachteten Spinaci et al. (2006) während der zweistündigen Lagerungsperiode $\left(20^{\circ} \mathrm{C}\right)$ frisch sortierter Schweinespermien eine weitgehende Rückbildung des im Rahmen des Sortierprozesses charakteristisch veränderten und als schädlich interpretierten Verteilungsmusters von HSP70. Es wäre also gut vorstellbar, dass der von uns nach dem Kühlen, Einfrieren und Wiederauftauen sortierter Rinderspermien nachgewiesene drastische Rückgang des prozentualen Anteils kondensierter Mittelstück-Mitochondrien eine schadensmindernde Funktion hat.

\section{4.3 Thermoresistenztest}

Der Thermoresistenztest (sechsstündige Inkubation sortierter, gekühlter, eingefrorener und wieder aufgetauter Spermien bei $37^{\circ} \mathrm{C}$ : ID11) prüft die Widerstandsfähigkeit der Spermien und soll die bei der künstlichen Besamung im weiblichen Genitaltrakt herrschenden Temperaturbedingungen imitieren (Underwood et al. 2009). Pathophysiologisch steht der an nichtsortierten Kaninchen- und Mäusespermien nachgewiesene temperaturabhängige Anstieg reaktiver Sauerstoffradikale im Vordergrund (Alvarez und Storey 1985), der durch die Gabe von Antioxidantien abgewendet werden kann (Klinc und Rath 2007). Für die von uns durchgeführten Tests sind diese Zusammenhänge deshalb von Bedeutung, weil der Anstieg reaktiver Sauerstoffradikale nach Mannella et al. (2008) ursächlich für eine Dilatation der Cristae mitochondriales sein könnte, die typischerweise bei kondensierten Mitochondrien auftritt. Unter den genannten Voraussetzungen wäre es also denkbar, dass die intensive Temperaturbelastung der sortierten Rinderspermien im Rahmen des Thermoresistenztests (ID11) zu einem Anstieg der Zahl kondensierter Mitochondrien führt, der möglicherweise durch reaktive Sauerstoffradikale ausgelöst wird. Tatsächlich ist der Anteil kondensierter Mitochondrien in Proben der ID11 bei allen drei untersuchten Probenpaaren (drei Tiere) höher als in den Proben der ID10 (sortierte, gekühlte, eingefrorene und wieder aufgetaute Spermien), wobei allerdings nur in einem Fall statistische Signifikanz erreicht wird. Unter der in Folgearbeiten zu prüfenden Arbeitshypothese, dass kondensierte Mitochondrien Ausdruck und/oder Ursache einer verminderten Spermienqualität sind, würden sortierte Spermien die durch den Sortiervorgang ausgelöste „ungünstige“ Mitochondrienkonformation demnach während der Aufarbeitungsprozedur weitgehend verlieren, mindestens zum Teil aber in den weiblichen Geschlechtswegen erneut annehmen. 


\section{ZUSAMMENFASSUNG}

Die geschlechtsspezifische Separierung X- und Y-chromosomaler Spermien wird weltweit unter zahlreichen human- und veterinärmedizinischen Indikationen praktiziert. Das Hauptmotiv für die Inangriffnahme methodischer Optimierungen der aktuell eingesetzten Sortiergeräte, die überwiegend auf der United States Department of Agriculture-Beltsville Sperm Sexing Technology beruhen, besteht darin, die Befruchtungsfähigkeit sortierter Spermien zu erhöhen. Die vorliegende Arbeit untersucht mittels Transmissionselektronenmikroskopie, ob geschlechtsspezifisch sortierte Rinderspermien, die routinemäßig in der Viehzucht eingesetzt werden, ultrastrukturelle Veränderungen aufweisen, die ihre gegenüber nichtsortierten Spermien verringerte Beweglichkeit und Befruchtungsfähigkeit erklären könnten.

Analysiert wurden insgesamt 66 Spermaproben, die von drei Bullen der Rasse Holstein-Friesian über einen Zeitraum von einem Jahr gewonnen worden waren. Angesichts der Tatsache, dass Rinderspermien die zur Sicherstellung ihrer Motilität erforderliche Energie überwiegend aus der Aktivität ihres Chondrioms beziehen, konzentrierten sich die Untersuchungen auf die helikal im Mittelstück der Spermien angeordneten Mitochondrien. Hierbei stellte sich zunächst heraus, dass mitochondriale Gefügestörungen, die hypothetisch durch die hohe mechanische Belastung der Spermien beim Durchgang durch das Sortiergerät hervorgerufen werden könnten, in annähernd gleicher Häufigkeit auch bei nichtsortierten Spermien vorkommen. Nebenbefundlich konnten wir in diesem $\mathrm{Zu}$ sammenhang elektronendichte Verbindungsstreben zwischen benachbarten Mitochondrien und/oder zwischen den Mitochondrien und der Plasmamembran des Rinderspermiums erstbeschreiben. Solche Verbindungsstreben unterstützen den strukturellen Zusammenhalt des Chondrioms offenbar selbst dann noch, wenn massive, die helikale Anordnung der Mitochondrien streckenweise aufhebende Gefügestörungen auftreten, oder wenn die Plasmamembran des Spermiums vollständig verloren geht.

Auch bezüglich der Häufigkeit der in unserem Untersuchungsgut nachgewiesenen hochgradig geschwollenen Mitochondrien, die in der Literatur vielfach als Ausdruck eines pathologischen Geschehens beschrieben worden sind, fanden wir praktisch nur in einem von 13 untersuchten Fällen einen statistisch signifikanten Unterschied zwischen den Proben sortierter und nichtsortierter Rinderspermien. Im Gegensatz hierzu zeigte sich anschließend, dass geschlechtsspezifisch sortierte Spermien - verglichen mit den jeweils korrespondierenden Proben nichtsortierter Spermien vom selben Entnahmetag - signifikant häufiger kondensiert konformierte Mitochondrien enthalten (Mann-Whitney-U-Test). Ultrastrukturell ist dieser während des Sortierprozesses erfolgende Über- 
gang der Mitochondrien von einer orthodoxen in eine kondensierte Form dadurch charakterisiert, dass die Weite des intracristalen Raumes - bei gleichzeitiger Kondensierung der mitochondrialen Matrix - offenbar solange zunimmt, bis ein weitgehend oder vollständig strukturfreies elektronenhelles Zentrum von einem hochgradig elektronendichten Matrixsaum umgeben wird, der selbst bei hoher elektronenmikroskopischer Auflösung kaum noch gegen die inneren und äußeren Mitochondrienmembranen abgegrenzt werden kann. Inwieweit die oben skizzierten intermitochondrialen Verbindungsstreben im Sinne einer „energetischen Kopplung“ mitursächlich für das überwiegend gruppiert massenhafte - und nicht individuell regellose - Auftreten kondensiert konformierter Mitochondrien in sortierten Rinderspermien sind, muss durch Anschlussuntersuchungen geklärt werden. Gleiches gilt für die im Schrifttum kontrovers diskutierte funktionelle Wertigkeit kondensiert konformierter Spermienmitochondrien, die nicht nur physiologisch in einem definierten Zeitfenster der Spermienentwicklung, sondern auch unter verschiedenen pathologischen Bedingungen beobachtet worden sind.

Der Nachweis eines eindeutigen ultrastrukturellen Kriteriums, mit dessen Hilfe Proben geschlechtsspezifisch sortierter und nichtsortierter Rinderspermien unterschieden werden können, ermutigte uns, einzelne oder Gruppen von Komponenten des Sortierprozesses experimentell zu isolieren, um den oder die Hauptverursacher des mitochondrialen Konformationswechsels ausfindig zu machen. Hierbei zeigte sich zunächst, dass allein die Zugabe des DNS-Farbstoffes Hoechst 33342 etwa in einem Drittel der Fälle eine signifikante Erhöhung des Prozentsatzes kondensiert konformierter Mitochondrien bewirkt. Unter Würdigung der in der Literatur beschriebenen funktionellen Defizite, die Hoechst 33342 bei Spermien hervorrufen kann, könnte das vermehrte Auftreten kondensiert konformierter Mitochondrien tatsächlich Ausdruck oder Ursache einer Schädigung sein. Andererseits erhöht sich die Häufigkeit kondensiert konformierter Mitochondrien signifikant, wenn die mit Hoechst 33342 behandelten Spermien anschließend im Standardverfahren sortiert werden. Von einer alleinigen Verursachung des mitochondrialen Konformationswechsels durch lediglich eine einzige Komponente des Sortierprozesses darf daher in keinem Fall ausgegangen werden.

Auch die am Piezokristall des Sortiergeräts eingestellte Spannung verhält sich gegenüber der Mitochondrienkonformation nicht neutral. Vielmehr bewirkt ihre Reduktion auf 5 Volt, die den auf der Plasmamembran der Spermien lastenden Druck verringert, bei immerhin einem von drei untersuchten Probenpaaren eine signifikante Erniedrigung des Prozentsatzes kondensiert konformierter Mitochondrien. Den unter allen untersuchten Gerätekomponenten tendenziell deutlichsten Beitrag zur Entstehung kondensiert konformierter Mitochondrien leisten jedoch die Hochspannungsplatten, die die mit Hoechst 33342 markierten, vom Laser zur Fluoreszenz angeregten und in Abhängigkeit von 
der geschlechtsspezifisch variierenden DNS-Menge mit unterschiedlichen Ladungen versehenen Xoder Y-chromosomalen Spermien in verschiedene Auffangbehälter leiten. Unter Einbeziehung von Befunden anderer Arbeitsgruppen lässt sich die Arbeitshypothese aufstellen, dass kondensierte Mitochondrien unter der Einwirkung reaktiver Sauerstoffradikale entstehen, die ihrerseits unter dem Einfluss der Hochspannungsplatten erzeugt werden, eine Senkung des mitochondrialen Membranpotenzials herbeiführen und für die verminderte Spermienmotilität verantwortlich sind.

Im Unterschied zu den mit den Hochspannungsplatten durchgeführten Experimenten führt das Ausschalten des Lasers offenbar nicht zu einem signifikanten Abfall der Prozentwerte kondensiert konformierter Mitochondrien unter das Niveau standardsortierter Spermienproben. Mit Blick auf die vorhandene Literatur halten wir es jedoch für möglich, dass Interaktionen zwischen dem Laser und dem DNS-Farbstoff Hoechst 33342 eine Potenzierung des Lasereinflusses und hierdurch eine Erhöhung des Prozentsatzes kondensiert konformierter Mitochondrien bewirken könnten. Die im Rahmen der vorliegenden Arbeit getesteten Modifikationen des Auffangmediums für geschlechtsspezifisch sortierte Rinderspermien zeigten gegenläufige Effekte. So führt die Entfernung des Eidotters aus dem Auffangmedium tendenziell zu einer Erniedrigung der Zahl kondensiert konformierter Mitochondrien, stellt aber angesichts der bekannten förderlichen Eigenschaften von Eidotter keinen gangbaren Weg zur Methodenoptimierung dar. Im Unterschied hierzu lässt sich nach Entfernung des Seminalplasmas aus dem Auffangmedium bisher kein belastbarer Trend bezüglich der Mitochondrienkonformation identifizieren.

Bei der abschließenden Analyse der Aufarbeitungsschritte, die geschlechtsspezifisch sortierte Rinderspermien vor ihrem jeweiligen „Einsatz“ durchlaufen, stellte sich überraschenderweise heraus, dass der Prozentsatz kondensiert konformierter Mitochondrien in den Proben sortierter Rinderspermien nach Zugabe eines Tiefgefriermediums, Abkühlung auf $5{ }^{\circ} \mathrm{C}$ sowie anschließendem Einfrieren und Wiederauftauen derart drastisch abnimmt, dass sie zumindest bezüglich dieses einen strukturellen Merkmals praktisch nicht mehr von den Proben nichtsortierter Spermien unterschieden werden können. Angesichts des von anderen Arbeitsgruppen publizierten Befundes, dass die stundenweise niedertemperaturige Lagerung geschlechtsspezifisch sortierter Schweinespermien die Quote erfolgreicher Befruchtungen steigert, könnte der von uns bei Rinderspermien beobachtete Rückgang des Prozentsatzes kondensiert konformierter Mitochondrien als „schadensmindernd“ interpretiert werden. Hierzu passt im hypothetischen Umkehrschluss auch, dass die Zahl kondensiert konformierter Mitochondrien in sortierten Rinderspermien, die bekanntermaßen keine optimalen Befruchtungsergebnisse erzielen, nach Durchführung eines Thermoresistenztests, der die im weiblichen Genitaltrakt herrschenden Temperaturbedingungen imitieren soll, erneut signifikant ansteigt. 


\section{LITERATURVERZEICHNIS}

Alvarez JG, Storey BT (1985): Spontaneous lipid peroxidation in rabbit and mouse epididymal spermatozoa: dependence of rate on temperature and oxygen concentration. Biol Reprod $\underline{32}$, 342-351

André J (1962): Contribution à la connaissance du chondriome. Étude de ses modifications ultrastructurales pendant la spermatogénèse. J Ultrastruct Res Suppl 3, 1-185

Bahr GF, Engler WF (1970): Considerations of volume, mass, DNA, and arrangement of mitochondria in the midpiece of bull spermatozoa. Exp Cell Res $\underline{60}, 338-340$

Barchanski A, Taylor U, Klein S, Petersen S, Rath D, Barcikowski S (2011): Golden perspective: application of laser-generated gold nanoparticle conjugates in reproductive biology. Reprod Domest Anim $\underline{46}(3), 42-52$

Bathgate R, Morton KM, Eriksson BM, Rath D, Sieg B, Maxwell WM, Evans G (2007): Non-surgical deep intra-uterine transfer of in vitro produced porcine embryos derived from sex-sorted frozenthawed boar sperm. Anim Reprod Sci 99, 82-92

Bergeron A, Manjunath P (2006): New insights towards understanding the mechanisms of sperm protection by egg yolk and milk. Mol Reprod Dev $\underline{73}, 1338-1344$

Bergmann A, Taylor U, Rath D (2013): Porcine sperm and endometrium interactions - slowly cracking the case. Reprod Domest Anim $\underline{48}$ (1), 74

Blondin GA, Green DE (1967): The mechanism of mitochondrial swelling. Proc Natl Acad Sci USA $\underline{58}, 612-619$

Buß HF: Verbesserung der Tiefgefrierfähigkeit geschlechtsspezifisch sortierter Hengstspermien. Med. Vet. Diss. Hannover 2005

Carvalho JO, Sartori R, Machado GM, Mourão GB, Dode MA (2010): Quality assessment of bovine cryopreserved sperm after sexing by flow-cytometry and their use in in vitro embryo production. Theriogenology $\underline{74}, 1521-1530$ 
Cinar B, Ekhlasi-Hundrieser M, Rath D, Bollwein H (2010): Effects of flow-cytometric sorting for gender on quality of bovine sperm. Reprod Domest Anim 45 (1), 8

Cinar B, Ekhlasi-Hundrieser M, Krienke M, Rath D, Bollwein H (2011): Media supplementation with seminal plasma proteins improves quality of bold sorted cryopreserved bovine sperm. Reprod Domest Anim $\underline{46}(3), 95$

Clermont Y (1963): The cycle of the seminiferous epithelium in man. Am J Anat $\underline{112}, 35-51$

Clermont Y (1972): Kinetics of spermatogenesis in mammals: seminiferous epithelium cycle and spermatogonial renewal. Physiol Rev $\underline{52}, 198-236$

de Ambrogi M, Spinaci M, Galeati G, Tamanini C (2006): Viability and DNA fragmentation in differently sorted boar spermatozoa. Theriogenology $\underline{66}, 1994-2000$

de Graaf SP, Leahy T, Marti J, Evans G, Maxwell WM (2008): Application of seminal plasma in sex-sorting and sperm cryopreservation. Theriogenology $\underline{70}, 1360-1363$

de Jarnette JM, Leach MA, Nebel RL, Marshall CE, McCleary CR, Moreno JF (2011): Effects of sex-sorting and sperm dosage on conception rates of Holstein heifers: Is comparable fertility of sexsorted and conventional semen plausible? J Dairy Sci $\underline{94}$, 3477-3483

de Kretser DM (1969): Ultrastructural features of human spermiogenesis. Z Zellforsch Mikrosk Anat $\underline{98}, 477-505$

Delgado CL, Rosegrant MW, Steinfeld H, Ehui SK, Courbois C (2001): Livestock to 2020: the next food revolution. Outlook on Agriculture $\underline{30}, 27-29$

de Martino C, Floridi A, Marcante ML, Malorni W, Scorza Barcellona P, Bellocci M, Silvestrini B (1979): Morphological, histochemical and biochemical studies on germ cell mitochondria of normal rats. Cell Tissue Res 196, 1-22

Dondorp W, de Wert G, Pennings G, Shenfield F, Devroey P, Tarlatzis B, Barri P, Diedrich K (2013): ESHRE Task Force on ethics and Law 20: sex selection for non-medical reasons. Hum Reprod $\underline{28}$, 1448-1454 
Dym M, Fawcett DW (1970): The blood-testis barrier in the rat and the physiological compartmentation of the seminiferous epithelium. Biol Reprod $\underline{3}, 308-326$

Evans KM, Gilligan TB, Gonzalez-Martin C (2013): Sperm staining and sorting methods. United States Patent Application. Publication No: US2013/0084558 A1

http://patents.com/us-20130084558.html (zuletzt abgerufen am 17. 02. 2014)

FAO (2009): Current status and options for livestock biotechnologies in developing countries. FAO International Technical Conference ABDC $\underline{10 / 5.2}, 2$

Fawcett DW (1975): The mammalian spermatozoon. Dev Biol 44, 394-436

Frijters AC, Mullaart E, Roelofs RM, van Hoorne RP, Moreno JF, Moreno O, Merton JS (2009): What affects fertility of sexed bull semen more, low sperm dosage or the sorting process? Theriogenology $\underline{71}, 64-67$

Fugger EF (1999): Clinical experience with flow-cytometric separation of human X-and Y-chromosome bearing sperm. Theriogenology $\underline{52}, 1435-40$

Gallon F, Marchetti C, Jouy N, Marchetti P (2006): The functionality of mitochondria differentiates human spermatozoa with high and low fertilizing capability. Fertil Steril ㅌ6, 1526-1530

Garner DL, Gledhill BL, Pinkel D, Lake S, Stephenson D, van Dilla MA, Johnson LA (1983): Quantification of the X- and Y-chromosome-bearing spermatozoa of domestic animals by flowcytometry. Biol Reprod 28, 312-321

Garner DL, Seidel GE Jr (2008): History of commercializing sexed semen for cattle. Theriogenology $\underline{69}, 886-895$

Gottlieb E, Armour SM, Harris MH, Thompson CB (2003): Mitochondrial membrane potential regulates matrix configuration and cytochrome c release during apoptosis. Cell Death Differ $\underline{10}$, 709-717

Graham EF, Crabo BG, Brown KI (1972): Effect of some zwitter ion buffers on the freezing and storage of spermatozoa. I. Bull. J Dairy Sci $\underline{55}$, 372-378 
Grossfeld R, Klinc P, Sieg B, Rath D (2005): Production of piglets with sexed semen employing a non-surgical insemination technique. Theriogenology $\underline{63}$, 2269-2277

Hackenbrock CR (1966): Ultrastructural bases for metabolically linked mechanical activity in mitochondria. I. Reversible ultrastructural changes with change in metabolic steady state in isolated liver mitochondria. J Cell Biol 30, 269-297

Hackenbrock CR (1968): Ultrastructural bases for metabolically linked mechanical activity in mitochondria. II. Electron transport-linked ultrastructural transformations in mitochondria. J Cell Biol $\underline{37}, 345-369$

Hackenbrock CR, Caplan AI (1969): Ion-induced ultrastructural transformations in isolated mitochondria. The energized uptake of calcium. J Cell Biol $\underline{42}, 221-234$

Hackenbrock CR, Rehn TG, Weinbach EC, Lemasters JJ (1971): Oxidative phosphorylation and ultrastructural transformation in mitochondria in the intact ascites tumor cell. J Cell Biol 51, 123-137

Heer P: Anpassung der Konservierungsprozesse für Hengstsperma an die Beltsville Sperm Sexing Technology. Med. Vet. Diss. Hannover 2007

Hermes R, Behr B, Hildebrandt TB, Blottner S, Sieg B, Frenzel A, Knieriem A, Saragusty J, Rath D (2009): Sperm sex-sorting in the Asian elephant (Elephas maximus). Anim Reprod Sci 112, 390-396

Hohenboken WD (1999): Applications of sexed semen in cattle production. Theriogenology $\underline{52}$, $1421-1433$

Holstein AF, Roosen-Runge EC: Atlas of human spermatogenesis. Grosse-Verlag, Berlin 1981

Johnson LA (1997): Advances in gender preselection in swine. J Reprod Fertil 2, 255-266

Johnson LA, Rath D, Vazquez JM, Maxwell WM, Dobrinsky JR (2005): Preselection of sex of offspring in swine for production: current status of the process and its application. Theriogenology $\underline{63}$, 615-624

Jones RC, Stewart DL (1979): The effects of cooling to 5 degrees C and freezing and thawing on 
the ultrastructure of bull spermatozoa. J Reprod Fertil 트, 233-238

Kaasik A, Safiulina D, Zharkovsky A, Veksler V (2007): Regulation of mitochondrial matrix volume. Am J Physiol Cell Physiol 292, C157-C163

Kadam K, D’Souza S, Natraj U (2007): Spatial distribution of actin and tubulin in human sperm nuclear matrix-intermediate filament whole mounts-a new paradigm. Microsc Res Tech $\underline{70}$, 589-598

Karabinus DS (2009): Flow-cytometric sorting of human sperm: MicroSort clinical trial update. Theriogenology $\underline{71}, 74-79$

Kasai T, Ogawa K, Mizuno K, Nagai S, Uchida Y, Ohta S, Fujie M, Suzuki K, Hirata S, Hoshi K (2002): Relationship between sperm mitochondrial membrane potential, sperm motility, and fertility potential. Asian J Androl 4, 97-103

Klinc P: Improved fertility of flow-cytometrically sex selected bull spermatozoa. Med. Vet. Diss. Hannover 2005

Klinc P, Rath D (2007): Reduction of oxidative stress in bovine spermatozoa during flowcytometric sorting. Reprod Domest Anim 42, 63-67

Knabe W, Kuhn HJ (1996): The role of microtubules and microtubule-organising centres during the migration of mitochondria. J Anat $\underline{189}, 383-391$

Kojima Y (1966): Electron microscopic study of the bull spermatozoon. IV. Jpn J Vet Res 14, 33-42

Kumari M, Aumüller G, Bergmann M, Meinhardt A, Seitz J (1990): Stage-dependent appearance of sulfhydryl oxidase during spermatogenesis in the testis of rat and hamster. An immunohistochemical study. Histochemistry $\underline{94}, 365-371$

Mancini R, Sieg B, Rath D (2013): Bull sperm motility and molecular kinetic of Hoechst dye are effected by the buffer system of extenders. Reprod Domest Anim $\underline{48}$ (1), 82

Mannella CA (2006): Structure and dynamics of the mitochondrial inner membrane cristae. Biochim Biophys Acta 1763, 542-548 
Mannella CA (2008): Structural diversity of mitochondria: functional implications. Ann N Y Acad Sci 1147, 171-179

Mannella CA, Lederer WJ, Jafri MS (2013): The connection between inner membrane topology and mitochondrial function. J Mol Cell Cardiol $\underline{62}, 51-57$

Maxwell WM, Welch GR, Johnson LA (1996): Viability and membrane integrity of spermatozoa after dilution and flow-cytometric sorting in the presence or absence of seminal plasma. Reprod Fertil Dev $\underline{8}, 1165-1178$

Meinhardt A, Parvinen M, Bacher M, Aumüller G, Hakovirta H, Yagi A, Seitz J (1995): Expression of mitochondrial heat shock protein 60 in distinct cell types and defined stages of rat seminiferous epithelium. Biol Reprod 52, 798-807

Meinhardt A, McFarlane JR, Seitz J, de Kretser DM (2000): Activin maintains the condensed type of mitochondria in germ cells. Mol Cell Endocrinol 168, 111-117

Mönch-Tegeder G, Struckmann C, Sieg B, Frenzel A, Taylor U, Baulain U, Rath D (2010): Influence of sodium fluoride on the lifespan of sex sorted bovine spermatozoa. Reprod Domest Anim $\underline{45}$ (3), 68

Morton KM, Herrmann D, Sieg B, Struckmann C, Maxwell WM, Rath D, Evans G, Lucas-Hahn A, Niemann H, Wrenzycki C (2007): Altered mRNA expression patterns in bovine blastocysts after fertilisation in vitro using flow-cytometrically sex-sorted sperm. Mol Reprod Dev $\underline{74}$, 931-940

O’Connell M, McClure N, Lewis SE (2002): The effects of cryopreservation on sperm morphology, motility and mitochondrial function. Hum Reprod 17, 704-709

Okunade GW, Miller ML, Pyne GJ, Sutliff RL, O’Connor KT, Neumann JC, Andringa A, Miller DA, Prasad V, Doetschman T, et al. (2004): Targeted ablation of plasma membrane $\mathrm{Ca}^{2+}$-ATPase (PMCA) 1 and 4 indicates a major housekeeping function for PMCA1 and a critical role in hyperactivated sperm motility and male fertility for PMCA4. J Biol Chem $\underline{279}$, 33742-33750

Olson GE, Hamilton DW (1976): Morphological changes in the midpiece of wooly opossum spermatozoa during epididymal transit. Anat Rec 186, 387-391 
Olson GE, Winfrey VP (1986): Identification of a cytoskeletal network adherent to the mitochondria of mammalian spermatozoa. J Ultrastruct Mol Struct Res 94, 131-139

Olson GE, Winfrey VP (1990): Mitochondria-cytoskeleton interactions in the sperm midpiece. J Struct Biol $\underline{103}, 13-22$

Olson GE, Winfrey VP (1992): Structural organization of surface domains of sperm mitochondria. Mol Reprod Dev $\underline{33}, 89-98$

Palermo GD, Colombero LT, Rosenwaks Z (1997): The human sperm centrosome is responsible for normal syngamy and early embryonic development. Rev Reprod $\underline{2}$, 19-27

Paranko J, Seitz J, Meinhardt A (1996): Developmental expression of heat shock protein 60 (HSP60) in the rat testis and ovary. Differentiation $\underline{60}, 159-167$

Parrilla I, Vazquez JM, Gil MA, Caballero I, Almiñana C, Roca J, Martinez EA (2005): Influence of storage time on functional capacity of flow-cytometrically sex-sorted boar spermatozoa. Theriogenology $\underline{64}, 86-98$

Pelliccione F, Micillo A, Cordeschi G, D`Angeli A, Necozione S, Gandini L, Lenzi A, Francavilla F, Francavilla S (2011): Altered ultrastructure of mitochondrial membranes is strongly associated with unexplained asthenozoospermia. Fertil Steril 95, 641-646

Perkins G, Renken C, Martone ME, Young SJ, Ellisman M, Frey T (1997): Electron tomography of neuronal mitochondria: three-dimensional structure and organization of cristae and membrane contacts. J Struct Biol $\underline{119}, 260-272$

Perkins GA, Ellisman MH (2011): Mitochondrial configurations in peripheral nerve suggest differrential ATP production. J Struct Biol $\underline{173}, 117-127$

Petersen S, Barchanski A, Taylor U, Klein S, Rath D, Barcikowski S (2011): Penetratin-conjugated gold nanoparticles - design of cell-penetrating nanomarkers by femtosecond laser ablation. J Phys Chem C $\underline{115}, 5152-5159$

Piomboni P, Focarelli R, Stendardi A, Ferramosca A, Zara V (2012): The role of mitochondria in 
energy production for human sperm motility. Int J Androl $\underline{35}$, 109-124

Rahmy TR, Ayoub MA (2002): In vitro action of cobra venom on goat spermatozoa ultrastructure by transmission and scanning electron microscopy. J Venom Anim Toxins $\underline{8}, 127-159$

Rasch B, Friese M, Hofmann W, Naumann E: Quantitative Methoden, Einführung in die Statistik. 2. erweiterte Auflage, Band 2; Springer Medizin Verlag, Heidelberg 2006

Rath D, Johnson LA, Dobrinsky JR, Welch GR, Niemann H (1997): Production of piglets preselected for sex following in vitro fertilization with $\mathrm{X}$ - and Y-chromosome-bearing spermatozoa sorted by flow-cytometry. Theriogenology $\underline{47}, 795-800$

Rath D, Barcikowski S, de Graaf S, Garrels W, Grossfeld R, Klein S, Knabe W, Knorr C, Kues W, [...], Michl J, et al. (2013): Sex selection of sperm in farm animals: status report and developmental prospects. Reproduction $\underline{145}$, R15-R30

Rens W, Welch GR, Johnson LA (1998): A novel nozzle for more efficient sperm orientation to improve sorting efficiency of X- and Y-chromosome-bearing sperm. Cytometry $\underline{33}$, 476-481

Rivera RM, Kelley KL, Erdos GW, Hansen PJ (2003): Alterations in ultrastructural morphology of two-cell bovine embryos produced in vitro and in vivo following a physiologically relevant heat shock. Biol Reprod 무, 2068-2077

Saacke RG, Almquist JO (1964): Ultrastructure of bovine spermatozoa. II. The neck and tail of normal, ejaculated sperm. Am J Anat 115, 163-183

Scalettar BA, Abney JR, Hackenbrock CR (1991): Dynamics, structure, and function are coupled in the mitochondrial matrix. Proc Natl Acad Sci USA $\underline{88}$, 8057-8061

Schmiedl A, Schnabel PA, Mall G, Gebhard MM, Hunneman DH, Richter J, Bretschneider HJ (1990): The surface to volume ratio of mitochondria, a suitable parameter for evaluating mitochondrial swelling. Correlations during the course of myocardial global ischaemia. Virchows Arch A Pathol Anat Histopathol $\underline{416}, 305-315$ 
Seidel GE Jr (2007): Overview of sexing sperm. Theriogenology $\underline{68}$, 443-446

Seidel GE Jr (2012): Sexing mammalian sperm - Where do we go from here? J Reprod Dev $\underline{58}$, 505-509

Seidel GE Jr, Garner DL (2002): Current status of sexing mammalian spermatozoa. Reproduction $\underline{124}, 733-743$

Sesso A, Belizário JE, Marques MM, Hiquchi ML, Schumacher RI, Colquhoun A, Ito E, Kawakami J (2013): Mitochondrial swelling and incipient outer membrane rupture in preapoptotic and apoptotic cells. Anat Rec 295, 1647-1659

Setchell BP (1980): The functional significance of the blood-testis barrier. J Androl 1, , 3-10

Sieg B, Tiedemann D, Kramer J, Taylor U, Rehbock C, Klein S, Kues W, Barcikowski S, Rath D (2013): Porcine sperm cell viability is not impaired by exposure to gold and silver nanoparticles. Reprod Domest Anim $\underline{48}$ (1), 87

Simpson AM, Swan MA, White IG (1986): Action of phosphatidylcholine in protecting ram sperm from cold shock. Gamete Res $\underline{15}, 43-56$

Simpson AM, Swan MA, White IG (1987): Calcium uptake, respiration, and ultrastructure of sperm exposed to ionophore A23187. Arch Androl 19, 5-18

Smith LC (1993): Membrane and intracellular effects of ultraviolet irradiation with Hoechst 33342 on bovine secondary oocytes matured in vitro. J Reprod Fertil $\underline{99}$, 39-44

Spinaci M, de Ambrogi M, Volpe S, Galeati G, Tamanini C, Seren E (2005): Effect of staining and sorting on boar sperm membrane integrity, mitochondrial activity and in vitro blastocyst development. Theriogenology $\underline{64}, 191-201$

Spinaci M, Volpe S, Bernardini C, de Ambrogi M, Tamanini C, Seren E, Galeati G (2006): Sperm sorting procedure induces a redistribution of Hsp70 but not Hsp60 and Hsp90 in boar spermatozoa. J Androl 27, 899-907 
Stinshoff H, Krienke M, Ekhlasi-Hundrieser M, Wilkening S, Hanstedt A, Frese D, Rath D, Bollwein H, Wrenzycki C (2012): Seminal plasma and seminal plasma proteins added to bulk sorted sperm do not alter the mRNA expression of in vitro produced bovine embryos. Theriogenology $\underline{78}, 132-139$

Storey BT (2008): Mammalian sperm metabolism: oxygen and sugar, friend and foe. Int J Dev Biol $\underline{52}, 427-437$

Suh TK, Schenk JL, Seidel GE Jr (2005): High pressure flow-cytometric sorting damages sperm. Theriogenology $\underline{64}, 1035-1048$

Suzuki-Toyota F, Ito C, Maekawa M, Toyama Y, Toshimori K (2010): Adhesion between plasma membrane and mitochondria with linking filaments in relation to migration of cytoplasmic droplet during epididymal maturation in guinea pig spermatozoa. Cell Tissue Res $\underline{341}$, 429-440

Szollosi D (1965): The fate of sperm middle-piece mitochondria in the rat egg. J Exp Zool 159, $367-377$

Taylor U, Petersen S, Barcikowski S, Rath D, Klein S (2009): Verification of gold nanoparticle uptake by bovine immortalized cells using laser scanning confocal microscopy. Cytom Part A $\underline{75 \mathrm{~A}}$, 714

Taylor U, Janssen E, Mittag A, Baulain U, Rath D (2010a): Evaluating telomere length in bovine spermatozoa before and after flow-cytometric sex sorting using quantitative fluorescence in situ hybridisation (qFISH). Reprod Domest Anim $4 \underline{5}$ (3), 109

Taylor U, Petersen S, Barchanski A, Mittag A, Barcikowski S, Rath D (2010b): Influence of gold nanoparticles on vitality parameters of bovine spermatozoa. Reprod Domest Anim $\underline{45}$ (3), 60

Taylor U, Klein S, Petersen S, Kues W, Barcikowski S, Rath D (2010c): Nonendosomal cellular uptake of ligand-free, positively charged gold nanoparticles. Cytom Part A $\underline{77}$, 439-446

Taylor U, Barchanski A, Barcikowski S, Rath D (2011): Influence of gold nanoparticles on the fertilising capacity of bovine spermatozoa in vitro. Reprod Domest Anim $\underline{46}$ (3), 154 
Taylor U, Barchanski A, Kues W, Barcikowski S, Rath D (2012): Impact of metal nanoparticles on germ cell viability and functionality. Reprod Domest Anim 47 (4), 359-368

Taylor U, Rath D, Kues W, Barcikowski S, Gamrad L, Werner D, Mancini R (2013): Specific nanotargeting of Y-chromosome bearing spermatozoa. Reprod Domest Anim $\underline{48}$ (1), 88

Tiedemann D, Taylor U, Rehbock C, Klein S, Stuenkel M, Kues W, Barcikowski S, Rath D (2013): Toxic effects of gold and silver nanoparticles on the maturation process of porcine oocytes. Reprod Domest Anim $\underline{48}(1), 71$

Underwood SL, Bathgate R, Maxwell WM, Evans G (2009): In vitro characteristics of frozenthawed, sex-sorted bull sperm after refreezing or incubation at 15 or 37 degrees $\mathrm{C}$. Theriogenology $\underline{72}, 1001-1008$

Walker DW, Benzer S (2004): Mitochondrial "swirls" induced by oxygen stress and in the Drosophila mutant hyperswirl. Proc Natl Acad Sci USA 101, 10290-10295

Wang X, Sharma RK, Gupta A, George V, Thomas AJ Jr, Falcone T, Agarwal A (2003): Alterations in mitochondria membrane potential and oxidative stress in infertile men: a prospective observational study. Fertil Steril $\underline{80}$ (2), 844-850

Watkins AM, Chan PJ, Kalugdan TH, Patton WC, Jacobson JD, King A (1996): Analysis of the flow-cytometer stain Hoechst 33342 on human spermatozoa. Mol Hum Reprod 2, 709-712

Weiß C: Basiswissen Medizinische Statistik. 5. Auflage; Springer Medizin Verlag, Heidelberg 2010

Wong CH, Cheng CY (2005): The blood-testis barrier: its biology, regulation, and physiological role in spermatogenesis. Curr Top Dev Biol 71, 263-296 


\section{Danksagung}

Mein besonderer Dank gilt meinem Doktorvater Herrn Prof. Dr. med. Wolfgang Knabe für die Überlassung des Themas sowie für die Förderung meiner Arbeit durch seine intensive fachliche und persönlich engagierte Betreuung. Seine zahlreichen Ratschläge und Kommentare, die weit über den Rahmen der vorliegenden Arbeit hinausgingen, werden mir in meiner beruflichen Zukunft von groBem Nutzen sein.

Bei Herrn Dr. med. Stefan Washausen möchte ich mich für seine freundliche und tatkräftige Unterstützung bei der Durchführung der Laborarbeiten sowie bei der Bewältigung technischer Probleme ganz herzlich bedanken.

Herrn Prof. Dr. med. vet. Detlef Rath und seinen Mitarbeiterinnen Frau Dr. med. vet. Ulrike Taylor, Frau Antje Frenzel und Frau Birgit Sieg vom Institut für Nutztiergenetik am Friedrich-Loeffler-Institut in Neustadt am Rübenberge danke ich für die Gewinnung und Aufarbeitung der untersuchten Rinderspermien sowie für die Einarbeitung in die Technik der Spermiensortierung.

Frau Sigrid Freese und Frau Irmgard Weiss (Institut für Anatomie und Embryologie der Georg-August-Universität Göttingen) möchte ich herzlich für die tatkräftige Unterstützung bei den Laborarbeiten und für die Anfertigung der zahlreichen Dünnschnitte für die Elektronenmikroskopie danken.

Herrn Prof. Dr. med. Christoph Viebahn danke ich für die Möglichkeit, die vorliegende Arbeit am Institut für Anatomie und Embryologie der Georg-August-Universität Göttingen in der Arbeitsgruppe von Herrn Prof. Dr. med. W. Knabe durchführen zu können. 